2014

\title{
Age-Related Differences in the Experience of Health Anxiety and Use of Coping Strategies
}

Lindsay A. Gerolimatos

West Virginia University

Follow this and additional works at: https://researchrepository.wvu.edu/etd

\section{Recommended Citation}

Gerolimatos, Lindsay A., "Age-Related Differences in the Experience of Health Anxiety and Use of Coping Strategies" (2014). Graduate Theses, Dissertations, and Problem Reports. 129.

https://researchrepository.wvu.edu/etd/129 
Age-Related Differences in the Experience of Health Anxiety and Use of Coping Strategies

\author{
Lindsay A. Gerolimatos, M.S. \\ Dissertation submitted to the Eberly College of Arts and Sciences \\ at West Virginia University \\ in partial fulfillment of the requirements \\ for the degree of \\ Doctor of Philosophy \\ in \\ Psychology \\ Barry Edelstein, Ph.D., Chair \\ Maria Brann, Ph.D. \\ Amy Fiske, Ph.D. \\ Kevin Larkin, Ph.D. \\ Aaron Metzger, Ph.D. \\ Department of Psychology \\ Morgantown, West Virginia \\ 2014
}

Keywords: Older adults, Aging, Health anxiety, Hypochondriasis,

Emotion regulation, Age differences 


\begin{abstract}
Age-Related Differences in the Experience of Health Anxiety and Use of Coping Strategies
\end{abstract}

\title{
Lindsay A. Gerolimatos
}

The experience of heath anxiety among older and young adults is poorly understood. Most studies (e.g., Abramowitz \& Moore, 2007; Gramling et al., 1996) have examined cognitions and behaviors associated with health anxiety, with little to no studies examining emotions and physiological arousal. The present study induced health anxiety in a laboratory setting with 36 older and 36 young adults by providing false health-related feedback. Outcome variables included physiological arousal (heart rate, blood pressure), self-reported arousal (distress, fear of body sensations), and self-reported emotions recorded across three periods: baseline, induction, and recovery. Repeated measures MANCOVAs were conducted with baseline measures as covariates. Coping strategies used during the recovery period were also assessed. Results revealed a main effect of time for distress and fear of body sensations. A main effect of time was revealed for anxiety, depression, and positive affect, such that anxiety and depression were highest during induction and positive affect was lowest during induction relative to recovery. A significant age by time interaction was found for anxiety, with young adults reporting greater anxiety than older adults during induction. No effects for blood pressure or heart rate were found. In general, older and young adults reported using similar coping strategies, although young adults showed a slight preference for avoidance-based strategies. Results indicate health anxiety is experienced as a combination of negative emotions and low positive affect for both older and young adults. Implications for the understanding of health anxiety among older adults are discussed. 


\section{Acknowledgements}

I would like to thank my advisor and committee chairperson Barry Edelstein for guidance in the design and completion of this study and feedback on drafts of this manuscript. Most importantly, I would like to thank him for serving as a true mentor and role model for the past five years. Thank you, as well, to Maria Brann, Amy Fiske, Kevin Larkin, and Aaron Metzger for comments and suggestions as dissertation committee members. I also wish to thank Marissa Pifer for her steadfast dedication to helping me collect data. Finally, I would like to thank my parents, Anthony and Barbara Gerolimatos, as well as my partner, Eamon Molloy, for their unconditional love and support. Thank you all. 


\section{Table of Contents}

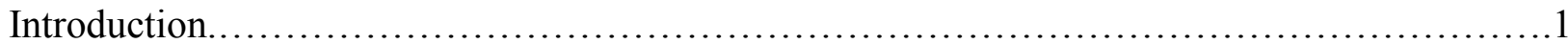

The Cognitive-Behavioral Model of Health Anxiety..............................4

Treatment of Health Anxiety and Hypochondriasis.................................5

Features of Health Anxiety.................................................6

Health Anxiety among Older Adults...........................................11

Coping with Health Anxiety...............................................13

Methods for Examining Health Anxiety......................................... 18

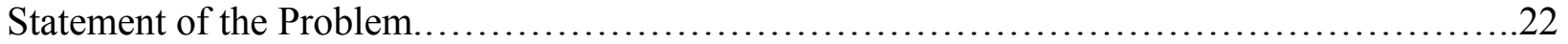

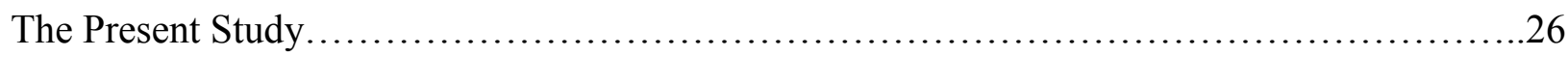

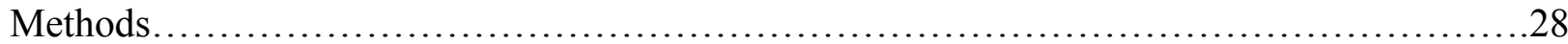

Participants.............................................................28

Physiological Measures................................................... 30

Pre-Experiment Self-Report Measures........................................ 32

Dependent Self-Report Measures..............................................35

Post-Experiment Self-Report Measures....................................... 39

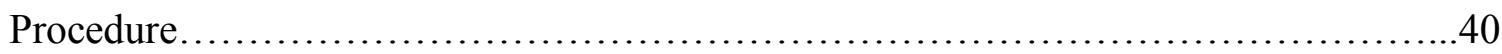

Results........................................................................ 45

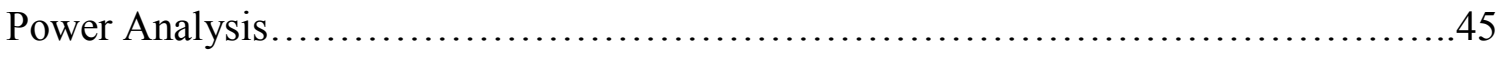

Checking Assumptions....................................................45

Calculating Heart Rate and Heart Rate Variability $\ldots \ldots \ldots \ldots \ldots \ldots \ldots \ldots \ldots \ldots \ldots \ldots . . .47$

Baseline Age-Related Differences.........................................48

Effects on Physiological Arousal.................................................48 
Effects on Subjective Arousal.

Effects on Emotions......................................................... 52

Use of Coping Strategies.................................................53

Manipulation Check........................................................... 55

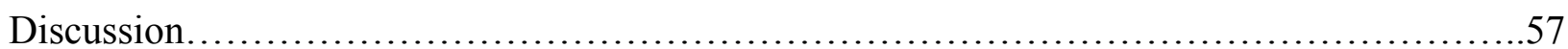

Implications for Assessment, Conceptualization, and Treatment....................65

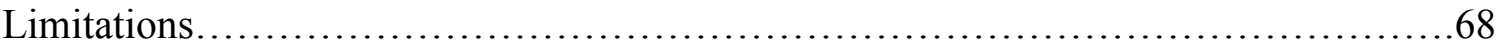

Future Directions........................................................... 70

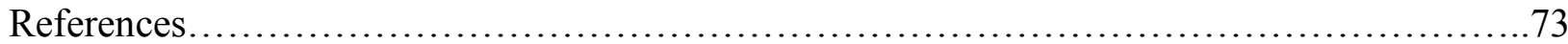

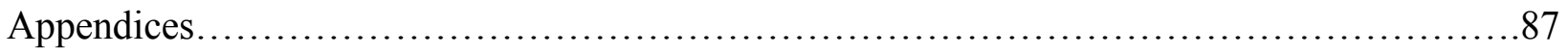

Tables............................................................................ 105

Figures..................................................................... 114 
Age-Related Differences in the Experience of Health Anxiety and

\section{Use of Coping Strategies}

Illness Anxiety Disorder (IAD) is marked by a persistent worrisome preoccupation that one has or may contract a serious health problem despite the absence of somatic symptoms (American Psychiatric Association, 2013). If somatic symptoms are present, these symptoms are minimal such that the concern (e.g., belief that one has brain cancer) is disproportionate to the symptoms (e.g., a mild headache). Thus, individuals with IAD tend to misinterpret ambiguous or vague body sensations as indicative of an illness. When experiencing such sensations, individuals with IAD often engage in safety behaviors, which may include visiting a physician, seeking reassurance from others, engaging in body checking, or gathering information about the symptoms (Abramowitz \& Moore, 2007). Despite safety behaviors, illness concerns persist.

Illness Anxiety Disorder was first introduced in the Diagnostic and Statistical Manual of Mental Disorders (DSM-5; APA, 2013), which was released in May 2013. Prior to the DSM-5, IAD was known as hypochondriasis, which was categorized as a somatoform disorder (APA, 2000). Although the diagnostic criteria of hypochondriasis were similar to those of IAD, IAD better reflects modern conceptualizations of the disorder, which emphasize cognitive symptoms (e.g., worry and preoccupation) as opposed to somatic symptoms. Moreover, researchers have argued for many years that hypochondriasis was more similar to the anxiety disorders, as opposed to the somatoform disorders. For example, Abramowitz and Moore (2007) demonstrated that the safety-seeking behaviors in hypochondriasis are functionally similar to compulsions in obsessive-compulsive disorder: they alleviate distress and anxiety. Alternatively, much research has determined that both panic disorder and hypochondriasis are marked by vigilance to body sensations and the interpretation of body sensations as suggestive of a serious 
medical concern (Deacon \& Abramowitz, 2008). Despite the name change, IAD is categorized under Somatic Symptom and Related Disorders as opposed to the anxiety disorders.

As indicated above, conceptualizations of hypochondriasis have changed over the years. Most substantially, recent conceptualizations posit that hypochondriasis is the severe form of health anxiety (Salkovskis \& Warwick, 1986; Taylor \& Asmundson, 2004), and there is some statistical support for this conceptualization (see Fergus \& Valentiner, 2009; Longely, BromanFulks, Calamari, Noyes, Wade, \& Orlando, 2010). That is, health anxiety is a dimensional construct, ranging from no or mild concern about one's health to frank hypochondriasis (now known as Illness Anxiety Disorder). Thus, when I discuss health anxiety, I am referring to the entire range of health concern, whereas when I discuss hypochondriasis or IAD, I am referring to concern that rises to the level of a diagnosable condition.

Because IAD is a new diagnosis, there is no published research on this disorder per se. However, as IAD is a refinement of the criteria for hypochondriasis, we can continue to cite the literature on hypochondriasis to understand IAD. Consequently, when I use the word hypochondriasis, it is because the research I have cited specifically studied hypochondriasis, though understand that hypochondriasis is very similar to IAD.

Prevalence estimates for hypochondriasis suggest that approximately 5\% of the United States population meets criteria for the disorder (Asmundson, Taylor, Sevgur, \& Cox, 2001), though there is considerable range in prevalence figures depending on methods used to diagnose the disorder (see Magariños, Zafar, Nissenson, \& Blanco, 2002). A complicating factor in estimating the prevalence of hypochondriasis is overlap with health problems. Consequently, rates of hypochondriasis tend to be higher among medical patients and older adults relative to the general population (see Creed \& Barsky, 2004 for a systematic review of epidemiological 
studies). However, the extent to which these prevalence rates reflect actual increases in hypochondriasis among these groups or merely that the groups are experiencing real and significant health problems is unclear. Many epidemiological studies do not account for the contribution of health problems to prevalence rates. Thus, estimates of the prevalence of hypochondriasis among older adults are questionable. IAD, which does not emphasize somatic symptoms, may better differentiate between those with the disorder and those with real health problems. However, epidemiologic data for IAD are not yet available.

Understanding the nature of health anxiety is extremely important. Severe health anxiety is associated with increased functional impairment and greater incidences of anxiety and depression (Noyes, Happel, \& Yagla, 1999). Individuals with severe health anxiety use healthcare services at higher rates than medial patients with lower levels of health anxiety (Fink, Ørnbøl, \& Christensen, 2010), which is problematic given the high cost of medical care in the US. Though individuals with hypochondriasis are more likely to rate their health as poor compared to non-clinical individuals, individuals with hypochondriasis are not actually less healthy than non-clinical individuals (Fink et al., 2010). Thus, accurate diagnosis and treatment of health anxiety is necessary to offset unneeded healthcare costs. Given that older adults experience higher rates of health problems compared to younger age groups (Administration on Aging, 2011), it is especially important to understand the nature of health anxiety among older adults. Specifically, it is important to differentiate between hypochondriacal symptoms and real health problems in order to deliver appropriate treatments to older adult clients.

Broadly, the present study aims to examine health anxiety among older and young adults. Additionally, this study will explore the experience of health anxiety and strategies for coping with health anxiety. As there is limited research on health anxiety among older adults, the 
present study's primary goal is to understand the nature of health anxiety in this population.

\section{The Cognitive-Behavioral Model of Health Anxiety}

In light of recent conceptualizations of health anxiety, researchers have developed models to account for the development and maintenance of health anxiety. Arguably, the model with the greatest empirical support is the cognitive-behavioral model of health anxiety proposed by Salkovskis and Warwick (1986).

As described in this model, health anxiety results from past experiences with illness, which can be firsthand or vicariously through others. Experiences with health problems influence attention to illness-related stimuli. Exposure to illness-related stimuli triggers subsequent healthanxious thoughts and behaviors. For example, an individual may have lost a relative to brain cancer, and as a result, may become hypervigilant to bodily sensations that may be signs of brain cancer (e.g., headaches). In addition to attention biases, the individual may adopt dysfunctional information processing strategies, such as overestimating the severity or likelihood of a symptom. These thought patterns persist despite evidence to the contrary. For example, information refuting the presence of a health problem may be interpreted by the health anxious individual as erroneous (e.g., the diagnostic test is wrong), which may lead health anxious individuals to seek a second opinion (Hadjistavropoulos, Craig, \& Hadjistavropoulos, 1998).

The maintenance of health anxiety, and the level of distress experienced by an individual, involves the interaction of four core factors (see Hadjistavropoulos, Janzen, Kehler, Leclerc, Sharpe, \& Bourgault-Fagnou, 2012): (a) the perceived likelihood of the illness (i.e., illness likelihood), (b) perceived cost of the illness (i.e., negative effects or consequences), (c) perceived ability to cope with the illness (i.e., coping factors), and (d) availability of rescue factors, such as cures. Consequently, if one of these factors is missing (e.g., a person does not perceive the 
effects of an illness as particularly negative), then that person's level of health anxiety will be relatively lower.

When health anxiety is activated, often as the result of experiencing a vague body sensation, one is more likely to engage in safety behaviors (Abramowitz \& Moore, 2007). Physician visits are one example of safety behaviors, which accounts in part for the higher rates of healthcare utilization among individuals with severe health anxiety compared to non-health anxious individuals with well-defined medical problems (Fink et al., 2010). Safety behaviors serve to alleviate distress and is negatively reinforcing (Abramowitz \& Moore, 2007), thereby maintaining health anxiety. Furthermore, discovery of a legitimate health problem during a visit to a physician reinforces safety behaviors.

\section{Treatment of Health Anxiety and Hypochondriasis}

Presently, the preponderance of treatment outcome studies for health anxiety and hypochondriasis tend to follow from the cognitive-behavioral model. Notably, these treatments are similar to treatment models that have been successful in reducing symptoms associated with anxiety disorders (Taylor \& Asmundson, 2004), thereby providing additional evidence that health anxiety and the anxiety disorders share similarities. Specifically, cognitive-behavioral treatments for health anxiety involve exposure and response prevention, cognitive restructuring, and relaxation training (e.g., Taylor \& Asmundson, 2004). A meta-analysis revealed that CBT is the most effective treatment for more severe health anxiety (i.e., hypochondriasis), though psychoeducation may be adequate for mild health anxiety (Taylor, Asmundson, \& Coons, 2005). This meta-analysis also suggested that fluoxetine shows promise for treating health anxiety (Taylor et al., 2005). However, few studies have examined the effectiveness of CBT for use with older adults with health anxiety. One promising randomized-control trial (Bourgault-Fagnou \& 
Hadjistavropoulos, 2013) compared six weeks of enhanced CBT (ECBT) to standard CBT (SCBT) and a wait-list control (WLC) among older adults with subclinical health anxiety (i.e., health anxiety that does not quite meet criteria for hypochondriasis). Results indicated that both ECBT and SCBT reduced health anxiety post-treatment, with greater reductions in health anxiety among the ECBT group; these results held three months post-treatment.

\section{Features of Health Anxiety}

The cognitive-behavioral model of health anxiety addresses cognitions and behaviors associated with health anxiety, though the literature notes that health anxiety is characterized by specific patterns of affect and physiological arousal in addition to cognitions and behaviors (e.g., Hadjistavropoulos et al., 2012; Longley, Watson, \& Noyes, 2005; Taylor \& Asmundson, 2004; Warwick \& Salkovskis, 1990). The importance of affect and physiological arousal in health anxiety is consistent with the tripartite model of emotion (Clark \& Watson, 1991). The tripartite model of emotion suggests that emotion is comprised of a higher order negative affect factor and two lower order factors: low positive affect and physiological arousal. Anxiety appears to be characterized by high levels of negative affect and high levels of physiological arousal (Teachman, Siedlecki, \& Magee, 2007). What's more, the tripartite model appears to be invariant across the lifespan (Teachman et al., 2007). A great deal of research has focused on cognitions and behaviors in health anxiety, and only recently have researchers begun to explore the role of affect and physiological arousal in health anxiety. Research examining each of these components will be discussed.

Cognitive processes. Many studies on health anxiety have examined the role of cognitive processes in maintaining health anxiety (e.g., Hadjistavropoulos et al., 1998; Lees, Mogg, \& Bradley, 2005). A critical review of studies examining cognitive processes implicated in health 
anxiety (Williams, 2004) reported that health anxious individuals tend to negatively interpret ambiguous body symptoms as indicating an illness, a phenomenon known as somatic amplification. As part of somatic amplification, individuals with health anxiety tend to overestimate the severity of body sensations. Gramling, Clawson, and McDonald (1996) found that individuals with hypochondriasis were more likely to rate a cold pressor task as more unpleasant than individuals without hypochondriasis, and Hadjistavropoulos and colleagues (1998) found that individuals with higher self-reported hypochondriasis symptoms rated pain during a cold pressor task as more intense than non-hypochondriacal participants. Similarly, it appears that health anxious individuals are also likely to overestimate the likelihood of the illness. One study by Haenen and colleagues (2000) examined cognitive biases among a group of patients diagnosed with hypochondriasis and among a non-clinical control sample that was matched on age, sex, and educational level. Participants read various scenarios describing healthrelated situations with ambiguous outcomes and rated the likelihood that the situation would result in a negative outcome. The hypochondriasis group provided significantly higher estimates of negative outcomes than the control group. In another study (Hadjistavropoulos et al., 1998), highly health anxious undergraduate college students were more likely to report that they were at greater risk for medical complications than their non-health anxious peers.

Williams (2004) also revealed that health anxious individuals tend to display attentional biases toward health-related information. Owens, Asmundson, Hadjistavropoulos, and Owens (2004) used a modified Stroop task in which participants were presented with words that were illness-related, positive emotions, negative emotions, or neutral. The high-health anxiety group showed significantly greater Stroop interference (i.e., longer reaction times) for illness-related words compared to other kinds of words, whereas the medium- and low-health anxiety groups 
did not exhibit differences in Stroop interference for any of the word types. These results suggest that health anxious individuals have a tendency to attend to health cues over other cues (e.g., the color of words). Also using a modified Stroop task, Lecci and Cohen (2002) showed that, when illness concern was activated in undergraduate college students, participants had greater interference for health-related words. Moreover, Stroop interference was greater for participants who scored higher on a measure of sensitivity to body sensations, suggesting that sensitivity to body sensations may increase attentional biases towards health-related cues. These findings are not surprising in light of findings from anxiety disorders research, which notes similar patterns.

Behaviors. Behaviors associated with health anxiety are generally referred to as safety behaviors, which function to protect one's health. As is the case with anxiety disorders, reassurance-seeking behaviors play a significant role in the maintenance of health anxiety (Abramowitz \& Moore, 2007; Olatunji, Etzel, Tomarken, Ciesielski, \& Deacon, 2011). In an experimental analysis of hypochondriasis symptoms, Abramowitz and Moore (2007) exposed outpatients diagnosed with hypochondriasis to personally relevant health-related stimuli. The participants were randomly assigned to one of two conditions: one group that was allowed to engage in their usual safety behaviors, and one group that was prevented from engaging in safety behaviors (i.e., response prevention group). Exposure to health-related stimuli increased selfreported anxiety for both groups. However, the safety behaviors group reported less anxiety than the response prevention group after engaging in the safety behaviors. In addition, the safety behaviors group showed a steeper decrease in anxiety over time, whereas the response prevention group displayed a more gradual reduction in anxiety levels. These findings suggest that the function of safety behaviors may be similar to that of compulsions in OCD, namely, the behaviors alleviate distress. 
Paradoxically, safety behaviors maintain health anxiety via negative reinforcement, which was demonstrated in an experiment by Olatunji and colleagues (2011). The researchers examined non-clinical undergraduate college students during a three-week period using a simple phase change ABA design. Participants were randomly assigned to one of two conditions: a safety behaviors condition and a control condition. Those in the safety behaviors group were instructed to monitor their safety behaviors during the first week (baseline phase), engage in high frequencies of safety behaviors during the second week (safety behavior phase), and then monitor their safety behaviors during the third week (return to baseline phase). Participants in the control condition were instructed to monitor their symptoms during the entire three-week period. The safety behaviors group reported higher levels of health anxiety and increases in hypochondriacal concerns, contamination fear, and avoidance of health-related cues during the return to baseline phase compared to the control condition. A follow-up mediation analysis revealed that increases in health-related thoughts (e.g., catastrophizing about health outcomes) accounted for the effect of safety behaviors on health anxiety. Thus, safety behaviors maintain elevated levels of health anxiety, potentially due to increased hypochondriacal cognitions. Findings from these studies fit with the existing literature on anxiety disorders.

Affective experience. The affective experience of health anxiety is not well understood, as few, if any, studies have examined emotions experienced during health anxiety. Some of the studies that have successfully induced health anxiety have not gathered data on the affective experience of health anxiety (e.g., Gramling et al., 1996). Other studies have asked participants for numerical ratings of their anxiety (e.g., Abramowitz \& Moore, 2007), which tells us little about specific emotions during health anxiety. Moreover, few existing measures of health anxiety assess for affect associated with health anxiety. For example, one recent measure, the 
Multidimensional Inventory of Hypochondriacal Traits (MIHT; Longley et al., 2005) includes a subscale assessing affect in health anxiety. Yet, it does not capture affect during the experience of health anxiety, rather, it asks for a retrospective account for how one typically experiences health anxiety. Furthermore, many of the items on the MIHT appear to capture worry or concern for health, but no other emotions associated with health anxiety. Of the limited available research, health anxiety appears to be associated with increased worry (Longley et al., 2005), anxiety (Abramowitz \& Moore, 2007), and fear (Fergus \& Valentiner, 2012) though overall, little is known about other emotions during the experience of health anxiety.

There is a small body of research on affect associated with anxiety and worry during laboratory inductions of anxiety. One study (McLaughlin, Brokovec, \& Sibrava, 2007) induced worry in the laboratory with young adults by asking participants to worry as they normally do. Following the induction, participants were instructed to describe their affective states during worry. Results revealed that worry was associated with decreases in positive affect and increases in negative affect, anxiety, and depression. Andrews and Borkovec (1988) used Velten worry statements to induce worry in the laboratory and had participants complete the Multiple Affect Adjective Checklist-Revised (MAACL-R; Zuckerman \& Lubin, 1985). Results revealed that worry was associated with greater depression, negative affect, hostility, and anxiety, but less positive affect and sensation seeking. Though these studies did not examine health anxiety, these findings may inform research on emotions in health anxiety. Because health anxiety shares some similar characteristics with anxiety disorders, one might expect health anxiety to also be related to increases in negative affect, anxiety, and depression, and decreases in positive affect.

Physiological arousal. Like affect, physiological arousal in health anxiety is not frequently studied and is poorly understood. Only one study of health anxiety (Gramling et al., 
1996) examined the physiological experience of health anxiety among hypochondriacal and nonhypochondriacal participants. In this study, recordings of heart rate, hand temperature, and electromyography were taken while participants completed two tasks: a cold pressor task and an imagery task in which they were asked to imagine sensations associated with serious medical conditions. The cold pressor task was associated with larger increases in heart rate and decreases in hand temperature among the hypochondriacal group compared to the non-hypochondriacal group. There were no differences across groups for the imagery task.

A greater understanding of physiological arousal in health anxiety may be accomplished by exploring research on anxiety disorders. Anxiety is associated with increases in heart rate (e.g., Steptoe \& Vögele, 1992; Svensson \& Theorell, 1982; Teachman \& Gordon, 2009), blood pressure (Diaper, Nutt, Munafò, White, Farmer, \& Bailey, 2012; Steptoe \& Vögele, 1992; Svensson \& Theorell, 1982), respiration rate (Meuret, Seidel, Rosenfield, Hofmann, \& Rosenfield, 2012; Steptoe \& Vögele, 1992), and skin conductance level (Steptoe \& Vögele, 1992). However, it is important to note that these patterns may differ as a result of age, as increased age is associated with less heart rate reactivity to stressors but greater systolic blood pressure reactivity (see Uchino, Birmingham, \& Berg, 2010). Although one may be able to assume patterns of physiological arousal in health anxiety will be similar to those seen in anxiety, this aspect of health anxiety remains largely unknown. Given the paucity of literature on physiological arousal in health anxiety, it remains an important area to examine.

\section{Health Anxiety among Older Adults}

Understanding health anxiety among older adults is particularly important, especially as older adults are more likely to have significant health problems than other age groups. Furthermore, rates of healthcare utilization are higher among older adults compared to younger 
age groups (Administration on Aging, 2011). Research indicates that older adults are more likely to worry about their health than young adults (Hunt, Wisocki, \& Yanko, 2003), and that two of the most commonly reported fears among older adults are cognitive decline and having an illness (Kogan \& Edelstein, 2004). It appears that health concern may be prominent among older adults, though at present, few studies examining health anxiety among older adults have been published. Studies on older adults have attempted to determine whether rates of health anxiety are higher among older adults compared to other age groups. Boston and Merrick (2010) found that older adults in New Zealand reported comparable levels of health anxiety relative to young adults. However, the researchers only collected data from older adults and compared their results with findings from previous research on young adults in the United States (e.g., Salkovskis, Rimes, Warwick, \& Clark, 2002). Bourgault-Fagnou and Hadjistavropoulos (2009) attempted to account for the potential influence of health problems on health anxiety by comparing health anxiety levels across three groups: young adults, high-frailty older adults, and low-frailty older adults. The researchers found that high-frailty older adults reported the highest levels of health anxiety compared to the other two groups, with similar levels of health anxiety between the lowfrailty older adults and the young adults. After controlling for health problems, the high-frailty older adults had similar levels of health anxiety as the young adults, with low-frailty older adults reporting the lowest levels of health anxiety. Yet based on these two studies alone, it remains unclear whether rates of health anxiety differ across age groups.

Studies have also attempted to examine which variables predict or contribute to health anxiety. Boston and Merrick (2010) examined the extent to which physical functioning predicted health anxiety, and found that, unsurprisingly, poorer physical health contributed to higher levels of health anxiety. Education also predicted health anxiety, such that lower education was 
associated with higher rates of health anxiety. Bourgault-Fagnou and Hadjistavropoulos (2009) found that trait anxiety and emotional preoccupation (i.e., a type of coping in which one focuses on the emotional consequences of one's health) predicted health anxiety, in that higher reported trait anxiety and emotional preoccupation contributed to greater health anxiety.

Building on research by Bourgault-Fagnou and Hadjistavropoulos (2009), Gerolimatos and Edelstein (2012) examined the role of anxiety-related constructs in accounting for potential age-related differences in health anxiety. They found that anxiety sensitivity (i.e., fear of anxietyrelated sensations) and intolerance of uncertainty (i.e., the tendency to react negatively to unpredictable situations) partially mediated the relation between age and health anxiety. The researchers also examined emotion regulation strategies as potential mediators, but these variables did not account for the relation. Though these studies are among the first to examine non-health factors that may explain differences in health anxiety across age groups, they are not without limitations. For example, each of these three studies relied on paper-and-pencil surveys and data were collected at a single point in time. Consequently, it is unknown whether the variables under examination influence the experience of health anxiety.

Considering the literature of older adult health anxiety as a whole, little is known about cognitions, behaviors, affect, and physiological arousal associated with health anxiety among older adults. Though some studies (e.g., Abramowitz \& Moore, 2007) have included older adults as participants, older adults have not been examined as a group with respect to these domains. Accordingly, virtually nothing is known about thoughts, behaviors, emotions, and arousal in the context of health anxiety among older adults.

\section{Coping with Health Anxiety}

The cognitive-behavioral model of health anxiety includes coping as integral to the 
development and maintenance of health anxiety, yet few studies have examined this construct as a contributing factor to health anxiety. One study (Fergus \& Valentiner, 2010) using a nonclinical college student sample examined the extent to which three coping strategies (cognitive avoidance, reappraisal, and suppression) predicted disease conviction (i.e., thoughts that one has an illness) and disease phobia (i.e., fear of having a serious illness), which are two components comprising health anxiety. Higher self-reported cognitive avoidance, which is a broad term describing several strategies such as substituting disturbing thoughts with pleasant ones, distracting oneself from upsetting thoughts, and avoiding threatening stimuli, predicted greater disease conviction. Reappraisal (i.e., reducing the impact of an emotion by thinking about it differently) also predicted disease conviction, however, greater use of reappraisal resulted in less disease conviction. Suppression (i.e., inhibiting the expression of emotions) did not predict either disease phobia or disease conviction. The results of this study indicate that the use of specific regulation strategies appear to relate to health anxiety. Another study (Bourgault-Fagnou \& Hadjistavropoulos, 2009) examined different coping strategies than Fergus and Valentiner. Using a sample of high- and low-frailty older adults, the researchers examined the extent to which emotional preoccupation (i.e., the extent to which one focuses on the emotional consequences of a health problem) predicted health anxiety. Results showed that higher levels of emotional preoccupation predicted higher levels of health anxiety. This study also supports the notion that coping influences health anxiety. However, both of these studies relied on retrospective accounts of coping strategies and did not assess which strategies participants use while they are experiencing health anxiety.

Only one study (Hadjistavropoulos et al., 1998) examined strategies used to cope with health anxiety during the experience of health anxiety-related sensations. Participants included 
college students who were categorized as health anxious or non-health anxious based on scores on a self-report measure. Participants were administered a cold pressor task and asked to keep their hand in the water until asked to remove it. Following the cold pressor task, participants completed a measure asking about coping strategies used during the task. Results showed that health anxious individuals were more likely to use negative monitoring of somatic symptoms (i.e., interpreting sensations negatively) and were also more likely to catastrophize compared to the non-health anxious group. The health anxious group also reported less perceived control over their pain compared to the other group. Overall, this study suggested that emotion-focused coping strategies may be especially relevant for coping with health anxiety.

There are several age-related differences in coping and emotion regulation that are important to acknowledge. In general, evidence suggests that older adults are particularly skilled at regulating emotions, and consequently, experience less distress compared to younger adults (e.g., Charles \& Carstensen, 2007; Gross \& John, 2003). There are a few mechanisms by which this pattern may occur. First, older adults are more likely to focus on positive emotions whereas young adults are more likely to focus on negative emotions (Mather \& Carstensen, 2005). Second, older adults are more likely to use emotion-regulatory problem-solving than younger adults (Blanchard-Fields, Stein, \& Watson, 2004). Use of specific types of strategies also appears to differ across age groups. Gerolimatos and Edelstein (2012) found that older adults reported greater use of reappraisal than younger adults. Similarly, older adults appear to use reappraisal more effectively than young adults (John and Gross, 2004). Because young adults appear to be less experienced with reappraisal, use of reappraisal may be costly for young adults in terms of cognitive load (Scheibe \& Blanchard-Fields, 2009), which may partially account for less effective use of reappraisal for young adults compared to older adults. 
On the other hand, there is some evidence that older adults may be less effective at regulating their emotions because it relies on complex cognitive processes that may become impaired with age (e.g., attention, inhibition; Urry \& Gross, 2010). Further, effortful use of reappraisal is less successful in attenuating anxious emotions and physiological arousal than automatic, non-effortful reappraisal (Williams, Bargh, Nocera, \& Gray, 2009), suggesting that reappraisal may tax cognitive resources. In light of these findings, it may be the case that emotion regulation is cognitively demanding for some older adults (e.g., the oldest old, those with significant cognitive impairment), but may be less demanding for older adults in their 60s or those with little or no cognitive decline (Urry \& Gross, 2010). Consequently, it is important to remember that older adults are not a homogenous group, and emotion regulation may not be an easy task for all older adults.

Theories of coping and emotion regulation. Several lifespan developmental theories of coping and emotion regulation may help clarify the role of coping in health anxiety as well as any age-related differences in emotion and coping. According to Socioemotional Selectivity Theory (Carstensen, 1991), as one's future time perspective becomes limited, individuals are motivated toward emotionally meaningful goals. Given that older adults are nearing the ends of their lives, they are more likely to pursue goals that are emotionally satisfying. With an openended time perspective, as may be the case with younger adults, individuals are more motivated towards information-gaining goals. The shift in goals from information-seeking to maintaining emotional meaningfulness is accompanied by changes in cognitive processing. Namely, with age, there is a shift in attention or preference for positive aspects over negative aspects, a phenomenon known as the positivity bias. In the case of health anxiety, older individuals may be less likely to attend to adverse stimuli (e.g., body sensations) and may instead pursue 
emotionally meaningful goals, which may be accomplished via coping and emotion regulation.

Dynamic Integration Theory (DIT; Labouvie-Vief, 2003) is another model that may help elucidate the nature of coping in health anxiety. As outlined in this model, optimal functioning involves the complex integration and balance of two aspects of emotion regulation: affect optimization, in which one maximizes positive emotions and minimizes negative emotions, and affect differentiation, in which one processes emotions with respect to the present context as well as past experiences. According to Labouvie-Vief, affect differentiation requires greater cognitive effort than affect optimization. DIT suggests that moderate levels of emotional activation allow for successful integration of the two aspects, but at greater levels of emotional activation, impairment in integration occurs. Based on this model, one might expect health anxious individuals to have difficulty regulating their emotions because health anxiety results in high levels of emotional activation. Furthermore, it may be the case that older adults may be more likely to have difficulty regulating emotions related to health anxiety compared to younger age groups given age-related decline in cognitive abilities that may be necessary for affect differentiation.

A model similar to DIT is the Strength and Vulnerability Integration (SAVI) model (Charles, 2010). Here, older adulthood is marked by both strengths and vulnerabilities. In terms of strengths, older adults have had a wealth of past experiences through which they have learned how best to cope with various stressors. Yet, older adulthood is also marked by vulnerabilities, such as declining health and greater susceptibility to illness. Consequently, older adults are generally able to manage stressors, but may fail to do so if the stressors become overwhelming. For example, emotion regulation strategies may not be enough to compensate for vulnerabilities. Health anxiety may be one area that is too overwhelming for individuals to adequately cope. 
Examining emotion-focused coping with respect to health anxiety may be best understood in light of Heckhausen and Schulz's (1995) model of primary and secondary control. They argue that individuals are driven to maintain control of their environment. Primary control strategies involve changing characteristics of the environment and can be thought of as similar to problem-focused coping. Conversely, secondary control strategies involve changing how one thinks or feels about a situation. Concerning chronic health problems, one can argue that there is little one can do to change one's health status (e.g., there may not be a cure for the disorder). Consequently, emotion-focused coping, or secondary control strategies, may be important in reducing health anxiety.

In sum, conceptual and empirical evidence emphasizes the importance of understanding and examining the role of coping in health anxiety.

\section{Methods for Examining Health Anxiety}

Overwhelmingly, research on health anxiety has relied on self-report surveys to understand the nature of health anxiety. Although self-report surveys can help answer important questions, their use is not without limitations. First, self-report measures are subject to self-report biases, such that one may attempt to exaggerate or minimize symptoms. Second, self-report surveys are often retrospective in nature, with some assessments asking respondents to recall information over weeks or months. Consequently, respondents may not answer questions accurately due to poor recall over long periods of time. Third, many of the existing health anxiety measures assess thoughts regarding catastrophizing or overestimation, or behaviors associated with health anxiety but do not tap into physiological arousal or affect in health anxiety. The limitations of self-report surveys suggest that information gathered with this method may not be accurate, or may not capture the full picture of health anxiety. 
An alternative to the sole use of self-report surveys is to induce health anxiety in the laboratory. To date, few laboratory examinations of health anxiety have been conducted. One potential reason for the paucity of laboratory studies is difficulty inducing health anxiety in an artificial setting. Some laboratory studies have induced health anxiety by providing false feedback to participants, causing what is called a "transient hypochondriasis" (Barsky \& Klerman, 1983, p. 274). Lecci and Cohen (2002) invited undergraduate college students into the laboratory and completed a physical examination and a health history, followed by measurement of their blood pressure. Participants in the experimental condition were then told that although their pulse was "normal" their blood pressure was "dangerously high" (p. 149), and that they should make a follow-up appointment at a health center. Participants then completed a modified Stroop task, which included health-related words and non-health related words. Individuals in the experimental condition (i.e., provided with false feedback) had longer reaction times to the health-related words compared to the control condition, which suggests that the technique of providing false feedback appeared to successfully increase health concern. Of note, this study did not actually assess for whether health anxiety increased in the experimental group compared to the control group.

Hadjistavropoulos et al. (1998) also used false feedback to activate health concern in the laboratory. Undergraduate college students were introduced to a computer program that combines various sources of information (e.g., heart rate, blood pressure, skin conductance) to determine whether the participants would be vulnerable to complications during painful medical procedures. Researchers pretended to take physiological recordings from participants, and generated a graph indicating whether the person had greater vulnerability to complications during painful medical procedures (positive feedback), no vulnerability to complications 
(negative feedback), or the results were ambiguous (ambiguous feedback). Participants given positive feedback displayed greater concern for their health than those who were given negative feedback and ambiguous feedback. This pattern held even when controlling for levels of health anxiety, suggesting that false feedback can activate health concern among non-clinical, nonhealth anxious individuals.

Alternative methods to activate health concern include having participants imagine health problems. Gramling et al. (1996) had two groups of women, one group with diagnoses of hypochondriasis and one non-clinical sample, "vividly imagine transient physiological symptoms such as fatigue, headache, and nausea as possible precursors of a serious illness such as AIDS or cancer" (p. 426). Afterwards, participants presented the complaints to a video camera as if they were explaining these symptoms to their physician. In this study, physiological data, including heart rate, hand temperature, and muscle electrical activity, were collected. Unfortunately, there were no changes in the physiological measures from baseline to the imagery task, suggesting that imagining significant health problems in this study did not adequately induce physiological change. Moreover, this study did not ask participants about their health anxiety during the imagery task, and relied solely on physiological data. Therefore, there may have been changes in the subjective experience of health anxiety that was not captured by the study.

Another method to activate health concern in the laboratory is to present participants with person-specific stimuli that trigger illness concern. Abramowitz and Moore (2007) interviewed participants with hypochondriasis about thoughts, bodily sensations, and situations that may cause the person to think he or she has a serious health problem. Examples of triggers included readings stories about a famous person who died of an illness, spinning on a swivel chair, looking at sores on the body, or visiting a hospital. Participants were then exposed to the trigger. 
Exposure to the trigger resulted in a significant increase in reported anxiety from baseline. One drawback to this design is that it likely can only be used with participants with elevated health anxiety. Secondly, the use of different triggers across participants makes it difficult to adequately control for confounds (e.g., one stimulus may be more anxiety-inducing than another). Finally, this study did not assess physiological arousal before and after exposure, and instead relied solely on self-report of anxiety. Accordingly, it is unknown whether there was accompanying physiological arousal associated with exposure to health-related stimuli.

One last method to activate health concern is to induce anxiety-related sensations. Though this approach does not induce health anxiety per se, it does create body sensations that may activate health concern (e.g., Abramowitz \& Moore, 2007; Gramling et al., 1996). Teachman and Gordon (2009) used this approach to examine age differences in triggers for anxiety and physiological response to anxiety-activation. Older and young adults engaged in four tasks: straw breathing, candle blowing, giving a speech, and foot tapping. During each task, heart rate was recorded, and participants provided a rating of subjective distress. Compared to baseline, young adults had higher heart rate and subjective ratings of distress during the speech task, candle blowing task, and straw breathing tasks, whereas older adults showed increases in heart rate and subjective distress for the straw breathing and candle blowing tasks only. The researchers concluded that older adults had higher anxiety levels during the physical tasks (i.e., straw breathing, candle blowing) than the social task (speech giving) because the physical tasks suggest threats to health, which are salient stressors for older adults. Conversely, for young adults, social stressors and health stressors may be salient. This study demonstrates that health concern may be activated by first inducing anxiety-related sensations. Moreover, this study improves upon previous research by including both objective and subjective measures of anxiety. 
Many of the studies were limited by their use of single data collection methods. Some studies relied solely on self-report (e.g., Abramowitz \& Moore, 2007; Hadjistavropoulos et al., 1998; Lecci \& Cohen, 2002), whereas other studies relied solely on physiological arousal data (e.g., Gramling et al., 1996). These studies were also limited by assessing only a single feature of health anxiety, such as cognitive biases (e.g., Lecci \& Cohen, 2002) or physiological arousal (e.g., Gramling et al., 1996). Because anxiety is characterized by many features, such as thoughts, behaviors, physiological arousal, and emotions, assessing a single feature limits our knowledge. Yartz and Hawk (2001) argue that multiple methods of assessing anxiety are necessary due to desynchrony among methods of measurement. For example, one's self-report of anxiety symptoms may be incomplete or may conflict with other measures, such as psychophysiological recordings. Thus, accurate assessment of anxiety may require behavioral observations, recordings of heart rate, blood pressure, and skin conductance, and a person's selfreport. This multimethod approach to assessment is crucial in understanding psychological phenomena, though this approach has seldom been applied in examinations of health anxiety.

In summary, these few studies provide evidence that health concern can be induced in the laboratory. These studies also highlight the need for research using multiple methods to examine both the subjective and the objective experience of health anxiety across several domains.

\section{Statement of the Problem}

Health anxiety is a dimensional construct, with hypochondriasis (i.e., Illness Anxiety Disorder) as its most severe form. Prevalence rates of hypochondriasis are as high as $5 \%$ of the population (Asmundson et al., 2001), with estimates higher among older adults or medically ill samples (Creed \& Barsky, 2004). Unsurprisingly, health anxiety is associated with high medical costs (Fink et al., 2010), as individuals with severe health anxiety burden the healthcare system 
with frequent doctor visits. Moreover, health anxiety is associated with increased incidences of depression, anxiety, and physical disability (Noyes et al., 1999), suggesting a high degree of impairment. Consequently, it is important to understand the nature of health anxiety to improve assessment and detection of the disorder so that individuals with significant health anxiety can receive appropriate treatment.

To date, virtually nothing is known about the experience of health anxiety. Most of what we know about health anxiety has been based on retrospective self-reports of health anxiety. There are several problems with this approach. First, the retrospective nature of many self-report surveys is subject to limitations, including self-report bias and problems with accuracy of recall. Second, this method does not capture the experience of health anxiety as it occurs. There are also limitations with current measures of health anxiety in that they tend to assess only cognitions and behaviors associated with health anxiety. Arguably, a richer understanding of health anxiety can be achieved by inducing health anxiety in the laboratory, which permits one to make statements about the effect of the induction on various outcome variables. Because only a handful of studies have induced health anxiety in the laboratory (e.g., Abramowitz \& Moore, 2007; Gramling et al., 1996), our understanding of health anxiety is limited.

Most studies of health anxiety have examined cognitions (e.g., Haenen et al., 2000; Owens et al., 2004) and to a lesser extent behaviors (Abramowitz \& Moore, 2007; Olatunji et al., 2011) associated with health anxiety, with few studies on affect and only one study (Gramling et al., 1996) on physiological arousal in health anxiety. That few studies have examined affect and physiological arousal in health anxiety is surprising in light of the broad acceptance of the tripartite model of emotion (Clark \& Watson, 1991), which notes that high levels of negative affect and high levels of physiological arousal are integral parts of anxiety (Teachman et al., 
2007). Furthermore, research suggests that health anxiety is characterized by affective components and physiological arousal (e.g., Hadjistavropoulos et al., 2012; Taylor \& Asmundson, 2004). Consequently, it is important to examine these specific aspects of health anxiety to clarify our understanding of the experience of health anxiety. Our knowledge of health anxiety is also limited by the use of a single method, often self-report surveys, to measure health anxiety. To develop an enriched understanding of health anxiety, a multimethod approach (Yartz \& Hawk, 2001) to studying health anxiety must be employed.

In addition to a poor understanding of the experience of health anxiety, our knowledge of health anxiety among older adults is considerably lacking, as there have been few studies on health anxiety among older adults. Although we know that health status contributes to health anxiety (Bourgault-Fagnou \& Hadjistavropoulos, 2009), we know little about other factors that may account for health anxiety among older adults. Furthermore, no studies have induced health anxiety in older adults and examined the experience of health anxiety in this population. Accordingly, our understanding of the nature of health anxiety among older adults is poor. What's more, we know little about age-related differences in health anxiety as only two studies (Bourgault-Fagnou \& Hadjistavropoulos, 2009; Gerolimatos \& Edelstein, 2012) have directly compared older and young adults.

Though the cognitive-behavioral model of health anxiety acknowledges the importance of coping in health anxiety, few studies have examined coping with health anxiety and only one study examined coping with health anxiety among older adults (Bourgault-Fagnou \& Hadjistavropoulos, 2009). Research from developmental psychology suggests that emotion regulation strategies may be particularly useful in decreasing distress (e.g., Gross \& John, 2003) and may also be effective in coping with health anxiety. At present, it is unknown which 
strategies individuals use to cope with health anxiety and whether these strategies are successful. Also, it is unknown whether there are age-related differences in how older and young adults cope with health anxiety as no studies have directly compared older and young adults on coping with health anxiety.

Finally, though there is support for the cognitive-behavioral model of health anxiety, there remain parts of the model for which there is little support. For example, cognitive processes associated with health anxiety have been extensively examined, but little is known about whether illness information triggers health anxiety as described in the model. Additionally, there are voids in the model. Affect and physiological arousal are largely ignored in the cognitivebehavioral model; thus, it is unknown how affect and physiological arousal may be incorporated into this model to account for health anxiety. Finally, this model has only limited support for use with older adults (Gerolimatos \& Edelstein, 2012).

The present study has implications for the conceptualization, assessment, and treatment of health anxiety. As outlined in the tripartite model of emotion (Clark \& Watson, 1991), anxiety is characterized by high negative affect and physiological arousal in both older and young adults (Teachman et al., 2007). Identifying patterns of emotions and physiological arousal associated with health anxiety may improve detection and assessment of the disorder. Also, clinicians may target physiological arousal and affect regulation as part of interventions. By understanding affect and physiology associated with health anxiety, the cognitive-behavioral model may be expanded to include these features and capture the multiple facets of health anxiety. Furthermore, exploration of these factors in older and young adults may clarify whether the model is similar across age groups (i.e., whether health anxiety is conceptually similar for older and young adults). By understanding coping strategies used by older and young adults, clinicians 
may be more likely to assess for coping skills and target coping as part of an intervention.

To address the limitations in the existing literature, the present study used a quasiexperimental within-subjects design. Older and young adult participants were provided false negative information about their health (to induce a state of health anxiety) and asked to think about the implications of the health-related information. Variables of interest included heart rate and blood pressure, which were recorded across Baseline, Induction, and Recovery periods. Additional outcome variables included subjective distress, affect (e.g., anxiety, depressed mood), and fear of body sensations, which participants rated for each of the three experimental periods. Participants also reported on coping strategies used during the recovery period in an attempt to understand how older and young adults cope with health anxiety.

\section{The Present Study}

The principal goal of the present study was to explore age-related differences in the experience of health anxiety. This study had three central aims: (1) examine the experience of health anxiety, (2) explore age-related differences in the experience of health anxiety, and (3) examine how older and young adults cope with health anxiety.

To understand the experience of health anxiety (Aim 1), the study addressed the following research questions: (Q1) What effect will activating health concern have on objective measures of anxious arousal, including heart rate (HR) and blood pressure (BP)? (Q2) What effect will activating health concern have on subjective measures of anxious arousal, that is, distress and fear of body sensations? (Q3) What effect will activating health concern have on affect? These questions help provide a better understanding of how individuals experience health anxiety, including older adults, which heretofore has garnered little attention.

With respect to Aim 2, the following questions were addressed: (Q4) To what extent do 
older and young adults differ on physiological arousal following activation of health concern (HR and BP)? (Q5) To what extent do older and young adults differ on the subjective experience of anxious arousal following activation of health concern (distress and fear of body sensations)? (Q6) To what extent do older and young adults differ on affect following activation of health concern? These questions were especially important to address, as there is evidence of agerelated differences in psychological arousal (e.g., Lau, Edelstein, \& Larkin, 2001; Teachman \& Gordon, 2009; Uchino et al., 2010). Moreover, a failure to appreciate age-related differences in various psychological problems can lead to the under-detection of disorders among older adults (see Stoner, O’Riley, \& Edelstein, 2010). Consequently, exploring potential age-related differences in health anxiety may help improve detection of health anxiety among older adults.

For Aim 3, the following questions were explored: (Q7) What strategies do older and young adults use to cope with health concern? This question builds upon previous research on coping with health anxiety among college students (Hadjistavropoulos et al., 1998) and young women with hypochondriasis (Gramling et al., 1996) by including older adults. A follow-up question is (Q8) Are there age-related differences in coping strategies used by older and young adults? Additional questions include (Q9) Are coping strategies used by older and younger adults effective in reducing physiological arousal following activation of health concern? (Q10) Are coping strategies effective in reducing subjective arousal following activation of health concern? And (Q11) do coping strategies influence affect following activation of health concern? Finally, are there age-related differences in the effect of coping strategies on (Q12) physiological arousal, (Q13) subjective arousal, and (Q14) affect following affect of health concern? Because only a small number of studies have explored coping in health anxiety, the present study seeks to provide a better understanding of how older and young adults cope with health anxiety and 
whether these strategies are effective in a controlled laboratory setting. In general, the results from this study will hopefully contribute to a greater understanding of the experience of health anxiety and factors relating to health anxiety in older and young adults.

\section{Methods}

\section{Participants}

Thirty-six young adults (ages 18 to 27) and 36 older adults (ages 60 to 84) participated in the study. There were 18 young adult females (50\%), 18 young adult males (50\%), 20 older adult females $(55.6 \%)$, and 16 older adult males $(44.4 \%)$. Mean age was 19.75 years $(S D=1.70)$ for young adults and 66.11 years $(S D=6.13)$ for older adults. The majority of participants were Caucasian, with 26 young adults (72.2\%) and 34 older adults (94.4\%) indentifying as white. Other ethnicities included African American (five younger adults), Asian American (three younger adults and one older adult), Latino (two younger adults), and Native American (one older adult). See Table 1 for descriptive statistics on demographic variables. Participants answered several questions regarding their health and those data are presented in Table 2.

Age groups significantly differed on years of education, $t(69)=3.88, p<.01$, with older adults $(M=16.14, S D=3.66)$ reporting more years of education than young adults $(M=13.67$, $S D=1.10)$. Older adults also reported a higher number of health problems $(M=5.83, S D=3.52)$ than younger adults $(M=2.33, S D=1.87)$, which was significant, $t(70)=5.27, p<.01$. Significant differences were found for ethnicity, as more older adults reported their ethnicity as Caucasian, $X^{2}(4, N=72)=10.83, p<.01$. Significant differences were also found for marital status, $X^{2}(3, N=72)=54.44, p<.01$, as all young adult participants reported they were single, and job status, $X^{2}(3, N=72)=65.14, p<.01$, as all young adult participants reported they were students. As for health-related variables, significant differences were found for alcohol use, $X^{2}$ 
$(5, N=72)=14.07, p<.05$, and physical activity, $X^{2}(3, N=72)=11.71, p<.01($ see Table 2$)$.

Only participants between the ages of 18 and 30 or between the ages of 60 and above were eligible for this study. Because the study involved recordings of heart rate and blood pressure, participants were excluded from the study if they were taking medications or had a history of health problems or behaviors (e.g., smoking cigarettes) known to affect heart rate or blood pressure. Participants were excluded if they were taking beta-blockers, antihypertensive medications (e.g., ACE inhibitors, diuretics), anxiolytics, stimulant medications, and diet pills. Participants were also excluded if they had a history of cardiovascular disease, specifically heart attack, heart surgery, arrhythmias, and pacemakers. Current smokers were excluded. The Montreal Cognitive Assessment (MoCA; Nasredine et al., 2005) was used to screen for participants with cognitive difficulties that may impair their ability to comply with the study instructions as intended. Participants had to score at least a 20 to be eligible for the study. No participants scored below a 20 on the MoCA, although one older adult scored a 20, another older adult scored a 21, and one young adult scored a 22 on the MoCA.

A total of 92 older adults and were screened for this study. Thirty-seven older adults were eligible to participate. One older adult declined to participate after completing the screener, resulting in 36 final participants. For young adults, 334 college students completed the screener online. Of these, 228 individuals were eligible and invited to sign up for the laboratory portion of the study. Thirty-six participants completed the study. See Figure 1 for additional information regarding ineligible participants. In general, ineligible older adults were older $(M=71.75, S D=$ 8.48, range 60-98), more likely to have significant cardiovascular health issues (e.g., atrial fibrillation, history of heart attack), and were more likely to be taking antihypertensive medications or beta-blockers than their eligible counterparts; use of antihypertensive medications 
was the most common reason for being ineligible to participate in the study among older adults (36 older adults who were excluded based on medications reported using antihypertensive medications). Moreover, none of the ineligible older adults rated their health as excellent, suggesting that ineligible older adults generally perceived their health as poorer than those that were eligible to participate. With regard to young adults, ineligible participants were more likely to be smokers and were more likely to be taking anxiolytic or stimulant medications than eligible young adult participants, suggesting higher rates of anxiety and ADHD among ineligible young adults versus eligible young adults. Perceived health did not differ among eligible and ineligible young adult participants.

\section{Physiological Measures}

Heart Rate. Heart rate was measured with the Polar 810i heart rate monitor (Lake Success, New York). The monitor was worn on a strap around the upper torso and placed directly against the skin. The monitor contained sensors which detect ECG signals and sent these signals to a wireless transmitter plugged into the USB port of a computer in an adjacent room. The monitor detected and recorded ECG signals throughout the duration of the study. Evaluations of the Polar heart rate monitors show that the monitor is both reliable and valid, and its measures of heart rate variability are highly correlated with other established measures of heart rate (e.g., Nunan, Donovan, Jakovljevic, Hodges, Sandercock, \& Brodie, 2009; RadespielTröger, Rauh, Mahlke, Gottschalk, \& Mück-Weymann, 2003; Vanderlei, Silva, Pastre, Azevedo, \& Godoy, 2008; Weippert, Kumar, Kreuzfeld, Arndt, Rieger, \& Stoll, 2010).

Blood Pressure. Blood pressure was measured with an Edan M3A NIBP monitor. A blood pressure cuff was attached to the machine and the blood pressure cuff was affixed to participants' non-dominant arm by the researcher. The device provided readings of systolic 
blood pressure (SBP) and diastolic blood pressure (DBP). The monitor can be programmed to give readings at various intervals; for the present study, blood pressure readings were taken two minutes apart for the entire duration of the Baseline, Induction, and Recovery tasks. Each recording of blood pressure took between 20s and 30s to complete. Data received from the manufacturer revealed that the Edan M3A blood pressure monitor performed similarly to the Datascope DPM3 blood pressure monitor. I also validated its accuracy against a standard occluding blood pressure cuff on 10 subjects. For each subject, three resting measures of blood pressure were taken with each device simultaneously within a 5 min period. Then, each participant was instructed to perform a mental arithmetic task in an effort to elevate blood pressure. Two additional measures of blood pressure were taken during the mental arithmetic task. The Edan M3A monitor performed within $5 \mathrm{mmHg}$ of the occluding cuff, which is considered adequate (e.g., Wan et al., 2010).

Spirometer. The present study used an AIRx Incentive Spirometer from ARK Therapeutic Services as a means of activating health concern in participants. Spirometers are used to measure pulmonary function, which can help diagnose conditions including chronic obstructive pulmonary disease (COPD), bronchitis, asthma, and pulmonary fibrosis, among other diseases. This particular device is used for therapeutic purposes to improve lung function. Participants first took a deep breath and then blew into a tube attached to the device. The objective was to keep a ball in the device raised for as long as possible. There was a setting on the spirometer that could be adjusted so as to require more or less effort to keep the ball elevated; the most difficult setting was used in the present study. Mouthpieces on the spirometer were disposable and the tube was detachable and could be washed with bleach. Spirometer data were not used in subsequent analyses. 


\section{Pre-experiment Self-Report Measures}

Screening Questionnaire. The screening questionnaire asked participants about exclusion criteria, including age, current medications, current health problems, and smoking status. The Screening Questionnaire is presented in Appendix A.

Demographics Questionnaire. Each participant completed a demographics questionnaire, which asked about height, weight, race, years of education, marital status, job status, income, smoking status, alcohol use, exercise frequency, and family medical history. See Appendix B for the demographics questionnaire.

Short Health Anxiety Inventory (SHAI; Salkovskis et al., 2002). The SHAI is an 18item self-report measure of health anxiety across a range of severity (not at all anxious to hypochondriasis) during the past six months. The SHAI excludes items that may be endorsed by individuals with health problems. Each item contains four answer choices based on a Guttmantype response scale and is scored from zero to three. The SHAI is comprised of two factors: Illness Likelihood, which describes one's perception that illness is probable, and Negative Consequences, which assesses the perceived impact a serious illness would have on one's life. Higher scores (maximum score $=54$ ) indicate more severe health anxiety.

In a sample of college students, convergent validity has been established through strong correlations $(r=.63$ ) with the Illness Attitude Scale (Kellner, Abbott, Winslow, \& Pathak, 1987), another measure of health anxiety (Abramowitz et al., 2007). The SHAI is moderately associated with the Beck Anxiety Inventory (BAI; Beck \& Steer, 1990) and the Social Interaction Anxiety Scale (Mattick \& Clark, 1998), with $r=.42$ for both scales (Abramowitz et al., 2007), which provides support for discriminant validity. Two-week test-retest reliability is adequate $(r=.81)$ in a sample of college students (Olatunji, Wolitzky-Taylor, Elwood, Connolly, Gonzales, \& 
Armstrong, 2009). The SHAI demonstrates good one-week test-retest reliability among patients with hypochondriasis $(r=.90$; Salkovskis et al., 2002). The SHAI demonstrates excellent internal consistency among college students $(\alpha=.96$; Abramowitz, Deacon, $\&$ Valentiner, 2007), clinical samples ( $\alpha=.95$; Salkovskis et al., 2002), and older adults ( $\alpha=.90$; Gerolimatos \& Edelstein, 2012). Internal consistency using Cronbach's alpha for the present study was .79 for young adults and .73 for older adults. The SHAI can be found in Appendix C.

Anxiety Sensitivity Index-3 (ASI-3; Taylor et al., 2007). The ASI-3 is an 18-item selfreport measure of fear of anxiety-related sensations. The ASI-3 has three dimensions: physical concerns (e.g., increased heart rate, sweating, and shortness of breath), cognitive concerns (e.g., thoughts related to anxiety), and social concerns (e.g., fear of publicly observable symptoms). Each item is rated on a Likert-type scale from zero ("very little") to four ("very much"). Higher scores (maximum score $=72$ ) indicate greater anxiety sensitivity.

To date, the psychometric properties of the ASI-3 have not been established among older adult samples. Convergent validity of the ASI-3 has been established through strong correlations with corresponding subscales of the original ASI (Reiss, Peterson, Gursky, \& McNally, 1986). In nonclinical student samples, correlation coefficients range from .93 for physical concerns to .99 for both cognitive and social concerns; in clinical samples, coefficients range from .94 for cognitive concerns to .99 for both physical and social concerns (Taylor et al., 2007).

Discriminant validity has been established, as the subscales of the ASI-3 are less strongly correlated with dissimilar subscales of the ASI compared to similar subscales of the ASI (Taylor et al., 2007). Test-retest reliability has not been examined for the ASI-3. Internal consistency of the ASI-3 total scale has not been examined, but internal consistency of each subscale has been examined in a sample of undergraduate students and clinical patients from Canada (Taylor et al., 
2007). For college students, Cronbach's alpha coefficients were: . 79 for physical concerns, .83 for cognitive concerns, and .78 for social concerns. In the clinical sample, Cronbach's alpha coefficients were: .86 for physical concerns, .91 for cognitive concerns, and .86 for social concerns. Cronbach's alpha coefficient for the total scale in the present study was .92 for young adults and .83 for older adults. See Appendix D for the ASI-3.

Montreal Cognitive Assessment (MoCA; Nasreddine et al., 2005). The MoCA is a 30point clinician-administered screening instrument of cognitive impairment developed to be sensitive to detecting mild cognitive impairment (MCI) and dementia in its early stages (Nasreddine et al., 2005). The MoCA assesses domains of cognitive functioning including visuospatial abilities, attention, memory, language, abstraction, and orientation. Higher scores indicate higher levels of cognitive functioning (i.e., less cognitive impairment). Nasreddine and colleagues recommended using a cut-off score of 26 , which has good sensitivity (90\%) and specificity (87\%) for detecting MCI. More recently, Luis, Keegan, and Mullan (2009) recommended a cut-off score of 23 , which yields higher sensitivity (96\%) and specificity (95\%) for detecting MCI.

In the present study, a cut-off score of 20 (i.e., participants must score a 20 or higher) was used. A score of 20 was selected in light of research that older adults can provide valid and reliable self-report with Mini Mental State Examination (MMSE; Folstein, Folstein, \& McHugh, 1975) scores as low as 20 (Bedard et al., 2003). The MMSE is a cognitive screening instrument. Research indicates that the MoCA is a more sensitive measure of cognitive impairment than the MMSE in vascular dementia (Dong et al., 2010), Parkinson's disease (Zadikoff et al., 2008), mild cognitive impairment (Nasreddine et al., 2005; Smith et al., 2007), and dementia (Nasreddine et al., 2005; Smith et al., 2007). Generally, findings show that participants tend to 
obtain higher scores on the MMSE relative to the MoCA. Consequently, individuals who score a 20 on the MMSE would likely score even lower on the MoCA. In other words, even a cut-off score of 20 on the MoCA is more conservative than a cut-off score of 20 on the MMSE, as these measures are not comparable.

Reliability of the MoCA has been examined in several samples. In a mixed sample of cognitively-impaired patients and non-cognitively impaired adults, test-retest reliability over an average of 35 days was .92 (Nasreddine et al., 2005). Internal consistency in this sample was .83 . Among patients with Parkinson's disease, test-retest reliability over an average of 133 days was $\operatorname{good}(r=.79)$, as was interrater reliability ( $r=.81$; Gill, Freshman, Blender, \& Ravina, 2008). Convergent validity has been established via strong correlations $(r=.87)$ with the MMSE in a mixed sample of cognitively-impaired patients and normal controls (Nasreddine et al., 2005). With Parkinson's patients, convergent validity has been established through strong correlations with a neuropsychologic battery $(r=.72)$ and the MMSE ( $r=.66$; Gill et al., 2008). Discriminant validity of the MoCA has not been examined. A copy of the MoCA is in Appendix E.

\section{Dependent Self-Report Measures}

Body Sensations Questionnaire (BSQ; Chambless, Caputo, Bright, \& Gallagher, 1984). The BSQ is a 17-item self-report measure that assesses fear of specific body sensations, such as nausea and sweating. Participants are asked to rate how afraid they are of each sensation using a Likert-type scale, from one ("not at all") to five ("extremely"). Participants can also indicate and rate additional sensations not included on the measure. Higher scores (maximum score $=85$ ) denote greater fear of body sensations.

The BSQ is strongly correlated with the Agoraphobic Cognitions Questionnaire $(r=.67)$, which measures catastrophic thoughts associated with feared body sensations (Chambless et al., 
1984). This finding provides evidence for convergent validity. Discriminant validity of the BSQ has been established in a mixed sample of panic disordered patients and non-clinical patients (Chambless et al., 1984), as moderate correlations $(r=.36$ ) have been found with the Beck Depression Inventory (BDI; Beck, Ward, Mendelsohn, Mock, \& Erbaugh, 1961) and weak correlations $(r=.21)$ have been found with the State-Trait Anxiety Inventory (STAI) Trait Scale (Spielberger, Gorsuch, \& Lushene, 1970). In a sample of older and younger adults, Teachman and Gordon (2009) found that the BSQ had high internal consistency $(\alpha=.95)$ averaged across several administrations. In a mixed sample of patients with panic disorder and non-clinical adults, Chambless and colleagues (1984) found high internal consistency for the BSQ $(\alpha=.87)$, as well as adequate one-month test-retest reliability $(r=.67)$. In the present study, the BSQ administered after Induction demonstrated good internal consistency $(\alpha=.88$ for young adults, $\alpha$ $=.58$ for older adults). See Appendix F for a copy of the BSQ.

Multiple Affect Adjective Checklist-Revised (MAACL-R; Zuckerman \& Lubin, 1985). The MAACL-R is a self-report checklist of 66 adjectives that may describe one's feelings. There is a state form and a trait form of the MAACL-R; only the state form was used in the present study. On the state form, participants are asked to mark the words "which describe how you feel right now, today" and to "check all the words that describe your feelings." The MAACL-R yields five subscales: anxiety, depression, hostility, positive affect, and sensation seeking.

The one-day test-retest reliability coefficient was .52, and five-day test-retest reliability coefficient was .09 in a sample of normal adults (Lubin \& Zuckerman, 1999). Importantly, testretest reliability of the state form of the MAACL-R is expected to be low (Lubin \& Zuckerman, 1999). Convergent validity of the state form has been examined in a sample of members of the US Air Force (Lubin et al., 1986). Participants completed self-ratings on five dimensions that 
corresponded to MAACL-R scales (e.g., self-rating on a tense-anxious scale compared to the MAACL-R anxiety scale) using a five-point scale. Results showed weak ( $r=.20$ for tenseanxious self-report and MAACL-R anxiety) to strong ( $r=.60$ for sad-depressed self-report and MAACL-R depression) correlation coefficients. Evidence for convergent validity of the trait form has been shown through moderate correlations of the MAACL-R scales ( $r$ s from .39 to .48) with the Symptoms Checklist (Derogatitis, 1977) in a sample of adolescents (Nickel, Lubin, \& Rinck, 1986), and moderate correlations of the MAACL-R scales with a checklist of depressive symptoms ( $r$ s from .42 to .46) in a sample of adults ages 50 and older (Beckingham, CoutuWakulczyk \& Lubin, 1993). Discriminant validity has not been examined. Among US Air Force recruits, Cronbach's alpha coefficients for internal consistency of the state form of the MAACL$\mathrm{R}$ ranged from .50 (sensation seeking) to .89 (positive affect), and in a sample of college students, Cronbach's alpha coefficients ranged from .74 (sensation seeking) to .95 (positive affect; Lubin et al., 1986). Although internal consistency has been examined in previous research, it was not examined in the present study, as it is inappropriate to assess with checklists in which respondents are not expected to endorse (i.e., check) all items. The MAACL-R can be found in Appendix G.

Subjective Units of Distress Scale (SUDS). To gain a self-reported measure of stress or anxiety experienced during the study, participants provided SUDS ratings, which range from 0 (no distress) to 100 (extreme distress). See Appendix H for the SUDS.

Brief COPE (Carver, 1997). The Brief COPE is a 28-item measure assessing use of coping strategies in fourteen domains. Each item is rated on a four-point Likert-type scale ranging from one ("I haven't been doing this at all") to four ("I've been doing this a lot"). The Brief COPE asks about strategies used in a particular situation. The creators of the Brief COPE 
allow users of this measure to alter the instructions to reflect specific situations. The creator of the Brief COPE also allows users to delete subscales that are irrelevant. In the present study, four subscales (eight items total) were deleted because the coping strategies represented by the items were not feasible during the present study (e.g. using substances, talking with friends). The resulting final version contained 20 questions (ten subscales with two items per subscale), which generally represented internal coping strategies. Higher scores (maximum score per subscale $=8$ ) indicate greater use of that particular coping method.

Psychometric support for the Brief COPE is limited, though more research on the psychometric properties of the original COPE exists (e.g., Carver, Scheier, \& Weintraub, 1989). Eight-week test-retest reliability for similar scales on the original COPE ranged from .48 (positive reframing) to .86 (religion) in a sample of college students (Carver et al., 1989); of note, test-retest reliability is not necessarily expected to be high given that the COPE is intended to assess coping with specific situations. Among college students, convergent validity of the COPE has been established through moderate-to-strong correlations with measures of various personality traits such as optimism, self-esteem, and hardiness (see Carver et al., 1989) as well as with related subscales of the Ways of Coping — Revised scale ( $r$ s ranging from .50 to .72; Clark, Bormann, Cropanzano, \& James, 1995). Discriminant validity of the COPE and the Brief COPE has not been examined. Internal consistency for subscales of the Brief COPE has been examined in a sample of adults recovering from Hurricane Andrew (Carver, 1997); internal consistency has not been examined among college students or older adults. In the Carver (1997) study, internal consistency for the subscales ranged from .54 (denial) to .82 (religion). In the present study, internal consistency of the subscales ranged from .36 (behavioral disengagement) to .93 (religion) for young adults, and from .11 (behavioral disengagement) to .90 (planning) for older 
adults. Of note, because each subscale of the Brief COPE contains only two items, Cronbach's alpha coefficient may be low given the positive association between number of test items and alpha (Carmines \& Zeller, 1979). The Brief COPE can be found in Appendix I.

\section{Post-experiment Self-Report Measures}

Manipulation Check. Given that the nature of the experimental manipulation is covert, a one-item question was administered to all participants asking if they engaged in the tasks as instructed by the researcher. The participants also answered one question regarding the extent to which they believed the false health-related feedback. A final question asked the extent to which the participant believed his or her health concern increased. Each item was rated using a Likerttype scale from one ("very untrue") to seven ("very true"). These questions are presented in Appendix J. Participants were also provided a blank sheet of paper asking them to describe their thoughts during the Induction period. The instructions for this open-ended writing exercise in displayed in Appendix K.

Health History Questionnaire. To get comprehensive information regarding participants' health history, a checklist of various physical and mental health problems were administered to participants. Participants were asked to indicate which problems on the checklist they had ever had, and they were allowed to write-in health problems that are not included on the list. Participants also indicated their surgical history. Final questions included whether participants had ever undergone testing of lung or respiratory function, been hospitalized as a result of lung or respiratory problems, or had procedures related to lung or respiratory function. Participants that answered "yes" to these questions were instructed to describe the nature of the tests, hospitalizations, and/or procedures. Information regarding lung problems was used to help interpret results. The Health History Questionnaire is presented in Appendix L. 


\section{Procedure}

Young adult participants were recruited from undergraduate and graduate psychology classes. Older adults were recruited from the local community via fliers posted at senior centers, assisted living facilities, physicians' offices, VFWs, continuing education classes, and religious centers. When permitted by the facility, recruitment occurred on-site. Intranet emails and a cable television ad were also used to recruit older adult participants. Older adults who participated in previous research and indicated an interest in participating in future research were contacted by mail and invited to participate in this study. Young adult participants earned course credit and $\$ 5$ as compensation and older adults earned $\$ 20$ as compensation for participation.

Young adults interested in participating in the study completed the screening questionnaire on a web-based agent, SONA, which operates under the auspices of the university. Participants that met the exclusion criteria were contacted through SONA and informed that they do not meet eligibility requirements and cannot participate in the study. Participants that were eligible to participate were sent an email inviting them to sign-up for the laboratory portion of the study. The day before the study was to take place, participants were contacted through SONA and asked to abstain from smoking, exercise, caffeine, and nicotine use for at least two hours prior to the start of the study.

Older adults interested in participating in the study called or emailed the researcher and the screening questionnaire was subsequently administered over the phone. In the event that recruitment was completed on-site, the screening questionnaire was administered in person. Older adult participants that did not meet eligibility requirements were informed immediately that they cannot participate in the study. If the potential participant met eligibility criteria, the lab portion was then scheduled. The participant was also informed to abstain from smoking, 
exercise, caffeine, and nicotine use for at least two hours prior to the start of the study

A flowchart depicting the laboratory portion of the study is presented in Figure 2. Upon arrival at the laboratory, participants were consented to participate and any questions were answered by the researcher. Participants were informed that "the purpose of the study is to understand how adults think about and cope with health-related information." They were told that they will perform a task measuring lung capacity (i.e., blowing into a spirometer), which will indicate whether they are at risk for serious lung problems. Participants were also informed that measures of heart rate and blood pressure will be taken throughout the duration of the study. Both heart rate and blood pressure were recorded because evidence suggests that older adults display lower heart rate reactivity but greater blood pressure reactivity than young adults (Uchino et al., 2010). Therefore, multiple indicators of psychological arousal were needed to account for potential age-related differences in physiological arousal.

Next, participants completed the demographics questionnaire. The researcher then administered the MoCA. Participants who scored 19 or below were excluded from the study; all participants scored at least a 20. The researcher then administered the SHAI and ASI-3.

The participants were instructed on how to put on the heart rate monitor with the following instructions:

This device is a heart rate monitor that sends information about your heart rate to a computer in the other room using a wireless signal. The heart rate transmitter belt will be worn throughout the entire study. You will wear the heart rate monitor and strap underneath your clothing, directly against your skin. It is important that you do not slouch, as the monitor can flip away from the body, which may disrupt the recordings. I will demonstrate where to place the monitor on myself, and then I will step out of the 
room so you can place it on yourself. [Researcher demonstrates placement of monitor]. After the participant placed the heart rate monitor, the researcher returned to the room and introduced the blood pressure monitor to the participant. The researcher said:

This is a blood pressure monitor. You may be familiar with this device. It is similar to blood pressure monitors used in doctor's offices and hospitals. However, this device inflates automatically and does not require the use of a stethoscope. I will put this cuff on your non-dominant arm [Researcher asks which arm is the non-dominant arm]. You will wear this throughout the entire duration of the study. Periodically, the cuff will inflate automatically, and your blood pressure will be recorded on the device. It is important to remain relatively still while the blood pressure cuff is inflating. The device has safety features to ensure that the cuff does not overinflate.

The researcher then affixed the blood pressure cuff to the participant's non-dominant arm.

Participants were instructed on how to complete the SUDS. They were informed that, each time the blood pressure cuff begins to inflate, they will rate their SUDS level at that moment and write the number that best describes their level of distress.

At this point, participants were asked to close their eyes and sit quietly for approximately three minutes to establish a baseline. The lights in the room were dimmed. The researcher set the blood pressure monitor to take two recordings two minutes apart during the baseline period (at minute 0 and minute 2.5; known as Baseline 1 and Baseline 2). Participants provided two SUDS ratings during this period coinciding with the blood pressure recordings. After the baseline period, participants were instructed on how to complete the MAACL-R and BSQ. The MAACL$\mathrm{R}$ and BSQ were counterbalanced across administrations.

Following completion of the baseline measures, participants were introduced to the 
spirometer. Participants were informed that:

This device is a spirometer. It can help determine whether a person has or may be at risk for respiratory problems such as emphysema, chronic obstructive pulmonary disease (COPD), asthma, chronic bronchitis, and other lung diseases. When I say "Go," I want you to take a deep breath, and then breathe into this tube. The goal is to keep the ball suspended in air for as long as possible with just one breath. I will time how long the ball is suspended in air. Are you ready? [Researcher waits until the participant says he or she is ready]. Go.

The researcher recorded the amount of time the ball was raised. Afterwards, the researcher asked the participant to sit quietly and comfortably while the data were examined.

After roughly 30 seconds, the researcher returned to the participant and informed the participant that:

Compared to other individuals your age, the amount of time you expelled air is quite low. This suggests that you may be at risk for lung diseases, such as chronic obstructive pulmonary disease (COPD), emphysema, chronic bronchitis, or other lung problems. These problems tend to be chronic and progressive. People with these lung problems often experience shortness of breath, like they cannot get enough oxygen. People may also experience wheezing, low energy levels, chronic cough, pain in the chest, and mucus production. Some people eventually require the use of oxygen tanks or surgery. After this experiment is done, I will give you some more information about these results, and I encourage you to speak with your physician.

The purpose of this feedback was to elicit a state of health anxiety. Providing false information has been shown to activate illness concern (see Hadjistavropoulos et al., 1998; Lecci \& Cohen, 
2002), which is a "transient hypochondriasis" (Barsky \& Klerman, 1983, p. 274).

Following the presentation of the illness information, participants were read the following instructions: "During this period, I would like you to think about the information I just told you and any potential negative consequences." After reading the instructions, the researcher set the blood pressure monitor to take two readings two minutes apart (minutes 0 and 2.5; referred to as Induction 1 and Induction 2), and participants provided two additional SUDS ratings. After this three-minute period, participants were then asked to complete the MAACL-R and BSQ again.

Participants were then instructed to think about the illness information again for about one minute. The purpose of this one-minute re-induction was to increase the participants' illness concern, which may have dwindled while completing assessments. After one minute, they were asked to complete the SUDS describing their peak level of anxiety during the last minute. The researcher then stated "we are also interested in how individuals cope with new health-related information. Please cope or deal with the illness information in the way that you usually do, until I ask you to stop." The researcher set the blood pressure monitor to take two final readings (minutes 0 and 2.5; referred to as Recovery 1 and Recovery 2), and participants provided two final SUDS ratings. After this recovery period, participants completed the MAACL-R and BSQ. They also completed the Brief COPE, which asked them to report which strategies they used during the three-minute recovery period.

Following the completion of the Brief COPE, participants were provided a sheet of paper and asked to describe their thoughts after receiving the health-related feedback pertaining to the spirometer. Next, they completed the manipulation check questions. One final questionnaire, the Health History Questionnaire, was administered to participants to gather information about health problems and history of respiratory problems. 
Finally, participants were debriefed and told that the goal of the study was to examine the experience of health anxiety and how individuals cope with health anxiety. They were informed that the feedback regarding the spirometer was false and that the spirometer was set to require more effort to keep the ball elevated. Participants were then instructed to engage in a deepbreathing exercise. The deep-breathing exercise lasted about five minutes, after which the heart rate monitor and blood pressure cuff were removed. Participants were then paid, provided with a list of resources on anxiety, and thanked for their participation.

\section{Results}

\section{Power Analysis}

A power analysis was conducted using G Power 3.1.3 (Faul, Erdfelder, Lang, \& Buchner, 2007), which suggested a sample size of 44 participants (22 young adults, 22 older adults) to obtain a power level of .80 to detect a medium-sized effect for age or time of measurement in a 2 x 3 repeated measures multivariate analysis of variance (MANOVA). Slightly larger sample sizes have been used by Gramling et al. (1996; total $n=30$ ) and Abramowitz and Moore (2007; total $n=27$ ) to examine the effects of a health anxiety induction on young adults. In the present study, data were collected from 72 participants, suggesting adequate power.

\section{Checking Assumptions}

Prior to conducting analyses, each dependent variable was examined for normality via skewness statistics. Each variable demonstrated problematic skew for at least one time point. The vast majority of variables were positively skewed, which is expected, as this is not a clinical sample and participants were screened for numerous health problems, resulting in a healthy sample. Each variable was transformed using a square root transformation. Normality of the transformed variables were evaluated; normality was achieved for all variables, except mean 
heart rate (HR), BSQ scores, and the MAACL-R subscale scores for anxiety, depression, and hostility continued to be positively skewed. These variables were log transformed. Because some of the MAACL-R subscale scores were zero, a value of one was added to each score and then this value was $\log$ transformed. Following the log transformation, normality was achieved for mean HR. Normality was not achieved for BSQ scores, although the degree of skew was attenuated. Accordingly, I used log transformed BSQ scores in analyses. With the log transformation, the MAACL-R subscale scores demonstrated greater skew than with the square root transformation. Although normality was not achieved, I opted to use the square root transformed MAACL-R variables in subsequent analyses. The failure to achieve a normal distribution was not expected to substantially alter results, as MANCOVAs are robust to slight deviations (Tabachnick \& Fidell, 2007).

Analyses were conducted with the transformed and non-transformed data. Because differences in results were found for transformed versus non-transformed data, results reflect analyses conducted with transformed data. However, descriptive statistics were conducted on non-transformed variables for ease of interpretation. Pre-experiment questionnaires, the MoCA, SHAI, and ASI-3, were also examined for skew. The MoCA demonstrated negative skew and the ASI-3 demonstrated positive skew. Both underwent a square root transformation and normality was achieved. Independent samples t-tests involving the transformed and non-transformed variables were conducted; no differences in results were found, so results from independent samples t-tests are reported based on non-transformed variables.

Dependent variables were also examined for univariate and multivariate outliers. Univariate outliers were defined as scores greater or less than 3.2 standard deviations from the mean, as recommended by Tabachnick and Fidell (2007). Observed scores that met these criteria 
were replaced with the highest or lowest value within 3.2 standard deviations from the mean. Twenty-three univariate outliers were identified and replaced; the variable with the most univariate outliers was mean HR, with 14 observations replaced. Multivariate outliers were examined using scatter plots. No multivariate outliers were identified.

Levene's test of homogeneity of variance was used to determine if the variables violated the assumption of homogeneity of variance. In cases of unequal sample sizes (due to missing data), Box's M test was used to test for homogeneity of covariance matrices. Because Box's M is considered a conservative test, a $p$ value of .001 was selected, as recommended by Weinfurt (2000). Mauchly's test of sphericity was used to test the assumption of sphericity for variables with more than two levels of measurement.

\section{Calculating Heart Rate and Heart Rate Variability}

To analyze heart rate data, the Polar Performance Precision Program was used and set at a low filtering level. The algorithm used in the program uses median and moving average-based filtering methods to detect aberrant recordings. Aberrant recordings (e.g., extremely high peaks or lost signals) were visually examined using the preview function available on the program and replaced with the participant's mean HR when appropriate. The mean percentage of recordings that required replacement ranged from $0.04 \%$ (Re-induction) to $0.21 \%$ (Induction) for young adults and $0.03 \%$ (Re-induction) to $0.16 \%$ (Induction) for older adults. Across each period of recording, the Polar Program provided mean HR values and several measures of heart rate variability (HRV), a measure of the variance in time between each beat of the heart (i.e., the inter-beat interval; IBI). In the present study, SDNN (i.e., standard deviation of the inter-beat interval) was calculated as a measure of HRV. SDNN was chosen because it "reflects the oscillating influences of the sympathetic and parasympathetic systems on the cardiac [system]" 
(Zucker, Samuelson, Muench, Greenberg, \& Gevirtz, 2009, p. 137). Thus, less HRV (i.e., smaller SDNN values) suggests greater influence of the sympathetic system, denoting a stress response. Conversely, larger SDNN values indicate enhanced parasympathetic activity. Baseline, induction, and recovery periods each lasted about three minutes. Mean HR and SDNN were calculated for each minute of each period (i.e., minute 1, minute 2, and minute 3).

\section{Baseline Age-Related Differences}

Independent-samples t-tests were conducted on measures administered at baseline comparing older and young adults. For measures that were administered more than one time during the baseline period (e.g., SUDS) and psychophysiological variables (e.g., heart rate, heart rate variability, systolic blood pressure, and diastolic blood pressure), the final recording was examined across age groups, as this score was believed to best represent participants' baseline level (i.e., participants may have been anxious about participating in the study at first). With regards to self-report measures, significant age differences at baseline were found for the SHAI, $t$ $(70)=2.58, p<.01$, BSQ, $t(70)=3.18, p<.01$, MAACL-R anxiety, $t(70)=2.10, p<.05$, and MAACL-R hostility, $t(70)=2.65, p<.01$, such that older adults reported lower health anxiety, fear of body sensations, anxiety, and hostility compared to young adults. Baseline differences were also found for SDNN, $t(70)=6.95, p<.01$, such that SDNN was lower among older adults, indicating that older adults exhibited less heart rate variability relative to young adults. Baseline differences were found for systolic blood pressure (SBP), $t(70)=2.28, p<.05$, and diastolic blood pressure (DBP), $t(70)=2.36, p<.05$, with older adults exhibiting higher systolic and diastolic blood pressure. See Table 3 for descriptive statistics for baseline measures.

\section{Effects on Physiological Arousal}

Blood pressure. To explore the effects of a health-anxiety induction and age on blood 
pressure, a 2 (Age: older vs. young) x 3 (Time: Induction 1, Induction 2, Recovery 1) repeated measures multivariate analysis of covariance (MANCOVA) was conducted with SBP and DBP as dependent variables. The second SBP and DBP recordings during recovery were included as covariates in the analysis, as this value was believed to best represent participants' true baseline systolic and diastolic blood pressures. That is, averaged across participants, the final recording of blood pressure during recovery was lower (SBP: $M=125.30 \mathrm{mmHg}$; DBP: $M=75.24 \mathrm{mmHg}$ ) than the measures of blood pressure during baseline (SBP: $M=127.38 \mathrm{mmHg}$; DBP: $M=75.64$ $\mathrm{mmHg}$ ), suggesting that participants did not actually achieve a true baseline during the baseline period, possibly due to stress associated with acclimating to the demands of the study.

Sample sizes were unequal (young adults: 35; older adults: 36 ) due to a malfunction of the blood pressure monitor. Box's M test was not significant, $X^{2}(21)=27.49, p=.25$, indicating that covariance matrices were equal across groups. Mauchly's test of sphericity was not significant for both SBP and DBP. Levene's test was significant for SBP at Induction 2 and DBP at Induction 2 and Recovery 1, indicating that the assumption of homogeneity of variance was violated for those three variables. However, the ratio of the largest variance to the smallest variance was 0.70 , which is far less than the recommended criterion of 10:1 (Tabachnick \& Fidell, 2007). Thus, variances across variables were not dramatically different and therefore likely did not influence results (Tabachnick \& Fidell, 2007). For both SBP and DBP, there were no main effects of time or age. There were no significant age by time interactions for either SBP or DBP.

Heart rate. To determine the effects of a health-anxiety induction and age on mean HR and HRV (as measured by SDNN), a 2 (Age: older vs. young) x 6 (Time: Induction 1, Induction 2, Induction 3, Re-induction, Recovery 1, Recovery 2) repeated measures MANCOVA was 
conducted with mean HR and SDNN as dependent variables; mean HR and SDNN during the final minute of the recovery period were included as covariates in the analysis. The final minute of the recovery period was selected to best represent participants' true baseline, as it appeared participants' heart rate continued to decline throughout the baseline period, and heart rate variability continued to increase, suggesting that a true, stable baseline was not achieved during the baseline period. Moreover, that the final minute of the recovery period produced the lowest mean heart rate $(M=74.67 \mathrm{bpm})$ and highest heart rate variability value $(M=41.41 \mathrm{~ms})$ provides further evidence that these values best represent participants' true baseline.

Sample sizes were unequal (young adults: 36; older adults: 35) due to problems with the heart rate monitor. In light of unequal sample sizes, Box's M was examined and was found to be significant, $X^{2}(78)=183.51, p<.001$, indicating that the assumption of equality of covariance matrices had been violated. Given that sample sizes were very similar and MANCOVA is a robust statistical analysis, I did not expect results to be affected by unequal covariance matrices (Tabachnick \& Fidell, 2007). Mauchly's test of sphericity was significant for both mean HR, $\chi^{2}$ $(14)=292.43, p<.01$, and SDNN, $\chi^{2}(14)=45.17, p<.01$. Degrees of freedom were corrected using Greenhouse-Geisser estimates of sphericity ( $\varepsilon=.32$ for mean HR and .81 for SDNN). Levene's test of equality of error variances was non-significant for all variables.

For mean HR, there was no significant main effect for time or age. There also was not a significant age by time interaction. When examining SDNN, there was no significant main effect for time, although a significant main effect for age did emerge, $F(1,67)=11.28, p<.01$, partial $\eta^{2}=.14$ (see Figure 3). An age by time interaction was not significant. Follow-up analysis for age revealed that older adults $(M=30.02 \mathrm{~ms}$ ) had significantly lower SDNN (i.e., less HRV) than young adults $(M=47.73 \mathrm{~ms})$. 


\section{Effects on Subjective Arousal}

SUDS. To examine the effect of a health anxiety induction and age on subjective arousal, a 2 (Age: older vs. younger) x 5 (Time: Induction 1, Induction 2, Re-induction, Recovery 1, Recovery 2) repeated measures analysis of covariance (ANCOVA) was conducted with SUDS as the dependent variable. The second SUDS rating during baseline was included as a covariate, as this score best represented participants' baseline distress (i.e., was the lowest SUDS score across all time periods). Levene's test of equality of error variances was non-significant, indicating that the assumption of equality of error variances was upheld. Mauchly's test of sphericity was significant, $\chi^{2}(9)=25.21, p<.01$. Degrees of freedom were corrected using Greenhouse-Geisser estimates of sphericity $(\varepsilon=.82)$.

Results revealed a main effect for time, $F(3.28,226.51)=8.33, p<.01$, partial $\eta^{2}=.11$. Follow-up polynomial contrasts revealed a significant quadratic effect for time, $F(1,69)=$ $14.05, p<.01$, partial $\eta^{2}=.17$ (see Figure 4 for a graph of the main quadratic effect for time). No main effect for age emerged. An age by time interaction neared significance, $F(3.28,226.51)=$ $2.53, p=.053$, partial $\eta^{2}=.04$. Figure 5 displays SUDS scores over time for older and young adults separately. Follow-up simple effects analysis applying a Bonferroni adjustment to account for family-wise error $(p<.01)$ revealed that SUDS ratings during Re-induction $(M=27.44)$ were significantly higher than Induction 2 ratings $(M=22.92)$, Recovery 1 ratings $(M=22.93)$, and Recovery 2 ratings $(M=18.17)$. Induction 1 ratings $(M=24.96)$ were significantly higher than Recovery 2 ratings only. Recovery 2 ratings were significantly lower than SUDS ratings at all time points.

BSQ. To investigate the effect of a health anxiety induction and age on fear of body sensations, a 2 (Age: older vs. younger) x 2 (Time: Induction, Recovery) repeated measures 
ANCOVA was conducted with BSQ scores as the dependent variable. Baseline BSQ scores were included as a covariate. Levene's test of equality of error variances was non-significant, indicating that error variances were equal across variables. Results indicated a main effect of time, $F(1,69)=7.10, p<.01$, partial $\eta^{2}=.09$. No main effect for age was found. No significant interaction between time and age was found. Follow-up simple effects analysis revealed significantly higher BSQ scores (i.e., greater fear of body sensations) during Induction $(M=$ 20.72) compared to Recovery $(M=19.51)$.

\section{Effects on Emotions}

To test the effect of a health anxiety induction and age on emotions, I conducted a 2 (Age: Older vs. Younger) x 2 (Period: Induction, Recovery) repeated measures MANCOVA with each subscale of the MAACL-R as the dependent variable. Baseline MAACL-R scores were included as covariates. Levene's test was significant for anxiety during the Recovery period $(F=5.45, p=.02)$ and hostility during the Induction period $(F=6.00, p=.02)$; the ratio of the largest variance to the smallest variance was 11.75 , which is greater than the criterion of 10:1 (Tabachnick \& Fidell, 2007). For both variables, young adults demonstrated greater variance in responding than older adults. In light of the large, equal-sized groups, as well as the fact that only two of the ten variables included in these analyses demonstrated unequal variances, findings were not expected to be influenced by unequal variances across groups (Metzger, personal communication, January 29, 2014).

Significant main effects for time emerged for the MAACL-R subscales of anxiety, $F$ (1, $66)=4.35, p<.05$, partial $\eta^{2}=.05$, depression, $F(1,66)=4.29, p<.05$, partial $\eta^{2}=.04$, and positive affect, $F(1,66)=4.32, p<.05$, partial $\eta^{2}=.04$. Follow-up simple effects analyses revealed that anxiety and depression scores were significantly higher during the Induction period 
( $M=1.79$ for anxiety; $M=0.82$ for depression) compared to the Recovery period ( $M=0.90$ for anxiety; $M=0.38$ for depression). Conversely, positive affect was significantly lower during Induction $(M=3.65)$ than Recovery $(M=4.28)$.

Significant main effects of age emerged for the MAACL-R subscales of hostility, $F$ (1, 66) $=4.52, p<.05$, partial $\eta^{2}=.06$, and sensation seeking, $F(1,66)=8.92, p<.01$, partial $\eta^{2}=$ .12. Follow-up analyses showed that younger adults reported greater hostility $(M=0.67)$ relative to older adults $(M=0.38)$, whereas older adults indicated greater sensation seeking $(M=3.89)$ compared to young adults $(M=3.29)$.

One significant age by time interaction emerged for the anxiety subscale of the MAACL$\mathrm{R}, F(1,66)=15.64, p<.01$, partial $\eta^{2}=.19$, which qualified the main effect of time. Follow-up analyses revealed that older adults $(M=0.83)$ and young adults $(M=0.97)$ did not significantly differ on anxiety during Recovery, whereas young adults $(M=2.53)$ reported significantly higher anxiety during Induction compared to older adults $(M=1.06)$. See Figure 6 for a graph of MAACL-R anxiety scores for older and young adults over time. No other significant interactions were found.

\section{Use of Coping Strategies}

Descriptive statistics on the Brief COPE subscale scores are presented in Table 4. Results indicated that older adults reported using active coping, planning, positive reframing, religion, and acceptance the most, whereas they used behavioral disengagement (i.e., "giving up" on coping), humor, denial, self-blame, and self-distraction the least. Young adults reported using self-distraction, active coping, planning, acceptance, and positive reframing the most, and used behavioral disengagement, self-blame, denial, humor, and religion the least (See Table 5 for a rank order list of coping strategies used by each age group). Significant differences between 
older and young adults were found for denial, $t(70)=1.77, p<.01$, and humor, $t(70)=2.20, p<$ .01 , such that young adults reported significantly greater use of denial and humor to cope with health-related feedback compared to older adults.

Pearson product moment correlations were conducted to examine the associations between each coping strategy and the dependent variables during the recovery period. Among older adults (see Table 6), greater use of denial was moderately associated with heart rate variability, as measured by SDNN, during minutes $2(r=.36)$ and $3(r=.39)$, such that greater use of denial was associated with increased heart rate variability. Active coping was moderately associated with mean heart rate at minutes $2(r=-.34)$ and $3(r=-.35)$ in that use of active coping was associated with reduced heart rate. Active coping was also moderately associated with sensation seeking $(r=.45)$, suggesting that individuals who scored higher on sensation seeking may have been more likely to use active coping strategies. Finally, self-blame was moderately associated with greater SUDS ratings ( $r$ s of .35 at both time periods), BSQ scores ( $r$ $=.34)$, depression $(r=.48)$, and hostility $(r=.34)$. Self-blame was also strongly associated with anxiety $(r=.53)$. Together, these results indicate that self-blame was associated with increased distress, fear of body sensations, and negative affect among older adults.

The associations among coping strategies and the dependent variables were also examined among young adults (see Table 7). Moderate to strong associations were found between humor and mean heart rate $(r=-.43$ at $\min 1, r=-.51$ at $\min 2$, and $r=-.56$ at $\min 3)$, such that greater use of humor was associated with reduced heart rate, and this relation strengthened across the recovery period. Humor was also moderately associated with heart rate variability at minutes $2(r=.47)$ and $3(r=.49)$, as greater use of humor was associated with increased heart rate variability. Religion was moderately associated with mean heart rate at 
minutes $2(r=-.39)$ and $3(r=-.38)$, denoting that greater use of prayer and other religious strategies were associated with reduce heart rate; however, greater use of prayer was also associated with greater self-reported depression $(r=.35)$. Self-distraction was moderately associated with SUDS at time $2(r=.36)$ and anxiety $(r=.39)$, suggesting that self-distraction may paradoxically increase distress and anxiety. Finally, self-blame was moderately associated with anxiety only $(r=.43)$.

\section{Manipulation Check}

Participants completed three post-experiment questions concerning the extent to which they followed study instructions, believed the health-related feedback, and became more concerned about their health. Independent-samples t-tests comparing older and young adults were conducted on mean responses to each question. No significant differences were found (see Table 4 for means and standard deviations for each manipulation check question). Results indicated that both older and young adults attempted to follow the instructions, with $97.2 \%$ of young adults and $94.4 \%$ of older adults giving ratings of six or seven, indicating it was very true they attempted to follow instructions. Findings were mixed with regard to whether participants believed the health-related feedback, as $30.5 \%$ of young adults and $19.4 \%$ of older adults generally did not believe the feedback (i.e., rated as one to three). Conversely, $38.8 \%$ of young adults and $72.2 \%$ of older adults generally did believe the feedback (i.e., rated as five to seven). A chi-square analysis for this item was conducted and revealed significant differences across age groups, $X^{2}(6, N=72)=14.00, p<.05$, suggesting that significantly more older adults believed the health-related feedback compared to young adults. Similarly, $36.1 \%$ of young adults and $25.0 \%$ of older adults did not become more concerned about their health following the feedback, compared to $50.0 \%$ of young adults and $52.8 \%$ of older adults who did become more concerned 
about their health. Chi-square analysis did not reveal differences across age groups.

Participants were also asked to describe their thoughts during the induction period and these responses were coded to identify common themes using a conventional content analysis approach. Because the administration of the thought description questionnaire was exploratory in nature and there were no a priori theories regarding the content of these descriptions, a conventional content analysis approach was deemed appropriate, as coding categories are derived directly from the data (see Hsieh, 2005). The unit of analysis was the sentence. In cases in which two sentences were combined through the use of a conjunction (e.g., and, but), each clause was considered an independent sentence. For example, "I thought about how I should have quit smoking earlier, and I decided I would exercise more frequently" would be considered two individual sentences. Emergent coding was adopted. That is, the first author read through the paragraphs for each participant identifying themes. As new themes were discovered, a definition of that theme and examples of statements representing the theme were compiled. Each sentence could only be coded as pertaining to a single theme. In ambiguous cases, the first author consulted with clinical researchers, and determined the appropriate theme through consensus. After all open-ended responses were reviewed and no additional themes were identified, the researcher reviewed the themes. Redundant or overlapping themes were condensed and themes that were too broad or general were clarified into more specific themes. For example, many participants reflected on their past health-related behaviors; this general category was then divided such that participants could reflect on past positive or past negative behaviors. Finally, all of the written responses were read again to code the responses based on the new, clarified themes. Only the first author coded the writing exercise as only she had access to the hard copies of the data; thus, inter-rater reliability could not be examined. However, as these analyses were 
exploratory in nature, researcher bias was not expected to influence results.

A rank order list of the most common themes by age group is presented in Table 8. For older adults, common themes included making future health-related plans (e.g., increasing exercise, discussing the results with their physician), reflecting on past healthy behaviors (e.g., exercising, quitting smoking), reflecting on past negative behaviors (e.g., smoking cigarettes, not exercising), thinking about family members, and not being surprised by the results (i.e., expecting to do poorly). For young adults, common themes included making future healthrelated plans, reflecting on past healthy behaviors, trying to keep the results in perspective (e.g., "breathing issues are not as serious as some other types of health problems"), active use of coping strategies (e.g., using deep breathing, distraction), and thinking about family members.

\section{Discussion}

The present study examined the effects of negative health-related feedback on physiological arousal, subjective arousal, and emotions, as well as use of coping strategies, across older and young adults. Results indicated that, for both older and young adults, health anxiety is experienced as a combination of decreased positive affect and increased self-reported distress, fear of body sensations, anxiety, and depression. When experiencing health anxiety, young adults reported significantly greater anxiety relative to older adults. With regards to coping strategies, older and young adults reported using similar strategies, although young adults appear to endorse using avoidance strategies more so than older adults in the present study.

This study was among the first studies to examine affect associated with health anxiety. Findings with respect to affect were consistent with the tripartite model of emotion (Clark \& Watson, 1991), which posits that anxiety is comprised of increased negative affect (i.e., anxiety and depression). That health anxiety is consistent with the tripartite model provides additional 
evidence that health anxiety is closely related to the anxiety disorders. Moreover, present findings expand upon the existing literature on health anxiety demonstrating increased anxiety when health concern is activated (e.g., Abramowitz \& Moore, 2007; Fergus \& Valentiner, 2012; Longley et al., 2005) by exploring other emotions (e.g., depression, hostility, positive affect), which more fully characterizes the experience of health anxiety. Age-related differences were found for hostility and sensation-seeking, such that young adults reported greater hostility than older adults across all time points and older adults reported greater sensation seeking at all time points. However, these emotions were not contingent upon the experimental induction, and therefore, it does not appear as though hostility and sensation seeking are integral components of the experience of health anxiety.

Consistent with Teachman et al. (2007), health anxiety was experienced similarly for older and young adults. That few age-related differences across the dependent variables were found may be a function of the nature of the stressor. In other words, health-related stressors may be threatening and/or distressing regardless of age. This finding is supported by the Teachman and Gordon (2009) study, which found increased heart rate and self-reported distress among both older and young adults in response to health-related stressors (i.e., candle-blowing and strawbreathing tasks that mimic health symptoms), whereas only young adults experienced increased heart rate and distress in response to a social stressor (i.e., giving an impromptu speech).

One key difference between age groups was that young adults experienced significantly more anxiety in response to health-related feedback than older adults. One could argue that this finding is counterintuitive, as older adults should be more anxious about their health given that health concerns and associated consequences of health problems are more salient for this age group. Furthermore, a greater percentage of older adult participants believed the health-related 
feedback and reported being more concerned about their health, suggesting that older adults may be expected to report greater anxiety. That older adults experienced less anxiety may be explained, at least in part, by older adults' past experiences with health problems. That is, older adults likely have had more experience with health problems (both in themselves and vicariously through others) during which they developed skills to cope with such problems. For example, their expectations may be more realistic (and possibly less anxiety-inducing), they may implement coping strategies more effectively, or they may choose to use coping strategies that are better suited to coping with health concerns (see Amirkhan \& Auyeung, 2007). Although older and young adults did report using similar coping strategies, the most commonly employed strategy for young adults was self-distraction, which is consistent with research suggesting that younger adults are more likely than older adults to use avoidance as a coping strategy (Amirkhan \& Auyeung, 2007). It is possible that self-distraction is not an effective means of coping with health anxiety, and may paradoxically increase anxiety (Hayes, Wilson, Gifford, Follette, \& Strosahl, 1996). Older adults also tend to exhibit a positivity bias (Mather \& Carstensen, 2005), focusing on positive rather than negative aspects. In this study, older adults may have focused on positive aspects of the feedback whereas young adults may have focused on negative aspects of the feedback. However, in consideration of participants' responses during the open-ended writing component, this hypothesis was not supported, as the most common themes for both older and young adults was making plans for the future and reflecting on past healthy behaviors. Consequently, it appears most likely that young adults' higher self-reported anxiety during Induction may be related to use of less effective coping strategies (i.e., self-distraction, which may be a form of avoidance) than older adults.

Health anxiety was associated with increased fear of body sensations for both age groups. 
This finding was consistent with the cognitive-behavioral model of health anxiety, as activated health concern increases vigilance to and concern regarding body sensations. Similarly, subjective distress increased during Induction and Re-induction, and decreased during Recovery. That distress increased when health concern was activated is consistent with Abramowitz and Moore (2007), and present findings expand upon the Abramowitz and Moore study by demonstrating that activating health concern increases distress even among non-clinical samples. Interestingly, distress was highest during the Re-induction period across both age groups. That distress was highest during Re-induction was surprising, as one might expect participants to habituate to the feedback over time. It may be that participants were implementing coping strategies during Induction, but were not attempting to cope during Re-induction. Because participants were not asked to report on their thoughts during Re-induction, it is unknown whether this is the case. Alternatively, thinking about the feedback during Induction may have resulted in sensitization, such that asking participants to think about the feedback a second time during Re-induction resulted in an amplified distress response. The phenomenon of sensitization in the context of anxiety has been documented with both animal and human models, as exposure to an acute stressor can cause an increased anxiety response to the stressor later on (see Grillon, Duncko, Covington, Kopperman, \& Kling, 2007).

As for physiological arousal, there did not appear to be any changes in heart rate or blood pressure as a result of the health-related stressor, which was surprising as anxiety disorders are associated with increased blood pressure (e.g., Diaper et al., 2012; Steptoe \& Vögele, 1992) and heart rate (e.g., Steptoe \& Vögele, 1992; Teachman \& Gordon, 2009. Moreover, findings with respect to physiological arousal were not consistent with the tripartite model of emotion (Clark \& Watson, 1991), as this model indicated that anxiety is also comprised of increased physiological 
arousal. The lack of findings suggests that blood pressure and heart rate as measures of physiological arousal may not be sensitive enough to detecting changes in arousal in response to the manipulation of the present study. Conversely, desynchrony among anxiety response systems has been documented in other types of anxiety, such as phobias (e.g., Abelson \& Curtis, 1989; Barlow, 1980). Thus, present findings are not entirely inconsistent with other anxiety disorders. Age-related differences in blood pressure and heart rate were found. At baseline, there were age-related differences in blood pressure, such that older adults exhibited greater SBP and DBP; this finding was not entirely unexpected, as increases in blood pressure are associated with advancing age (Uchino et al., 2010), for example, hypertension is increasingly common as one ages (Administration on Aging, 2001). Older adults were found to have less heart rate variability relative to young adults, indicating that older adults experience a greater stress response in general. Research suggests that decreased HRV among older adults may reflect normative agerelated changes in the cardiovascular system (see Uchino et al., 2010). Importantly, decreased HRV also implies that older adults may be less equipped to handle stressors, including healthrelated stressors. As posited by the Strength and Vulnerability Integration model (SAVI; Charles, 2007), older adulthood is associated with physiological vulnerabilities (such as decreased HRV, which connotes decreased ability to cope with a stressor), and when overwhelmed, older adults may be less able to cope with stressors in light of these vulnerabilities. In the present study, older adults appeared to adequately cope with health-related stressors (as evidenced by return to baseline during the Recovery period for self-report variables such as SUDS and MAACL-R anxiety), suggesting that the present manipulation did not tax older adults' resources considerably. That is, we might expect older adults to exhibit greater difficulty with coping with more intense or longer lasting stressors. This possibility is speculative, as the intensity and length 
of the stressor was not manipulated across participants.

Surprisingly, older and young adults did not significantly differ on the use of most coping strategies. When examining the relative use of different coping strategies, the most commonly used coping strategies reported by older and young adults were similar. Specifically, four of the top five coping strategies were the same for older and young adults (i.e., active coping, planning, positive reframing, and acceptance). One could argue that active coping and planning are problem-focused approaches, whereas positive reframing and acceptance are emotion-focused approaches (see Heckhausen \& Schulz, 1995). That both age groups reported using these strategies stands in contrast to previous literature suggesting that older adults are more likely to use emotion-focused strategies and young adults are more likely to use problem-focused strategies (Blanchard-Fields et al., 2004). Significant age-related differences did emerge in the present study such that young adults reported greater use of denial and humor; however, these strategies were not the most commonly employed strategies for either age group. It is important to note that the types of coping strategies available for use in the present study were constrained, for example, participants could not use alcohol or discuss their concerns with friends given the setting and nature of the study. Thus, it is possible that participants would have coped with health concerns differently in an alternate context, and more age differences may have emerged.

Age-related differences with respect to how various coping strategies were related to physiological arousal, self-reported arousal, and negative emotions associated with health anxiety were observed. Not surprisingly, active coping was associated with reduced heart rate among older adults. In contrast, humor was associated with reduced heart rate and increased heart rate variability among young adults. Although humor may seem useful in the short term, as in the case of this study, it may not be an effective long-term coping strategy for health concerns, 
unlike other strategies such as active coping. In other words, without active steps to cope with health problems (e.g., increase exercise, follow-up with physician visits), health problems are likely to worsen. Thus, older adults' use of active coping and younger adults' use of humor appears consistent with research suggesting that older adults are more skilled at matching the type of emotion regulation strategy to the context (Blanchard-Fields, 2007). Interestingly, selfblame was strongly associated with various negative emotions (e.g., anxiety, depression, and hostility) and distress among older adults, whereas self-blame was associated with anxiety only among young adults. Overall, these results suggest that self-blame may not be effective for coping with health anxiety, and may lead to even more negative emotions among older rather than young adults. Similarly, among young adults, self-distraction was associated with an increase in distress and anxiety, suggesting that this strategy is not helpful in coping with health concern. This finding is not surprising, as experiential avoidance is known to increase anxiety (Hayes et al., 1996). Self-distraction was not associated with any of the dependent variables among older adults, which suggests that older adults may have learned that self-distraction is not a useful strategy, and therefore, they avoid using such a strategy. Finally, religion was associated with decreased heart rate but also increased depression among young adults. Although seemingly paradoxical, desynchrony between physiological arousal and self-reported emotion is consistent with research on anxiety (see Abelson \& Curtis, 1989; Barlow, 1980).

The results of the present study both support and expand upon the cognitive-behavioral model of health anxiety. First, this study showed that illness-related information does trigger health concern and subsequent sequelae. Second, this study expands upon the model by identifying specific emotions (e.g., subjective distress, anxiety, depression, decreased positive affect) in response to health-related triggers. Currently, the model addresses cognitions and 
behaviors only, and present results provide good support for a revision of the model to include affective components so as to better characterize the nature of health anxiety. Importantly, physiological arousal did not appear to be an integral component of health anxiety per current findings, and inclusion of physiological arousal as part of the cognitive-behavioral model of health anxiety would be premature. Third, the present study elaborates on coping factors, which is considered an integral component predicting whether one will experience health anxiety, by identifying which strategies may reduce health anxiety (e.g., self-distraction and self-blame may not effectively reduce health anxiety). The present study adds additional support to the notion that certain coping factors appear to protect against developing health anxiety, as some coping strategies (e.g., humor, active coping) were associated with lower physiological arousal. Finally, the present study provides support that the cognitive-behavioral model of health anxiety is generally similar for older and young adults, as few age-related differences were found.

Although results were significant, effect sizes were small for many analyses, indicating that the manipulation may have been weak. This notion is partially supported by the manipulation check questions, as a number of participants (younger adults more so than older adults) did not believe the feedback they were given and the feedback did not elicit health concern for a portion of participants. It is possible that participants misunderstood the question regarding the extent to which they believed the health-related feedback. This question was intended to assess whether participants suspected the deception, but may not have been worded clearly. When examining participants' open-ended descriptions of their thoughts during the induction period, some participants noted that the feedback stood in contrast to how they viewed themselves (e.g., "I go jogging every week; how could I have lung problems?"). Statements such as these suggest that participants did not necessarily believe they were being deceived; rather, 
they questioned how the feedback applied to themselves. Similarly, it is possible that the participants that did not become more concerned about their health were already implementing coping strategies to prevent themselves from becoming concerned. This is supported by the fact that some participants wrote about using coping strategies in their open-ended responses. Finally, the manipulation simply may not have been robust enough, and that other health problems may have more effectively induced concern.

\section{Implications for Conceptualization, Assessment, and Treatment}

The present results indicate that health anxiety is experienced as a combination of increased fear of body sensations, distress, anxiety, depression, and decreased positive affect, with no changes in physiological arousal (heart rate and blood pressure). These findings suggest that health anxiety is partially consistent with the tripartite model of emotion; the tripartite model of emotion indicates that anxiety is comprised of increased negative affect with physiological arousal (Clark \& Watson, 1991; Teachman et al., 2007), and the present findings support this model with respect to affect only. That findings were partially consistent with the tripartite model of emotion provides some support for the conceptualization of health anxiety as an anxiety disorder. That findings regarding physiological arousal and self-reported distress and affect differed is consistent with previous research denoting desynchrony in anxiety response systems (e.g., Barlow, 1980), which nevertheless also lends some support to health anxiety as sharing characteristics with the anxiety disorders. Current conceptualizations of health anxiety, including the cognitive-behavioral model of health anxiety (Salkovskis \& Warwick, 1986), focus exclusively on cognitions (e.g., cognitive preoccupation with illness, catastrophic thoughts that symptoms indicate serious illness) and behaviors (e.g., safety seeking behaviors, such as reading about illnesses). In fact, current diagnostic criteria for Illness Anxiety Disorder (APA, 2013) 
address only cognitions and behaviors. Results of this study suggest that changes in affect may be part of the presenting picture. Therefore, revision of the cognitive-behavioral model of health anxiety as well as diagnostic criteria for Illness Anxiety Disorder may be warranted, so as to more fully capture the experience of health anxiety. Inclusion of the affective elements in the diagnostic criteria for Illness Anxiety Disorder would also be consistent with diagnostic criteria for some anxiety disorders (e.g., Social Anxiety Disorder), which specify emotions (e.g., fear of social situations), cognitions (e.g., beliefs that a situation will be humiliating), associated physiological arousal (e.g., increased heart rate, muscle tension), and behaviors (e.g., avoidance of social situations). Findings with respect to physiological arousal did not bear out, and it may be the case that physiological arousal is not part of the presentation for health anxiety. Conversely, it may also be the case that health anxiety is associated with other types of arousal (e.g., muscle tension, disrupted sleep), as is the case for GAD (APA, 2013).

In terms of assessment of healthy anxiety, it may be prudent to assess symptoms with regard to affect. Current assessment instruments may be revised to more comprehensively address the affective components of health anxiety, and any new measures of health anxiety developed in the future should be sure to include items assessing this area. Assessment of health anxiety should also take into account any age-related differences. Although the same general pattern was found for older and young adults, one key difference was that younger adults experienced greater anxiety in response to health-related feedback than older adults. When assessing older adults, it is important to account for the fact that older clients may not experience anxiety as intensely as younger age groups, yet may experience symptoms that continue to be impairing and may nevertheless require intervention. Thus, use of different cut-off scores on measures of anxiety may be necessary for various age groups. The exact cut-off score used 
should be based on empirical literature, although age-related cut-off scores have not been established for existing measures of health anxiety to date.

The results of this study have potential treatment implications as well. Affect (i.e., increased negative affect and decreased positive affect) associated with health anxiety may be considered specific targets for intervention. For example, behavioral activation can be added to treatments to provide opportunities for increased positive affect. These results also provide support for improving coping skills as a target for intervention, as use of coping skills were associated with decreased health anxiety in the present study. For example, problem-solving therapy or treatment components that address emotion regulation (such as skills taught in Dialectical Behavior Therapy) may help improve coping strategies among individuals with health anxiety. Coping strategies may be especially helpful when a person is acutely distressed, as it does appear to quickly reduce health anxiety (i.e., within a few minutes). As the study used a non-clinical sample, conclusions concerning clinical samples are limited; it may very well be the case that coping strategies may work best for those with less severe health anxiety, whereas treatments involving exposure with response prevention may be the best approach for severe health anxiety. This suggestion is at least partially supported by Taylor et al. (2005), who found that CBT (e.g., exposure and response prevention) was effective for treating severe health anxiety (i.e., hypochondriasis) and psychoeducation was effective for mild health anxiety. The present study also suggests which coping strategies may be most effective, including active coping, planning, positive reframing, and acceptance, which were used relatively equally by both age groups. These strategies include both emotion- and problem-focused coping, indicating that a combination of both types of strategies may be best in regards to coping with health anxiety.

It is important remember that some degree of health anxiety, as is the case with anxiety in 
general, is adaptive; being concerned about one's health can motivate one to seek medical attention and receive necessary treatment so as to avoid morbidity or possibly death. Thus, treatment for health anxiety should be reserved for cases in which the level of health anxiety is out of proportion to the circumstances and is also impairing rather than adaptive (i.e., severe health anxiety or Illness Anxiety Disorder). However, there certainly may be cases in which a person's anxiety about their health may be distressing but nevertheless adaptive, for example, a patient with cancer who has recently completed chemotherapy and is worried the cancer may return. In these cases, teaching skills to cope with anxiety may be especially useful, as we very much want the patient to remain vigilant to signs of illness, but also do not want that anxiety to interfere with the patient's life.

\section{Limitations}

This study employed a non-clinical sample of older and young adults, and present results may not extend to those with health anxiety. In light of screening criteria, participants were likely healthier than typical same-aged peers. Other characteristics, such as education level and ethnicity, may not be representative of the general population.

As described earlier, the manipulation may not have effectively induced health concern in some participants. It is possible that the manipulation may not have been similarly effective across age groups. One might argue that the manipulation was more salient for older adults, as older adults are more likely to have health problems, which may explain why a greater number of older adults found the manipulation believable. Because of age-related differences in the prevalence of health problems, it is challenging to find health problems that are equally concerning for these age groups. However, few differences in response to the health-related feedback were found for older and young adults, suggesting that the induction did work for both 
age groups. Nevertheless, other health problems, such as cancer, may have elicited greater health concern.

The within-subjects design is also a limitation. Use of a between-subjects design, in which one group received negative health-related feedback and one group received positive or neutral health-related feedback, would have provided additional support for the effectiveness of the manipulation. However, I also would have needed to recruit a much larger sample of participants. Because of the stringent inclusion criteria, it would have been remarkably challenging to find enough eligible older adult participants if a between-subjects design was employed.

The physiological measures used may not have been sensitive to differences in arousal across experimental periods. Though both the heart rate monitor and blood pressure monitor were deemed valid and reliable, neither instrument is considered the "gold standard" for measuring heart rate and blood pressure. Given the design of the study, use of gold standard measures (EEG for heart rate and a standard occluding blood pressure cuff for blood pressure) were not possible. The same could be true for the self-report instruments. To accommodate for limitations of any one measure, multiple measures employing various methods (e.g., self-report, physiological recordings) were used. Moreover, the present study did not assess all facets of physiological arousal (e.g., skin conductance, respiration, muscle tension); doing so likely would have been cumbersome to patients.

One final limitation of this study is the statistical approach used to measure change over time. Measuring change over time is a complicated issue, which is beyond the scope of this paper (see Hertzog \& Nesselroade, 2003 for an overview of issues with measuring change). Traditionally, common methods have included calculating change scores (i.e., subtracting Time 
1 score from Time 2 score), or using baseline scores as covariates in ANCOVAs or MANCOVAs (as used in the present study). However, ANCOVAs and MANCOVAs examine differences in group means, and individual differences in change over time are ignored. Recent statistical approaches, primarily multilevel modeling (i.e., hierarchical linear modeling), allow for an exploration of group and individual differences over time, and better accounts for missing data (Hertzog \& Nesselroade, 2003). However, this approach requires a large sample size to achieve adequate power, and therefore was inappropriate to conduct for the present study.

\section{Future Directions}

Replication of findings with diverse samples, including clinical samples, less healthy samples, and ethnically diverse samples, may provide additional support for current findings. Similarly, inclusion of oldest-old adults (i.e., 80+) and middle-aged adults would clarify how health anxiety is experienced across the adult lifespan.

Future studies manipulating the characteristics of a health-related stressor would also help clarify the experience of health anxiety. It would be interesting to examine the experience of health anxiety across varying levels of threat. For example, the same study could be completed with less concerning health problems (e.g., a cold) to more severe health problems (e.g., cancer, dementia). Another future study, which would partially replicate the Hadjistavropoulos et al. (1998) study, could examine differences in the experience of health anxiety when feedback is negative versus ambiguous. Another possible study could examine how health anxiety changes as a function of the duration of the stressor.

In expanding on present findings, future studies could examine additional physiological measures (e.g., skin conductance, respiration, muscle tension) to better characterize physiological arousal in the context of health anxiety. Similarly, exploration of other emotions 
may further clarify how health anxiety is experienced. The present study focused on affect and physiological arousal in the context of health anxiety, but no studies have examined each aspect of health anxiety (i.e., cognitions, behaviors, affect, and physiological arousal); doing so would further elucidate the experience of health anxiety and would allow us to better understand how such factors may interact. Use of multiple methods (e.g., self-repot of heart rate and objective recordings of heart rate) to assess the various components of health anxiety would provide rich data on the experience of health anxiety.

A follow-up to the present study may be to identify which factors predict the extent to which one experiences arousal and distress in response to negative-health related feedback. Possible factors may include baseline anxiety sensitivity, neuroticism, and vigilance to body sensations. Each of the aforementioned factors are generally regarded as traits; establishing relations between these traits and health anxiety would support the expansion of the cognitivebehavioral model of health anxiety to include baseline risk factors. Particular attention may be paid to neuroticism, as evidence traditionally suggests the neuroticism is associated with poorer self-assessed health and increased hypochondriacal concerns (see Williams, 2004). However, recent evidence suggests that high levels of neuroticism, coupled with high levels of conscientiousness, may result in health benefits (Turiano, Mroczek, Moynihan, \& Chapman, 2013). This so-called "healthy neuroticism" may be examined as a protective factor against health anxiety. Thus, in addition to expanding the cognitive-behavioral model of health anxiety to include risk factors, the model could also be expanded to include protective factors. Finally, with larger samples, the nature of health anxiety across time may be best understood employing multilevel modeling. Multilevel modeling would elucidate the extent of individual variability across time, as well as predictors of group and individual change. 
The experience of health anxiety is characterized by increased negative affect, distress, fear of body sensations, and decreased positive affect, indicating that the cognitive-behavioral model could be expanded to include emotions. Although health anxiety was experienced similarly for older and young adults, young adults reported significantly greater anxiety, suggesting that age-related differences should be taken into account when assessing health anxiety. Likewise, older and young adults generally reported using similar coping strategies, which appear to be effective in reducing health anxiety, providing evidence that enhancing coping skills could be part of treatment for health anxiety. 


\section{References}

Abelson, J. L., \& Curtis, G. C. (1989). Cardiac and neuroendocrine responses to exposure therapy in height phobics: Desynchrony within the 'physiological response system.' Behavior Research and Therapy, 27, 561-567. doi: 10.1016/0005-7967(89)90091-0.

Abramowitz, J. S., Deacon, B. J., \& Valentiner, D. P. (2007). The short health anxiety inventory: Psychometric properties and construct validity in a non-clinical sample. Cognitive Therapy and Research, 31(6), 871-883. doi: 10.1007/s10608-006-9058-1

Abramowitz, J. S., \& Moore, E. L. (2007). An experimental analysis of hypochondriasis. Behaviour Research and Therapy, 45, 413-424. doi: 10.1016/j.brat.2006.04.005

Administration on Aging. (2011). A profile of older Americans, 2011: Health and health care. Retrieved from http://www.aoa.gov/AoARoot/Aging_Statistics/Profile/2010/14.aspx.

American Psychiatric Association. (2000). Diagnostic and statistical manual of mental disorders, $\left(4^{\text {th }}\right.$ Edition, Text Revision). Washington, D.C.: Author.

American Psychiatric Association. (2013). Diagnostic and statistical manual of mental disorders, $\left(5^{\text {th }}\right.$ Edition $)$. Washington, D.C.: Author.

Amirkhan, J., \& Auyeung, B. (2007). Coping with stress across the lifespan: Absolute vs. relative changes in strategy. Journal of Applied Developmental Psychology, 28, 298-317. doi: 10.1016/j.appdev.2007.04.002.

Andrews, V. H., \& Borkovec, T. D. (1988). The differential effects of inductions of worry, somatic anxiety, and depression on emotional experience. Journal of Behavior Therapy and Experimental Research, 19, 21-26. doi: 10.1016/0005-7916(88)90006-7

Asmundson, G. J. G., Taylor, S., Sevgur, S., \& Cox, B. J. (2001). Classification and clinical features. In G. J. G. Asmundson, S. Taylor, \& B. J. Cox (eds.), Health anxiety: Clinical 
and research perspectives on hypochondriasis and related disorders (pp. 3-21). London: John Wiley \& Sons.

Barlow, D. H. (1980). Patterns of desynchrony in agoraphobia: A preliminary report. Behavior Research and Therapy, 18, 441-448. doi: 10.1016/0005-7967(80)90009-1.

Barsky, A. J., \& Klerman, G. L. (1983). Overview: Hypochondriasis, bodily complaints, and somatic styles. The American Journal of Psychiatry, 140, 273-283.

Beck, A. T., \& Steer, R. A. (1990). Manual for the Beck Anxiety Inventory. San Antonio, TX: Psychological Corporation.

Beck, A. T., Ward, C. H., Mendelsohn, M., Mock, J., \& Erbaugh, J. (1961). An inventory for measuring depression. Archives of General Psychiatry, 4, 561-571.

Beckingham, A. C., Coutu-Wakulczyk, G., \& Lubin, B. (1993). French-language validation of the DACL and MAACL-R. Journal of Clinical Psychology, 49, 685-695.

Bedard, M., Squire, L., Minthorn-Biggs, M., Molloy, D. W., Dubois, S., O’Donnell, M., \& Lever, J. A. (2003). Validity of self-reports in dementia research: The Geriatric Depression Scale. Clinical Psychologist, 26, 155-162. doi: 10.1300/J018v26n03_13.

Blanchard-Fields, F. (2007). Everyday problem solving and emotion: An adult developmental perspective. Current Directions in Psychological Science, 16, 26-31. doi: 10.1111/j.14678721.2007.00469.x.

Blanchard-Fields, F., Stein, F., \& Watson, T. L. (2004). Age differences in emotion-regulation strategies in handling everyday problems. Journal of Gerontology: Psychological Sciences, 59B, P261-P269. doi: 10.1093/geronb/59.6.P261

Boston, A. F., \& Merrick, P. L. (2010). Health anxiety among older people: An exploratory study of health anxiety and safety behaviors in a cohort of older adults in New Zealand. 
International Psychogeriatrics, 22, 549-558. doi: 10.1017/S1041610209991712

Bourgault-Fagnou, M. D., \& Hadjistavropoulos, H. D. (2009). Understanding health anxiety among community dwelling seniors with varying degrees of frailty. Aging and Mental Health, 13, 226-237. doi: 10.1080/13607860802380664

Bourgault-Fagnou, M. D., \& Hadjistavropoulos, H. D. (2013). A randomized trial of two forms of cognitive behaviour therapy for an older adult population with subclinical health anxiety. Cognitive Behavior Therapy, 42, 31-44. doi: 10.1080/16506073.2012.717302.

Carmines, E. G., \& Zeller, R. A. (1979). Reliability and validity assessment. Thousand Oaks, CA: Sage.

Carstensen, L. L. (1991). Socioemotional selectivity theory: Social activity in life-span context. Annual Review of Gerontology and Geriatrics. 17, 195-217.

Carver, C. S. (1997). You want to measure coping but your protocol's too long: Consider the Brief COPE. International Journal of Behavioral Medicine, 4, 92-100.

Carver, C. S., Scheier, M. F., \& Weintraub, J. K. (1989). Assessing coping strategies: A theoretically based approach. Journal of Personality and Social Psychology, 56, 267-283. doi: 10.1037/0022-3514.56.2.267

Chambless, D. L., Caputo, G. C., Bright, P., \& Gallagher, R. (1984). Assessment of fear of fear in agoraphobics: The Body Sensations Questionnaire and the Agoraphobic Cognitions Questionnaire. Journal of Consulting Psychology, 52, 1090-1097. doi: 10.1037/0022006X.52.6.1090

Charles, S. T. (2010). Strength and vulnerability integration: A model of emotional well-being across adulthood. Psychological Bulletin, 136, 1068-1091. doi: 10.1037/a0021232

Charles, S. T., \& Carstensen, L. L. (2007). Emotion regulation and aging. In J.J. Gross (Ed.), 
Handbook of Emotion Regulation, (pp. 307-327), New York, NY: Guilford Press.

Clark, K. K., Bormann, C. A., Cropanzano, R. S., \& James, K. (1995). Validation evidence for three coping measures. Journal of Personality Assessment, 65, 434-455. doi: 10.1207/s15327752jpa6503_5

Clark, L. A., \& Watson, D. (1991). Tripartite model of anxiety and depression: psychometric evidence and taxonomic implications. Journal of Abnormal Psychology, 100, 316-336.

Creed, F., \& Barsky, A. (2004). A systematic review of the epidemiology of somatization disorder and hypochondriasis. Journal of Psychosomatic Research, 56, 391-408. doi: $10.1016 / \mathrm{S} 0022-3999(03) 00622-6$

Deacon, B., \& Abramowitz, J. S. (2008). Is hypochondriasis related to obsessive compulsivedisorder, panic disorder, or both? An empirical evaluation. Journal of Cognitive Psychotherapy, 22(2), 115-127. doi:10.1891/0889-8391.22.2.115

Derogatitis, L. R. (1977) SCL-90 administration, scoring and procedure manual-1. Baltimore, MD: Johns Hopkins University Press.

Diaper, A., Nutt, D. J., Munafò, M. R., White, J. L., Farmer, E. W., \& Bailey, J. E. (2012). The effects of $7.5 \%$ carbon dioxide inhalation on task performance in health volunteers. Journal of Psychopharmacology, 26, 487-496. doi: 10.1177/0269881111415729

Dong, Y., Sharma, V. K., Chan, B. P., Venketasubramanian, N., Teoh, H. L., Seet, R. C. . Chen, C. (2010). The Montreal Cognitive Assessment (MoCA) is superior to the Mini-Mental State Examination (MMSE) for the detection of vascular cognitive impairment after acute stroke. Journal of the Neurological Sciences, 299, 15-18. doi: 10.1016/j.jns.2010.08.051.

Faul, F., Erdfelder, E., Lang, A. G., \& Buchner, A. (2007). G*Power 3: A flexible statistical power analysis for the social, behavioral, and biomedical sciences. Behavior Research 
Methods, 39, 175-191.

Fergus, T. A., \& Valentiner, D. P. (2009). Reexamining the domain of hypochondriasis:

Comparing the Illness Attitudes Scale to other approaches. Journal of Anxiety Disorders, 23, 760-766. doi:10.1016/j.janxdis.2009.02.016

Fergus, T. A., \& Valentiner, D. P. (2010). Disease phobia and disease conviction are separate dimensions underlying hypochondriasis. Journal of Behavior Therapy and Experimental Psychiatry, 41, 438-444. doi: 10.1016/j.jbtep.2010.05.002

Fergus, T. A., \& Valentiner, D. P. (2012). The affective and cognitive dimensions of health anxiety are associated with different orientations to health threat. Journal of Cognitive Psychotherapy, 26, 34-42. doi: 10.1891/0889-8391.26.1.34

Fink, P., Ørnbøl, E., \& Christensen, K. S. (2010). The outcome of health anxiety in primary care: A two-year follow-up study on health care costs and self-rated health. PLos ONE, 5(3), e9873. doi:10.1371/journal.pone.0009873

Folstein, M. F., Folstein, S. E., \& McHugh, P. R. (1975). Mini-mental state: A practical method for grading the cognitive state of patients for the clinician. Journal of Psychiatric Research, 2, 189-198. doi: 10.1016/0022-3956(75)90026-6

Gerolimatos, L. A., \& Edelstein, B. A. (2012). Anxiety-related constructs mediate the relation between age and health anxiety. Aging and Mental Health. doi:

$10.1080 / 13607863.2012 .688192$

Gill, D. J., Freshman, A., Blender, J. A., \& Ravina, B. (2008). The Montreal Cognitive Assessment as a screening tool for cognitive impairment in Parkinson's Disease. Movement Disorders, 23, 1043-1046. doi: 10.1002/mds.22017

Gramling, S. E., Clawson, E. P., \& McDonald, M. K. (1996). Perceptual and cognitive 
abnormality model of hypochondriasis: Amplification and physiological reactivity in women. Psychosomatic Medicine, 58, 423-431. doi: 0033-3174/96/5805-0423

Grillon, C., Duncko, R., Covington, M. F., Kopperman, L., \& Kling, M. A. (2007). Acute stress potentiates anxiety in humans. Biological Psychiatry, 62, 1183-1186. doi: 10.1016/j.biopsych.2007.06.007.

Gross, J. J., \& John, O. P. (2003). Individual differences in two emotion regulation processes: Implications for affect, relationships, and well-being. Journal of Personality and Social Psychology, 85, 348-362. doi: 10.1037/0022-3514.85.2.348

Hadjistavropoulos, H. D., Craig, K. D., \& Hadjistavropoulos, T. (1998). Cognitive and behavioral responses to illness information: The role of health anxiety. Behaviour Research and Therapy, 36, 149-164. doi: S0005-7967(98)00012-X

Hadjistavropoulos, H. D., Janzen, J. A., Kehler, M. D., Leclerc, J. A., Sharpe, D., \& BourgaultFagnou, M. D. (2012). Core cognitions related to health anxiety in self-reported medical and non-medical samples. Journal of Behavioral Medicine, 35, 167-178. doi: $10.1007 / \mathrm{s} 10865-011-9339-3$

Haenen, M., de Jong, P. J., Schmidt, A. J., Stevens, S., \& Visser, L. (2000). Hypochondriacs’ estimation of negative outcomes: Domain-specificity and responsiveness to reassuring and alarming information. Behaviour Research and Therapy, 38, 819-833. doi: 10.1016/S0005-7967(99)00128-X

Hayes, S. C., Wilson, K. G., Gifford, E. V., Follette, V. M., \& Strosahl, K. (1996). Experiential avoidance and behavioral disorders: A functional dimensional approach to diagnosis and treatment. Journal of Consulting and Clinical Psychology, 64, 1152-1168.

Heckhausen, J., \& Schulz, R. (1995). A life-span theory of control. Psychological Review, 102, 
284-304. doi: 10.1037/0033-295X.102.2.284

Hertzog, C., \& Nesselroade, J. R. (2003). Assessing psychological change in adulthood: An overview of methodological issues. Psychology and Aging, 18, 639-657. doi: 10.1037/0882-7974.18.4.639.

Hseieh, H. (2005). Three approaches to qualitative content analysis. Qualitative Health Research, 15, 1277-1288. doi: 10.1177/1049732305276687.

Hunt, S., Wisocki, P., \& Yanko, J. (2003). Worry and use of coping strategies among older and younger adults. Anxiety Disorders, 17, 547-560. doi: 10.1016/S0887-6185(02)00229-3

John, O. P., \& Gross, J. J. (2004). Healthy and unhealthy emotion regulation personality processes, individual differences, and life span development. Journal of Personality, 72, 1301-1334. doi: 10.1.1.152.105

Kellner, R., Abbott, P., Winslow, W. W., \& Pathak, D. (1987). Fears, beliefs, and attitudes in DSM-III hypochondriasis. Journal of Nervous and Mental Disease, 175, 20-25. doi: 10.1097/00005053-198701000-00004

Kogan, J. N., \& Edelstein, B. A. (2004). Modification and psychometric examination of a selfreport measure of fear in older adults. Anxiety Disorders, 18, 397-409. doi: $10.1016 / \mathrm{S} 0887-6185(02) 00260-8$

Labouvie-Vief, G. (2003). Dynamic Integration: Affect, cognition, and the self in adulthood. Current Directions in Psychological Science, 26, 201-206. doi: 10.1046/j.09637214.2003.01262.x

Lau, A. W., Edelstein, B. A., \& Larkin, K. T. (2001). Psychophysiological arousal in older adults: A critical review. Clinical Psychology Review, 21, 609-630. doi: 10.1016/S02727358(00)00052-0 
Lecci, L., \& Cohen, D. J. (2002). Perceptual consequences of an illness-concern induction and its relation to hypochondriacal tendencies. Health Psychology, 21, 147-156. doi: $10.1037 / / 0278-6133.21 .2 .147$

Lees, A., Mogg, K., \& Bradley, B. P. (2005). Health anxiety, anxiety sensitivity, and attentional biases for pictorial and linguistic health-threat cues. Cognition and Emotion, 19, 453-462. doi:10.1080/02699930441000184

Longley, S. L., Broman-Fulks, J. J., Calamari, J. E., Noyes, R., Wade, M., \& Orlando, C. M. (2010). A taxometric study of hypochondriasis symptoms. Behavior Therapy, 41, 505514. doi: $10.1016 /$ j.beth.2010.02.002

Longley, S. L., Watson, D., \& Noyes, R. (2005). Assessment of the hypochondriasis domain: The Multidimensional Inventory of Hypochondriacal Traits (MIHT). Psychological Assessment, 17, 3-14. doi: 10.1037/1040-3590.17.1.3

Lubin, B., \& Zuckerman, M. (1999). The Multiple Affect Adjective Check List-Revised ( $3^{\text {rd }}$ ed.). San Diego, CA: Educational and Industrial Testing Service.

Lubin, B., Zuckerman, M., Hanson, P. G., Armstrong, T., Rinck, C. M., \& Seever, M. (1986). Reliability and validity of the Multiple Affect Adjective Check List-Revised. Journal of Psychopathology and Behavioral Assessment, 8, 103-117. doi: 10.1007/BF00963575

Luis, C. A., Keegan, A. P., \& Mullan, M. (2009). Cross validation of the Montreal Cognitive Assessment in community dwelling older adults residing in the southeastern US. International Journal of Geriatric Psychiatry, 24, 197-201. doi: 10.1002/gps.2101

McLaughlin, K. A., Borkovec, T. D., \& Sibrava, N. J. (2007). The effects of worry and rumination on affect states and cognitive activity. Behavior Therapy, 38, 23-38. doi: 10.1016/j.beth.2006.03.003 
Margariños, M., Zafar, U., Nissenson, K., \& Blanco, C. (2002). Epidemiology and treatment of hypochondriasis. CNS Drugs, 16, 9-22. doi: 10.2165/00023210-200216010-00002

Mather, M., \& Carstensen, L. L. (2005). Aging and motivated cognition: The positivity effect in attention and memory. Trends in Cognitive Sciences, 9, 496-502. doi: 10.1016/j.tics.2005.08.005

Mattick, R. P., \& Clarke, J. C. (1998). Development and validation of measures of social phobia scrutiny fear and social interaction anxiety. Behaviour Research and Theapy, 36, 455470. doi:10.1016/S0005-7967(97)10031-6

Meuret, A. E., Seidel, A., Rosenfield, B., Hofmann, S. G., \& Rosenfield, D. (2012). Does fear reactivity during exposure predict panic symptom reduction? Journal of Consulting and Clinical Psychology, 80, 773-785. doi: 10.1037/a0028032

Nasreddine, Z. A., Phillips, N. A., Bédirian, V., Charbonneau, S., Whitehead, V., Collin, I., et al. (2005). The Montreal Cognitive Assessment, MoCA: A brief screening tool for mild cognitive impairment. Journal of the American Geriatrics Society, 53, 695-699. doi: $10.1111 / \mathrm{j} .1532-5415.2005 .53221 . \mathrm{x}$

Nickel, E. J., Lubin, B., \& Rinck, C. M. (1986). The new MAACL scales with adoelscents: Preliminary reliability and validity determinations. Adolescence, 21, 81-86.

Noyes, R., Happel, R.L., \& Yagla, S.J. (1999). Correlates of hypochondriasis in a nonclinical population. Psychosomatics, 40, 461-469.

Nunan, D., Donovan, G., Jakovljevic, D. G., Hodges, L. D., Sandercock, G. R., \& Brodie, D. A. (2009). Validity and reliability of short-term heart-rate variablility from the Polar S810. Medicine and Science in Sports and Exercise, 41, 243-250. doi: 10.1249/MSS.0b013e318184a4b1 
Olatunji, B. O., Etzel, E. N., Tomarken, A. J., Ciesielski, B. G., \& Deacon, B. (2011). The effects of safety behaviors on health anxiety: An experimental investigation. Behavior Research and Therapy, 49, 719-728. doi: 10.1016/j.brat.2011.07.008

Olatunji, B. O., Wolitzky-Taylor, K. B., Elwood, L., Connolly, K., Gonzales, B., \& Armstrong, T. (2009). Anxiety sensitivity and health anxiety in a nonclinical sample: Specificity and prospective relations with clinical stress. Cognitive Therapy and Research, 33, 416-424. doi:10.1007/s10608-008-9188-8

Owens, K. M. B., Asmundson, G. J. G., Hadjistavropoulos, T., \& Owens, T. J. (2004). Attentional bias toward illness threat in individuals with elevated health anxiety. Cognitive Therapy and Research, 28, 57-66. doi:

10.1023/B:COTR.0000016930.85884.29

Radespiel-Tröger, M., Rauh, R., Mahlke, C., Gottschalk, T., \& Mück-Weymann, M. (2003). Agreement of two different methods for measurement of heart rate variability. Clinical Autonomic Research, 13, 99-102. doi: 10.1007/s10286-003-0085-7

Reiss, S., Peterson, R. A., Gursky, D. M., \& McNally, R. J. (1986). Anxiety sensitivity, anxiety frequency and the prediction of fearfulness. Behaviour Research and Therapy, 24, 1-8. doi: 10.1016/0005-7967(86)90143-9

Salkovskis, P. M., Rimes, K. A., Warwick, H. M. C., \& Clark, D. M. (2002). The Health Anxiety Inventory: Development and validation of scales for the measurement of health anxiety and hypochondriasis. Psychological Medicine, 32, 843-853. doi: $10.1017 / \mathrm{S} 0033291702005822$

Salkovskis, P. M., \& Warwick, H. M. (1986). Morbid preoccupations, health anxiety, and reassurance: a cognitive-behavioral approach to hypochondriasis. Behavior Research 
Therapy, 24, 597-602. doi: 10.1016/0005-7967(86)90041-0

Scheibe, S., \& Blanchard-Fields, F. (2009). Effects of regulating emotions on cognitive performance: What is costly for young adults is not so costly for older adults. Psychology and Aging, 24, 217-223. doi: 10.1037/a0013807

Smith, T., Gildeh, N., \& Clive, H. (2007). The Montreal Cognitive Assessment: Validity and utility in a memory clinic setting. The Canadian Journal of Psychiatry, 52, 329-332.

Spielberger, C. D., Gorsuch, R. R., \& Luchene, R. E. (1970). The State-Trait Anxiety Inventory. Palo Alto, CA: Consulting Psychologists Press.

Steptoe, A., \& Vögele, C. (1992). Individual differences in the perception of bodily sensations: The role of trait anxiety and coping style. Behaviour Research and Therapy, 30, 597-607. doi: $10.1016 / 0005-7967(92) 90005-2$

Stoner, S., O'Riley, A., \& Edelstein, B. (2010). Assessment of mental health. In J. C. Cavanaugh, C. K. Cavanaugh, S. Qualls, L. McGuire, J. C. Cavanaugh, C. K. Cavanaugh, ... L. McGuire (Eds.), Aging in America, Vol 2: Physical and mental health (pp. 141-170). Santa Barbara, CA: Praeger/ABC-CLIO.

Svensson, J. C., \& Theorell, T. (1982). Cardiovascular effects of anxiety induced by interviewing young hypertensive male subjects. Journal of Psychosomatic Research, 26, 359-370. doi: $10.1016 / 0022-3999(82) 90009-5$

Tabachnick, B. G., and Fidell, L. S. (2007). Using multivariate statistics. (5th ed). Boston, MA: Allyn and Bacon.

Taylor, S., \& Asmundson, G.J.G. (2004). Treating health anxiety: A cognitive-behavioral approach. NewYork: The Guilford Press.

Taylor, S., Asmundson, G. J. G., \& Coons, M. J. (2005). Current directions in the treatment of 
hypochondriasis. Journal of Cognitive Psychotherapy, 19, 285-304.

Taylor, S., Zvolensky, M. J., Cox, B. J., Deacon, B., Heimberg, R. G., Ledley, D. R., et al. (2007). Robust dimensions of anxiety sensitivity: Development and initial validation of the Anxiety Sensitivity Index-3. Psychological Assessment, 19, 176-188. doi: $10.1037 / 1040-3590.19 .2 .176$

Teachman, B. A., \& Gordon, T. (2009). Age differences in anxious responding: Older and calmer, unless the trigger is physical. Psychology and Aging, 24, 703-714. doi: $10.1037 / \mathrm{a} 0016813$

Teachman, B. A., Siedlecki, K. L., \& Magee, J. C. (2007). Aging and symptoms of anxiety and depression: Structural invariance of the tripartite model. Psychology and Aging, 22, 160170. doi: $10.1037 / 0882-7974.22 .1 .160$

Turiano, N. A., Mroczek, D. K., Moynihan, J., \& Chapman, B. P. (2013). Big 5 Personality Traits and Interleuken-6: Evidence for "Healthy Neuroticism" in a US Population Sample. Brain, Behavior, and Immunity, 28, 83-89. doi: 10.1016/j.bbi.2012.10.020.

Uchino, B. N., Birmingham, W., \& Berg, C. A. (2010). Are older adults less or more physiologically reactive? A meta-analysis of age-related differences in cardiovascular reactivity to laboratory tasks. Journals of Gerontology: Psychological Sciences, 65B, 154-162. doi: 10.1093/geronb/gbp127

Urry, H. L., \& Gross, J. J. (2010). Emotion regulation in older age. Current Directions in Psychological Science, 19, 352-357. doi: 10.1177/0963721410388395

Vanderlei, L. C., Silva, R. A., Pastre, C. M., Azevedo, F. M., \& Godoy, M. F. (2008). Comparison of the Polar S810i monitor and ECG for the analysis of heart rate variability in the time and frequency domains. Brazilian Journal of Medical and Biological 
Research, 41, 854-859.

Wan, Y., Heneghan, C., Stevens, R., McManus, R. J., Ward, W., Perera, R., et al. (2010).

Determining which automatic digital blood pressure device performs adequately: A systematic review. Journal of Human Hypertension, 24, 431-438. doi:

10.1038/jhh.2010.37

Warwick, H. M. C., \& Salkovskis, P. M. (1990). Hypochondriasis. Behaviour Research and Therapy, 28, 105-117. doi:10.1016/0005-7967(90)90023-C

Weinfurt, K. P. (2000). Repeated measures analyses: ANOVA, MANOVA, and HLM. In L. G. Grimm, \& P. R. Yarnold (Eds.), Reading and understanding more multivariate statistics (pp. 317-363). Washington, DC: American Psychological Association.

Weippert, M., Kumar, M., Kreuzfeld, S., Arndt, D., Rieger, A., \& Stoll, R. (2010). Comparison of three mobile devices for measuring R-R intervals and heart-rate variability: Polar S810i, Suunto t6, and an ambulatory ECG system. European Journal of Applied Physiology, 109, 779-786. doi: 10.1007/s00421-010-1415-9

Williams, P. G. (2004). The psychopathology of self-assessed health: A cognitive approach to health anxiety and hypochondriasis. Cognitive Therapy and Research, 28, 629-644. doi: 0147-5916/04/1000-0629/0

Williams, L. E., Bargh, J. A., Nocera, C. C., \& Gray, J. R. (2009). The unconscious regulation of emotion: Nonconscious reappraisal goals modulate emotional reactivity. Emotion, 9, 847854. doi: $10.1037 / \mathrm{a} 0017745$

Yartz, A. R., \& Hawk, L. W. (2001). Psychophysiological assessment of anxiety: Tales from the heart. In M. M. Antony, S. M. Orsillo, \& L. Roemer (Eds.), Practitioner's guide to empirically based measures of anxiety. New York: Kluwer Academic/Plenum Publishers, 
p. 25-30.

Zadikoff, C., Fox, S. H., Tang-Wai, D. F., Thomsen, T., de Bie, R. M.A., Wadia, P. . Marras, C. (2008), A comparison of the mini mental state exam to the montreal cognitive assessment in identifying cognitive deficits in Parkinson's disease. Movement Disorders, 23, 297299. doi: $10.1002 / \mathrm{mds} .21837$

Zucker, T. L., Samuelson, K. W., Muench, F., Greenberg, M. A., \& Gevirtz, R. N. (2009). The effects of respiratory sinus arrhythmia biofeedback on heart rate variability and posttraumatic stress disorder symptoms: A pilot study. Applied Psychophysiology and Biofeedback, 34, 135-143.

Zuckerman, M., \& Lubin, B. (1985). Manual for the Multiple Affect Adjective Check List (2 ${ }^{\text {nd }}$ ed.). San Diego, CA: Educational and Industrial Testing Service. 


\section{Appendix A}

\section{Screening Questionnaire}

To determine if you are eligible for this research study, I am going to ask you some questions. Participation in this screening is voluntary. You are free to stop participating in the screening at any time.

What is your age?

[exclude if not $18-30$ or $60+$ ]

What is your sex? $\square$ Male $\square$ Female

1. On average, how often do you smoke cigarettes? [exclude if smoker at present time]

$\square$ Never

$\square$ I am not currently smoking

$\square$ less than one pack per day

$\square$ 1-2 packs per day

$\square$ 2-3 packs per day

greater than 3 packs per day

1. Please describe any cardiovascular related illness that you may have, including high blood pressure:

2. Please list any other medical or psychiatric problems that you have:

3. Please list any drugs (legal or otherwise) that you are currently taking including; birth control (contraceptives), heart medications, hypertension medications, cold or allergy medications, over the counter medications, asthma medications, Beta-Blockers (i.e. Inderal, Tenormin), psychoactive drugs (i.e. Adderall, Xanax, Haldol, Lithium, Prozac), or diet pills. 


\section{Appendix B}

\section{Demographics Questionnaire}

Please answer the following questions.

Years of Education: $($ high school $=12$ years $)$

Marital Status: Please check one.

$\square$ Single $\square$ Married $\square$ Separated $\square$ Divorced $\square$ Widowed $\square$ Other (specify):

Ethnicity: (race) Please check all that apply.

$\square$ African American (Black)

$\square$ Asian

Caucasian (White)
Hispanic

Native American

Other:

What is your current job or occupation status? Please check one.

$\square$ Working full time

$\square$ Homemaker

$\square$ Retired

$\square$ Student
Working part time

Unemployed and/or looking for work

Disabled - unable to work

Please answer the following questions about your health as best as you can.

1. On average, how often do you use smokeless tobacco?

$\square$ never

$\square$ I am not currently using smokeless tobacco

$\square$ 1-4 times per day

$\square$ 5-8 times per day

$\square$ 9-13 times per day

$\square$ greater than 13 times per day 
2. How often do you drink alcohol?

$\square$ never

$\square$ infrequently (a few drinks per year)

$\square$ occasionally (1-2 drinks per month)

$\square$ weekly (1-3 drinks per week)

$\square$ weekly (4-6 drinks per week)

$\square$ daily (7-14 drinks per week)

$\square$ daily (more than 14 drinks per week)

3. How many cups of caffeinated coffee, tea, or soda do you have per day?

$\square 0$ cups per day

$\square$ 1-2 cups per day

$\square$ 3-4 cups per day

$\square$ 5-6 cups per day

7-8 cups per day

$\square$ greater than 8 cups per day

4. How many times per week do you engage in aerobic physical activity?

$\square$ never

$\square$ 1-2 times

3-6 times

$\square 7$ or more times 


\section{Family Information:}

5. What is your best estimate of your family's net income (before expenses are accounted for)?

$\square$ Less than 25,000

$\square 25,000$ to 49,999

$\square 50,000$ to 74,999

$\square 75,000$ or Greater

6. Below is a list of health problems. Please check off the box next to the condition if your mother or father has or had any of the following health problems.

$\square \quad$ High blood pressure (hypertension) $\quad \square \quad$ Diabetes

$\square \quad$ Angina (chest pains)

$\square \quad$ Kidney Disease

$\square \quad$ Heart attack

Cancer

$\square \quad$ Coronary heart disease

7. What is your height?

8. How much do you weigh? 


\section{Appendix C}

\section{Short Health Anxiety Inventory (SHAI)}

Each question in this section consists of a group of four statements. Please read each group of statements carefully and then select the one which best describes your feelings, over the past six months. Identify the statement by ringing the letter next to it, i.e. if you think that statement a.) is correct, ring statement a.). It may be that more than one statement applies, in which case, please ring any that are applicable.

1. a.) I do not worry about my health.

b.) I occasionally worry about my health.

c.) I spend much of my time worrying about my health.

d.) I spend most of my time worrying about my health.

2. a.) I notice aches/pains less than most other people (of my age).

b.) I notice aches/pains as much as most other people (of my age).

c.) I notice aches/pains more than most other people (of my age).

d.) I am aware of aches/pains in my body all the time.

3. a.) As a rule I am not aware of bodily sensations or changes.

b.) Sometimes I am aware of bodily sensations or changes.

c.) I am often aware of bodily sensations or changes.

d.) I am constantly aware of bodily sensations or changes.

4. a.) Resisting thoughts of illness is never a problem.

b.) Most of the time I can resist thoughts of illness.

c.) I try to resist thoughts of illness but am often unable to do so.

d.) Thoughts of illness are so strong that I no longer even try to resist them.

5. a.) As a rule I am not afraid that I have a serious illness.

b.) I am sometimes afraid that I have a serious illness.

c.) I am often afraid that I have a serious illness.

d.) I am always afraid that I have a serious illness.

6. a.) I do not have images (mental pictures) of myself being ill.

b.) I occasionally have images of myself being ill.

c.) I frequently have images of myself being ill.

d.) I constantly have images of myself being ill.

7. a.) I do not have any difficulty taking my mind off thoughts about my health.

b.) I sometimes have difficulty taking my mind off thoughts about my health.

c.) I often have difficulty in taking my mind off thoughts about my health.

d.) Nothing can take my mind off thoughts about my health. 
8. a.) I am lastingly relieved if my doctor tells me there is nothing wrong.

b.) I am initially relieved but the worries sometimes return later.

c.) I am initially relieved but the worries always return later.

d.) I am not relieved if my doctor tells me there is nothing wrong.

9. a.) If I hear about an illness I never think I have it myself.

b.) If I hear about an illness I sometimes think I have it myself.

c.) If I hear about an illness I often think I have it myself.

d.) If I hear about an illness I always think I have it myself.

10. a.) If I have a bodily sensation or change I rarely wonder what it means.

b.) If I have a bodily sensation or change I often wonder what it means.

c.) If I have a bodily sensation or change I always wonder what it means.

d.) If I have a bodily sensation or change I must know what it means.

11. a.) I usually feel at very low risk for developing a serious illness.

b.) I usually feel at fairly low risk for developing a serious illness.

c.) I usually feel at moderate risk for developing a serious illness.

d.) I usually feel at high risk for developing a serious illness.

12. a.) I never think I have a serious illness.

b.) I sometimes think I have a serious illness.

c.) I often think I have a serious illness.

d.) I usually think that I am seriously ill.

13. a.) If I notice an unexplained bodily sensation I don't find it difficult to think about other things.

b.) If I notice an unexplained bodily sensation I sometimes find it difficult to think about other things.

c.) If I notice an unexplained bodily sensation I often find it difficult to think about other things.

d.) If I notice an unexplained bodily sensation I always find it difficult to think about other things.

14. a.) My family/friends would say I do not worry enough about my health.

b.) My family/friends would say I have a normal attitude to my health.

c.) My family/friends would say I worry too much about my health.

d.) My family/friends would say I am a hypochondriac. 
For the following questions, please think about what it might be like if you had a serious illness of a type which particularly concerns you (e.g., heart disease, cancer, multiple sclerosis and so on). Obviously you cannot know for definite what it would be like; please give your best estimate of what you think might happen, basing your estimate on what you know about yourself and serious illness in general.

15. a.) If I had a serious illness I would still be able to enjoy things in my life quite a lot.

b.) If I had a serious illness I would still be able to enjoy things in my life a little.

c.) If I had a serious illness I would be almost completely unable to enjoy things in my life.

d.) If I had a serious illness I would be completely unable to enjoy life at all.

16. a.) If I developed a serious illness there is a good chance that modern medicine would be able to cure me.

b.) If I developed a serious illness there is a moderate chance that modern medicine would be able to cure me.

c.) If I developed a serious illness there is a very small chance that modern medicine would be able to cure me.

d.) If I developed a serious illness there is no chance that modern medicine would be able to cure me.

17. a.) A serious illness would ruin some aspects of my life.

b.) A serious illness would ruin many aspects of my life.

c.) A serious illness would ruin almost every aspect of my life.

d.) A serious illness would ruin every aspect of my life.

18. a.) If I had a serious illness I would not feel that I had lost my dignity.

b.) If I had a serious illness I would feel that I had lost a little of my dignity.

c.) If I had a serious illness I would feel that I had lost quite a lot of my dignity.

d.) If I had a serious illness I would feel that I had totally lost my dignity. 


\section{Appendix D}

\section{Anxiety Sensitivity Index-3 (ASI-3)}

Please rate each item by selecting one of the five answers for each question. Please answer each statement by circling the number that best applies to you.

\begin{tabular}{|c|c|c|c|c|c|}
\hline & $\begin{array}{l}\text { Very } \\
\text { Little }\end{array}$ & $\begin{array}{c}\text { A } \\
\text { Little } \\
\end{array}$ & Some & Much & $\begin{array}{l}\text { Very } \\
\text { Much }\end{array}$ \\
\hline $\begin{array}{l}\text { 1. It is important for me not to appear } \\
\text { nervous }\end{array}$ & 0 & 1 & 2 & 3 & 4 \\
\hline $\begin{array}{l}\text { 2. When I cannot keep my mind on a task, I } \\
\text { worry that I might be going crazy }\end{array}$ & $\mathbf{0}$ & 1 & 2 & 3 & 4 \\
\hline 3. It scares me when my heart beats rapidly & 0 & 1 & 2 & 3 & 4 \\
\hline $\begin{array}{l}\text { 4. When my stomach is upset, I worry that I } \\
\text { might be seriously ill }\end{array}$ & $\mathbf{0}$ & 1 & 2 & 3 & 4 \\
\hline $\begin{array}{l}\text { 5. It scares me when I am unable to keep my } \\
\text { mind on a task }\end{array}$ & $\mathbf{0}$ & 1 & 2 & 3 & 4 \\
\hline $\begin{array}{l}\text { 6. When I tremble in the presence of others, I } \\
\text { fear what other people might think of me }\end{array}$ & $\mathbf{0}$ & 1 & 2 & 3 & 4 \\
\hline $\begin{array}{l}\text { 7. When my chest feels tight, I get scared that I } \\
\text { won't be able to breathe properly }\end{array}$ & $\mathbf{0}$ & 1 & 2 & 3 & 4 \\
\hline $\begin{array}{l}\text { 8. When I feel pain in my chest, I worry that I'm } \\
\text { going to have a heart attach }\end{array}$ & $\mathbf{0}$ & 1 & 2 & 3 & 4 \\
\hline 9. I worry that other people will notice my anxiety & 0 & 1 & 2 & 3 & 4 \\
\hline $\begin{array}{l}\text { 10. When I feel "spacey" or spaced out I worry } \\
\text { that I may be mentally ill }\end{array}$ & 0 & 1 & 2 & 3 & 4 \\
\hline 11. It scares me when I blush in front of people & $\mathbf{0}$ & 1 & 2 & 3 & 4 \\
\hline $\begin{array}{l}\text { 12. When I notice my heart skipping a beat, I } \\
\text { worry that there is something seriously wrong } \\
\text { with me }\end{array}$ & $\mathbf{0}$ & 1 & 2 & 3 & 4 \\
\hline $\begin{array}{l}\text { 13. When I begin to sweat in social situations, I } \\
\text { fear people will think negatively of me }\end{array}$ & $\mathbf{0}$ & 1 & 2 & 3 & 4 \\
\hline $\begin{array}{l}\text { 14. When my thoughts seem to speed up, I worry } \\
\text { that I might be going crazy }\end{array}$ & 0 & 1 & 2 & 3 & 4 \\
\hline $\begin{array}{l}\text { 15. When my throat feels tight, I worry that I } \\
\text { could choke to death }\end{array}$ & 0 & 1 & 2 & 3 & 4 \\
\hline $\begin{array}{l}\text { 16. When I have trouble thinking clearly, I worry } \\
\text { that there is something wrong with me }\end{array}$ & 0 & 1 & 2 & 3 & 4 \\
\hline $\begin{array}{l}\text { 17. I think it would be horrible for me to faint in } \\
\text { public }\end{array}$ & 0 & 1 & 2 & 3 & 4 \\
\hline $\begin{array}{l}\text { 18. When my mind goes blank, I worry there is } \\
\text { something terribly wrong with me }\end{array}$ & 0 & 1 & 2 & 3 & 4 \\
\hline
\end{tabular}




\section{Appendix E}

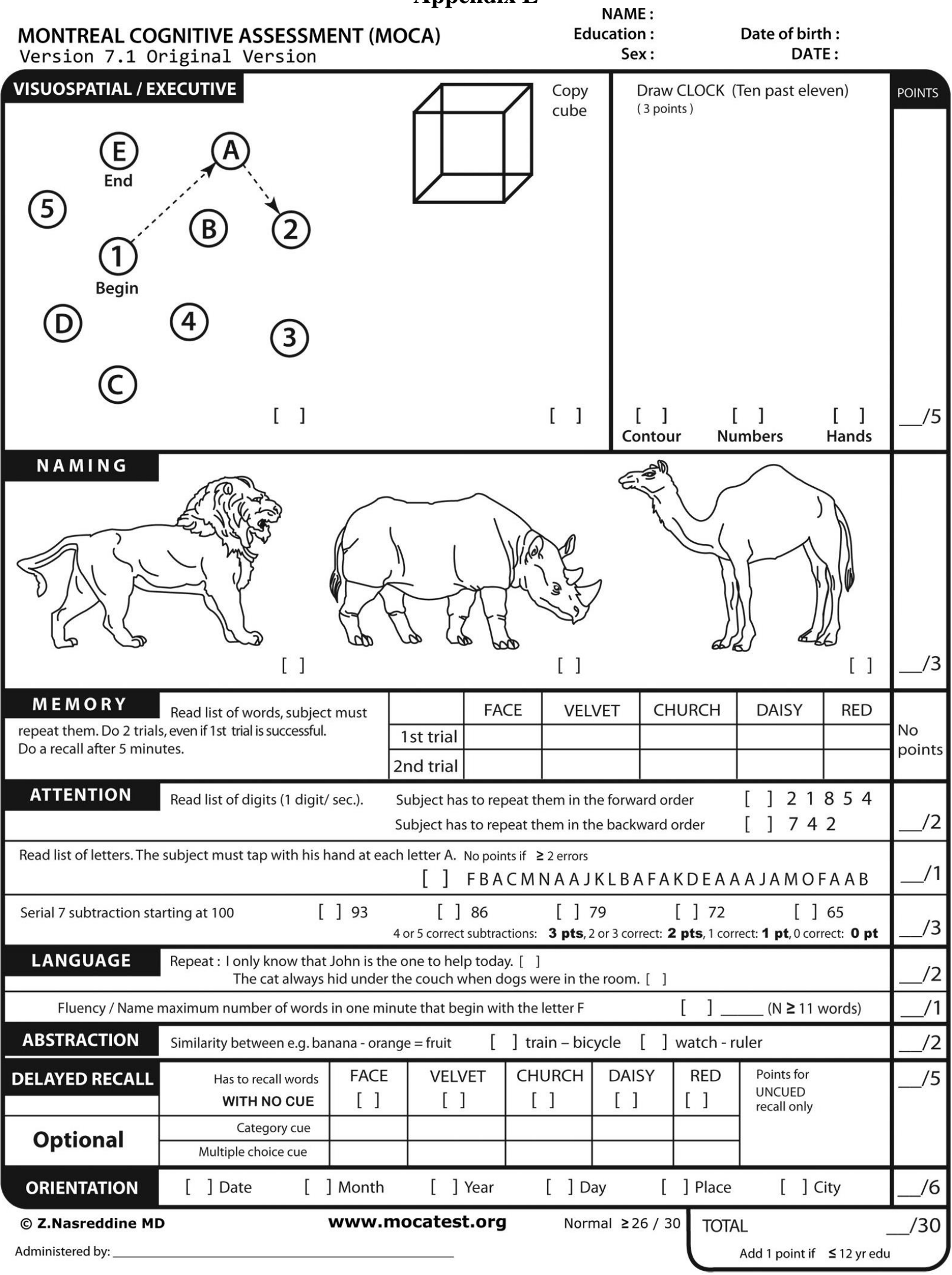




\section{Appendix F}

\section{Body Sensations Questionnaire (BSQ)}

Below is a list of specific body sensations that may occur when you are nervous or in a feared situation. Please mark down how afraid you were of these feelings during the previous period. Use the following five-point scale:

$\begin{array}{ccccc}1 & 2 & 3 & 4 & 5 \\ \text { Not at all } & \text { Somewhat } & \text { Moderately } & \text { Very } & \text { Extremely }\end{array}$

frightened by this sensation.

1. Heart palpitations

2. Pressure or a heavy feeling in chest

3. Numbness in arms and legs

4. Tingling in the fingertips

5. Numbness in another part of your body

6. Feeling short of breath

7. Dizziness

8. Blurred or distorted vision

9. Nausea

10. Having "butterflies" in your stomach

11. Feeling a knot in your stomach

12. Having a lump in your throat

13. Wobbly or rubber legs

14. Sweating

15. A dry throat

16. Feeling disoriented and confused

17. Feeling disconnected from your body: only partly present

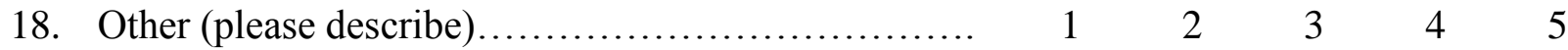

$\begin{array}{lllll} & \end{array}$




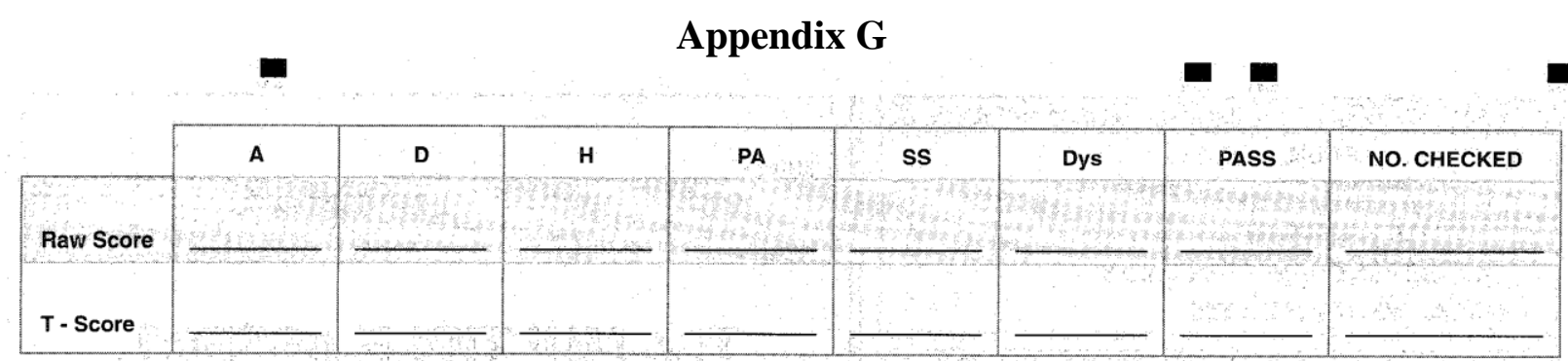

\section{Multiple Affect Adjective Check List - R (MAACL-R)}

1. $O$ active

2. $\bigcirc$ adventurous

3. $O$ affectionate

4. $\bigcirc$ afraid

5. $\bigcirc$ agitated

6. $\bigcirc$ agreeable

7. $\bigcirc$ aggressive

8. $O$ alive

9. $O$ alone

10. $\bigcirc$ amiable

11. $O$ amused

12. $\bigcirc$ angry

13. $O$ annoyed

14. $\bigcirc$ awful

15. $\bigcirc$ bashful

16. $\bigcirc$ bitter

17. $O$ blue

18. $O$ bored

19. $O$ calm

20. $O$ cautious

21. O cheerful

22. $\bigcirc$ clean

23. complaining

24. $O$ contented

25. O contrary

26. $O \mathrm{cool}$

27. $O$ cooperative

28. $O$ critical

29. $O$ cross

30. $O$ cruel

31. $O$ daring

32. $\bigcirc$ desperate

33. $\bigcirc$ destroyed
34. $\bigcirc$ devoted

35. $O$ disagreeable

36. $O$ discontented

37. $\bigcirc$ discouraged

38. $O$ disgusted

39. $O$ displeased

40. $\bigcirc$ energetic

41. $\bigcirc$ enraged

42. $O$ enthusiastic

43. $O$ fearful

44. $O$ fine

45. $\bigcirc$ fit

46. $O$ forlorn

47. $\bigcirc$ frank

48. $O$ free

49. $O$ friendly

50. $O$ frightened

51. O furious

52. O lively

53. $\bigcirc$ gentle

54. $\bigcirc \mathrm{glad}$

55. $\bigcirc$ gloomy

56. $\bigcirc$ good

57. $\bigcirc$ good-natured

58. $\bigcirc$ grim

59. $\bigcirc$ happy

60. $\bigcirc$ healthy

61. O hopeless

62. O hostile

63. O impatient

64. $O$ incensed

65. $O$ indignant

66. $\bigcirc$ inspired
67. $\bigcirc$ interested

68. O irritated

69. $\bigcirc$ jealous

70. $\bigcirc$ joyful

71. O kindly

72. O lonely

73. O lost

74. O loving

75. O low

76. O lucky

77. $\bigcirc \mathrm{mad}$

78. O mean

79. O meek

80. O merry

81. $O$ mild

82. miserable

83. O nervous

84. $O$ obliging

85. $O$ offended

86. $O$ outraged

87. O panicky

88. Opatient

89. O peaceful

90. O pleased

91. O pleasant

92. $O$ polite

93. O powerful

94. $O$ quiet

95. O reckless

96. O rejected

97. $O$ rough

98. $\mathrm{sad}$

99. $O$ safe
100. O satisfied

101. O secure

102. O shaky

103. $O$ shy

104. $O$ soothed

105. O steady

106. O stubborn

107. $O$ stormy

108. O strong

109. O suffering

110. $O$ sullen

111. $O$ sunk

112. sympathetic

113. Otame

114. $O$ tender

115. $\bigcirc$ tense

116. $O$ terrible

117. $O$ terrified

118. $O$ thoughtful

119. O timid

120. $\bigcirc$ tormented

121. $O$ understanding

122. $\bigcirc$ unhappy

123. $O$ unsociable

124. $\bigcirc$ upset

125. $O$ vexed

126. $O$ warm

127. $O$ whole

128. O wild

129. $\bigcirc$ willful

130. $\bigcirc$ wilted

131. O worrying

132. $\bigcirc$ young 


\section{Appendix H \\ Subjective Units of Distress Scale (SUDS)}

Please rate how distressed you are right now using the scale below.

not at all $\quad$ extremely




\section{Appendix I}

\section{Brief COPE}

These items deal with ways you've been coping with learning new health-related information. There are many ways to try to deal with problems. These items ask what you've been doing to cope with this one. Obviously, different people deal with things in different ways, but I'm interested in how you tried to deal with it. Each item says something about a particular way of coping. I want to know to what extent you've been doing what the item says, in other words, how much or how frequently. Don't answer on the basis of whether it seems to be working - just whether or not you're doing it. Use these response choices. Try to rate each item separately in your mind from the others. Make your answers as true FOR YOU as you can.

\section{$1 \quad 2 \quad 3 \quad 4$}

I haven't been doing I've been doing this a I've been doing this a I've been doing this a this at all little bit medium amount lot

1. I've been turning to work or other activities to take my mind off things.

2. I've been concentrating my efforts on doing something about the situation I'm in.

3. I've been saying to myself "this isn't real."

4. I've been giving up trying to deal with it.

5. I've been taking action to try to make the situation better.

6. I've been refusing to believe that it has happened.

7. I've been trying to see it in a different light, to make it seem more positive.

8. I've been criticizing myself.

9. I've been trying to come up with a strategy about what to do.

10. I've been giving up the attempt to cope.

11. I've been looking for something good in what is happening.

12. I've been making jokes about it. 
$1 \quad 2 \quad 3 \quad 4$

I haven't been doing I've been doing this a I've been doing this a I've been doing this a this at all medium amount

lot

13. I've been doing something to think about it less, such as going to movies, watching TV, reading, daydreaming, sleeping, or shopping.

14. I've been accepting the reality of the fact that it has happened.

15. I've been trying to find comfort in my religion or spiritual beliefs.

16. I've been learning to live with it.

17. I've been thinking hard about what steps to take.

18. I've been blaming myself for things that happened.

19. I've been praying or meditating.

20. I've been making fun of the situation. 


\section{Appendix J}

\section{Manipulation Check Questions}

Please read each item carefully. Answer the items by circling the number on the scale below each question.

1. I attempted to follow the induction instructions.

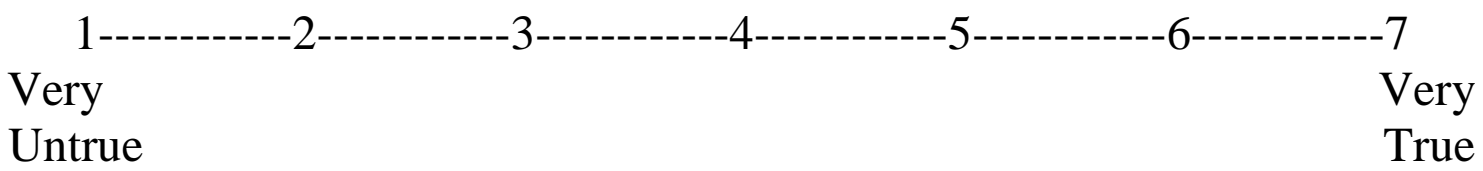

2. I believed the health-related feedback I was given.

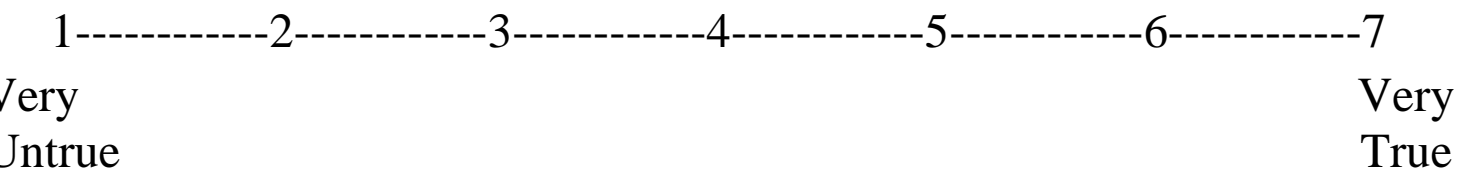

3. After receiving the health-related feedback, I was more concerned about my health.

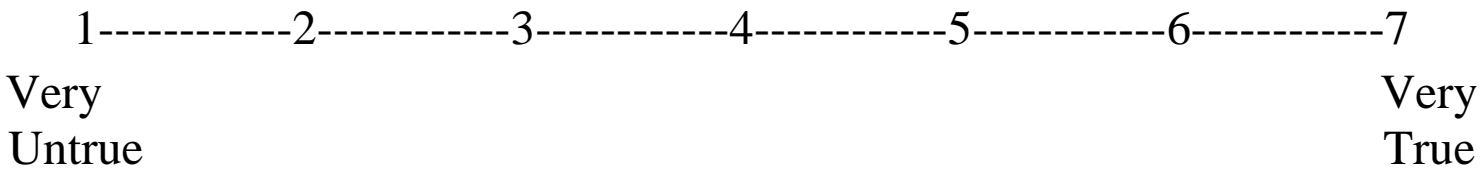




\section{Appendix K}

\section{Thought Description}

On the lines provided below, please record any thoughts you had during the period following the feedback about your health. Please be as descriptive as you can. Record any thought you remember having, even those that may not be related to the current study. 


\section{Appendix L}

\section{Health History}

\section{Have you ever had any of the following conditions? Circle all that apply.}

$\square$ Anemia

$\square$ Angina

$\square$ Anxiety

Arthritis

$\square$ Asthma/Bronchitis

$\square$ Autoimmune disease

$\square$ Bleeding disorder

Blood clots

$\square$ Cancer

$\square$ Cardiac Arrhythmia

$\square$ Cataracts

$\square$ Coronary Artery Disease

$\square$ Crohn's Disease/Colitis

$\square$ Deep Venous Thrombosis

$\square$ Depression

Diabetes

Diverticulitis/Diverticulosis

$\square$ Other (specify): $\square$ Emphysema

$\square$ Epilepsy/Seizures

$\square$ Fibromyalgia

$\square$ Gastroesophageal reflux disorder (GERD)

$\square$ Genetic Condition

Gout

Glaucoma

Headaches

Hearing loss

Heart Attack

$\square$ Hepatitis

High cholesterol

HIV/AIDS

Hormonal problems/imbalances

High blood pressure

Irritable Bowel Syndrome
Kidney or Gallbladder stones

$\square$ Lupus

$\square$ Macular Degeneration

$\square$ Mononucleosis

$\square$ Multiple Sclerosis

$\square$ Neuropathy

$\square$ Osteoporosis

$\square$ Parkinson's Disease

$\square$ Pneumonia

$\square$ Polio

$\square$ Rheumatic Fever

$\square$ Scarlet Fever

$\square$ Sexually Transmitted Disease

Sinus/Upper respiratory infection

Stomach ulcers

$\square$ Stroke

Thyroid problems

2. Please list any major surgeries you have had in the past: 
3. Have you ever undergone testing in lung or respiratory function? $\square$ YES $\square$ NO If yes, please describe:

4. Have you ever been hospitalized as a result of lung or respiratory problems?

YES $\square$ NO

If yes, please describe:

5. Have you ever had medical procedures as a result of lung or respiratory problems?

$\square$ YES $\square$ NO

If yes, please describe: 
Table 1. Descriptive Statistics for Demographic Variables by Age Group.

\begin{tabular}{|c|c|c|c|c|c|c|}
\hline & \multicolumn{2}{|c|}{ Young Adults } & \multicolumn{2}{|c|}{ Older Adults } & \multirow{2}{*}{$t$ or $X^{2}$} & \multirow{2}{*}{$p$} \\
\hline & $M$ or $n$ & $S D$ or $\%$ & $M$ or $n$ & $S D$ or $\%$ & & \\
\hline Age (years) & 19.75 & 1.70 & 66.11 & 6.13 & 43.76 & .01 \\
\hline Education (years) & 13.67 & 1.10 & 16.14 & 3.66 & 3.88 & .01 \\
\hline Gender (females) & 18 & $50 \%$ & 20 & $55.6 \%$ & .22 & .64 \\
\hline Ethnicity & & & & & 10.83 & .05 \\
\hline Caucasian & 26 & $72.2 \%$ & 34 & $94.4 \%$ & & \\
\hline African American & 5 & $13.9 \%$ & 0 & $0 \%$ & & \\
\hline Asian & 3 & $8.3 \%$ & 1 & $2.8 \%$ & & \\
\hline Latino & 2 & $5.6 \%$ & 0 & $0 \%$ & & \\
\hline Native American & 0 & $0 \%$ & 1 & $2.8 \%$ & & \\
\hline Marital Status & & & & & 54.44 & .01 \\
\hline Single & 36 & $100 \%$ & 5 & $13.9 \%$ & & \\
\hline Married & 0 & $0 \%$ & 19 & $52.8 \%$ & & \\
\hline Divorced & 0 & $0 \%$ & 7 & $19.4 \%$ & & \\
\hline Widowed & 0 & $0 \%$ & 5 & $13.9 \%$ & & \\
\hline Job Status & & & & & 65.14 & .01 \\
\hline Student & 36 & $100 \%$ & 0 & $0 \%$ & & \\
\hline Working full time & 0 & $0 \%$ & 15 & $41.7 \%$ & & \\
\hline Working part time & 0 & $0 \%$ & 4 & $11.1 \%$ & & \\
\hline Unemployed & 0 & $0 \%$ & 1 & $2.8 \%$ & & \\
\hline Retired & 0 & $0 \%$ & 16 & $44.4 \%$ & & \\
\hline Income & & & & & 5.90 & .12 \\
\hline Less than $\$ 25,000$ & 4 & $11.1 \%$ & 7 & $20.0 \%$ & & \\
\hline$\$ 25,000$ to $\$ 49,999$ & 9 & $25.0 \%$ & 15 & $42.9 \%$ & & \\
\hline$\$ 50,000$ to $\$ 74,999$ & 7 & $19.4 \%$ & 6 & $17.1 \%$ & & \\
\hline$\$ 75,000$ or greater & 16 & $44.4 \%$ & 7 & $20.0 \%$ & & \\
\hline
\end{tabular}

Notes: Variables that significantly differ across age groups are in bold. 
Table 2. Descriptive Statistics for Health-Related Variables.

\begin{tabular}{|c|c|c|c|c|c|c|}
\hline & \multicolumn{2}{|c|}{ Young Adults } & \multicolumn{2}{|c|}{ Older Adults } & \multirow{2}{*}{$t$ or $X^{2}$} & \multirow{2}{*}{$p$} \\
\hline & $M$ or $n$ & $S D$ or $\%$ & $M$ or $n$ & $S D$ or $\%$ & & \\
\hline Smoking Status & & & & & 2.89 & .09 \\
\hline Never smoked & 31 & $86.1 \%$ & 25 & $69.4 \%$ & & \\
\hline Not currently smoking & 5 & $13.9 \%$ & 11 & $30.6 \%$ & & \\
\hline Smokeless Tobacco & & & & & 1.33 & .72 \\
\hline Never & 33 & $91.6 \%$ & 33 & $91.6 \%$ & & \\
\hline Not currently & 2 & $5.6 \%$ & 1 & $2.8 \%$ & & \\
\hline 1-4 times per day & 1 & $2.8 \%$ & 2 & $5.6 \%$ & & \\
\hline Drink alcohol & & & & & 14.07 & .02 \\
\hline Never & 4 & $11.1 \%$ & 10 & $27.8 \%$ & & \\
\hline Few drinks per year & 10 & $27.8 \%$ & 12 & $33.3 \%$ & & \\
\hline Few drinks per month & 14 & $38.9 \%$ & 3 & $8.3 \%$ & & \\
\hline 1-3 drinks per week & 5 & $13.9 \%$ & 5 & $13.9 \%$ & & \\
\hline 4-6 drinks per week & 3 & $8.3 \%$ & 2 & $5.6 \%$ & & \\
\hline 7-14 drinks per week & 0 & $0 \%$ & 4 & $11.1 \%$ & & \\
\hline Daily caffeine intake & & & & & 10.50 & .06 \\
\hline 0 cups & 11 & $30.6 \%$ & 5 & $13.9 \%$ & & \\
\hline $1-2$ cups & 21 & $58.3 \%$ & 16 & $44.4 \%$ & & \\
\hline 3-4 cups & 4 & $11.1 \%$ & 10 & $27.8 \%$ & & \\
\hline $5-6$ cups & 0 & $0 \%$ & 2 & $5.6 \%$ & & \\
\hline 7-8 cups & 0 & $0 \%$ & 2 & $5.6 \%$ & & \\
\hline more than 8 cups & 0 & $0 \%$ & 1 & $2.8 \%$ & & \\
\hline Weekly physical activity & & & & & 11.71 & .01 \\
\hline Never & 1 & $2.8 \%$ & 8 & $22.2 \%$ & & \\
\hline 1-2 times & 17 & $47.2 \%$ & 8 & $22.2 \%$ & & \\
\hline 3-6 times & 18 & $50.0 \%$ & 17 & $47.2 \%$ & & \\
\hline 7 or more times & 0 & $0 \%$ & 3 & $8.3 \%$ & & \\
\hline Health & & & & & 5.26 & .15 \\
\hline Excellent & 7 & $19.4 \%$ & 16 & $44.4 \%$ & & \\
\hline Very good & 16 & $44.4 \%$ & 11 & $30.6 \%$ & & \\
\hline Good & 11 & $30.6 \%$ & 8 & $22.2 \%$ & & \\
\hline Fair & 2 & $5.6 \%$ & 1 & $2.8 \%$ & & \\
\hline
\end{tabular}




\begin{tabular}{lcccccc}
\hline & \multicolumn{2}{c}{ Young Adults } & \multicolumn{2}{c}{ Older Adults } & & \\
\cline { 2 - 5 } & $M$ or $n$ & $S D$ or $\%$ & $M$ or $n$ & $S D$ or $\%$ & & $p$ \\
\hline $\begin{array}{l}\text { Past health problems } \\
\text { Lung testing }\end{array}$ & $\mathbf{2 . 3 3}$ & $\mathbf{1 . 8 7}$ & $\mathbf{5 . 8 3}$ & $\mathbf{3 . 5 2}$ & $\mathbf{5 . 2 7}$ & $\mathbf{. 0 1}$ \\
$\quad$ Yes & 8 & $22.2 \%$ & 13 & $36.1 \%$ & & .20 \\
$\quad$ No & 28 & $77.8 \%$ & 23 & $63.9 \%$ & & \\
$\begin{array}{l}\text { Hospitalization for lung } \\
\text { problems }\end{array}$ & & & & & & \\
$\quad$ Yes & 3 & $8.3 \%$ & 5 & $13.9 \%$ & & \\
$\quad$ No & 33 & $91.7 \%$ & 31 & $86.1 \%$ & & \\
$\begin{array}{l}\text { Medical procedures for lung } \\
\text { problems }\end{array}$ & & & & & & \\
$\quad$ Yes & 1 & $2.8 \%$ & 3 & $8.3 \%$ & & \\
$\quad$ No & 35 & $97.2 \%$ & 33 & $91.7 \%$ & & \\
\hline
\end{tabular}

Notes: Variables that significantly differ across age groups are in bold. 
Table 3. Descriptive Statistics for Dependent Measures at Baseline.

\begin{tabular}{|c|c|c|c|c|c|c|}
\hline & \multicolumn{2}{|c|}{ Young Adults } & \multicolumn{2}{|c|}{ Older Adults } & \multirow{2}{*}{$t$} & \multirow{2}{*}{$p$} \\
\hline & $M$ & $S D$ & $M$ & $S D$ & & \\
\hline SHAI & 12.61 & 5.37 & 9.64 & 4.36 & 2.58 & .01 \\
\hline ASI-3 & 13.83 & 11.27 & 10.64 & 6.97 & 1.45 & .14 \\
\hline MoCA & 26.83 & 2.02 & 26.39 & 2.58 & 0.81 & .11 \\
\hline BSQ & 22.00 & 6.09 & 18.47 & 2.66 & 3.18 & .01 \\
\hline \multicolumn{7}{|l|}{ MAACL-R } \\
\hline Anxiety & 0.78 & 1.48 & 0.22 & 0.59 & 2.10 & .04 \\
\hline Depression & 0.36 & 0.68 & 0.36 & 0.59 & 0.00 & 1.00 \\
\hline Hostility & 0.17 & 0.38 & 0.00 & 0.00 & 2.65 & .01 \\
\hline Positive Affect & 6.11 & 5.58 & 7.89 & 5.04 & 1.42 & .16 \\
\hline Sensation Seeking & 3.31 & 1.51 & 3.28 & 1.67 & 0.07 & .94 \\
\hline \multicolumn{7}{|c|}{ Average Heart Rate (bpm) } \\
\hline Min 1 & 77.35 & 16.51 & 76.05 & 15.90 & 1.09 & .28 \\
\hline $\operatorname{Min} 2$ & 79.13 & 16.40 & 75.73 & 16.24 & 0.89 & .38 \\
\hline Min 3 & 77.63 & 12.93 & 74.26 & 13.26 & 0.34 & .74 \\
\hline \multicolumn{7}{|l|}{ SDNN (ms) } \\
\hline Min 1 & 54.92 & 27.26 & 21.44 & 11.47 & 6.79 & .01 \\
\hline Min 2 & 49.83 & 22.40 & 22.60 & 14.43 & 6.13 & .01 \\
\hline $\operatorname{Min} 3$ & 53.75 & 24.66 & 21.41 & 13.10 & 6.95 & .01 \\
\hline \multicolumn{7}{|c|}{ Systolic Blood Pressure (mmHg) } \\
\hline Recording 1 & 126.25 & 19.17 & 137.83 & 17.05 & 2.71 & .03 \\
\hline Recording 2 & 122.44 & 19.02 & 132.31 & 17.62 & 2.28 & .01 \\
\hline \multicolumn{7}{|c|}{ Diastolic Blood Pressure (mmHg) } \\
\hline Recording 1 & 74.25 & 12.50 & 80.36 & 11.64 & 2.15 & .04 \\
\hline Recording 2 & 72.39 & 11.40 & 78.89 & 11.92 & 2.36 & .02 \\
\hline \multicolumn{7}{|l|}{ SUDS } \\
\hline Recording 1 & 17.44 & 19.98 & 11.61 & 15.42 & 1.39 & .17 \\
\hline Recording 2 & 13.44 & 18.92 & 10.72 & 13.60 & 0.70 & .49 \\
\hline
\end{tabular}

Notes: SHAI=Short Health Anxiety Inventory; ASI-3=Anxiety Sensitivity Index-3; MoCA= Montreal Cognitive Assessment; BSQ=Body Sensations Questionnaire; MAACL-R=Multiple Affect Adjective Checklist, Revised; SUDS=Subjective Units of Distress; SDNN is a measure of heart rate variability. Significant differences between age groups are denoted by boldface. 
Table 4. Descriptive Statistics for the Brief COPE and Manipulation Check Questions.

\begin{tabular}{|c|c|c|c|c|c|c|}
\hline & \multicolumn{2}{|c|}{ Young Adults } & \multicolumn{2}{|c|}{ Older Adults } & \multirow{2}{*}{$t$} & \multirow{2}{*}{$p$} \\
\hline & $M$ & $S D$ & $M$ & $S D$ & & \\
\hline \multicolumn{7}{|l|}{ Brief COPE } \\
\hline Self-distraction & 5.08 & 1.90 & 3.49 & 1.70 & 0.44 & .51 \\
\hline Active coping & 5.06 & 1.76 & 4.97 & 2.06 & 2.01 & .16 \\
\hline Denial & 3.42 & 1.78 & 2.78 & 1.24 & 7.06 & .01 \\
\hline Behavioral disengagement & 2.50 & 0.97 & 2.31 & 0.71 & 2.88 & .09 \\
\hline Positive reframing & 4.78 & 1.96 & 4.75 & 2.06 & 0.14 & .71 \\
\hline Planning & 4.83 & 1.96 & 4.91 & 2.37 & 2.47 & .12 \\
\hline Humor & 3.53 & 1.81 & 2.74 & 1.09 & 8.58 & .01 \\
\hline Acceptance & 4.83 & 1.91 & 4.43 & 1.96 & 0.01 & .96 \\
\hline Religion & 3.83 & 2.16 & 4.51 & 2.13 & 0.02 & .89 \\
\hline Self-blame & 3.28 & 1.63 & 2.97 & 1.42 & 0.92 & .34 \\
\hline \multicolumn{7}{|l|}{ Manipulation Check Items } \\
\hline Follow instructions & 6.78 & 0.48 & 6.72 & 0.66 & 0.87 & .36 \\
\hline Believed feedback & 4.33 & 1.84 & 5.14 & 2.04 & 0.22 & .64 \\
\hline $\begin{array}{l}\text { More concerned about } \\
\text { health }\end{array}$ & 4.03 & 2.01 & 4.58 & 2.12 & 0.10 & .76 \\
\hline
\end{tabular}

Notes: Significant differences between age groups are denoted in boldface. 
Table 5. Rank Order of Brief COPE Subscales by Age Group.

\begin{tabular}{llll}
\hline \multicolumn{2}{c}{ Young Adults } & \multicolumn{2}{c}{ Older Adults } \\
\hline & $M(S D)$ & & $M(S D)$ \\
\hline Self-distraction & $5.08(1.90)$ & Active Coping & $4.97(2.06)$ \\
Active coping & $5.06(1.76)$ & Planning & $4.91(2.37)$ \\
Planning & $4.83(1.96)$ & Positive reframing & $4.75(2.06)$ \\
Acceptance & $4.83(1.91)$ & Religion & $4.51(2.13)$ \\
Positive reframing & $4.78(1.96)$ & Acceptance & $4.43(1.96)$ \\
Religion & $3.83(2.16)$ & Self-distraction & $3.49(1.70)$ \\
Humor & $3.53(1.81)$ & Self-blame & $2.97(1.42)$ \\
Denial & $3.42(1.78)$ & Denial & $2.78(1.24)$ \\
Self-blame & $3.28(1.63)$ & Humor & $2.74(1.09)$ \\
Behavioral disengagement & $2.50(0.97)$ & Behavioral disengagement & $2.31(0.71)$ \\
\hline
\end{tabular}


Table 6. Intercorrelations among Dependent Variables and Coping Measures during Recovery for Older Adults.

\begin{tabular}{|c|c|c|c|c|c|c|c|c|c|c|}
\hline & $\begin{array}{c}\text { Self- } \\
\text { Distraction }\end{array}$ & $\begin{array}{l}\text { Active } \\
\text { Coping }\end{array}$ & Denial & $\begin{array}{c}\text { Beh. } \\
\text { Disengage }\end{array}$ & $\begin{array}{c}\text { Pos. } \\
\text { Reframe }\end{array}$ & Planning & Humor & Accept & Religion & $\begin{array}{l}\text { Self- } \\
\text { Blame }\end{array}$ \\
\hline SBP 1 & -0.12 & 0.02 & -0.11 & 0.18 & 0.09 & -0.07 & -0.01 & -0.30 & 0.05 & 0.01 \\
\hline DBP 1 & -0.16 & -0.04 & -0.05 & 0.06 & 0.00 & 0.02 & -0.19 & -0.28 & -0.25 & 0.11 \\
\hline DBP 2 & -0.10 & 0.05 & -0.06 & 0.06 & 0.02 & 0.08 & -0.16 & -0.26 & -0.12 & 0.12 \\
\hline HR 2 & -0.20 & $-0.34^{*}$ & -0.13 & 0.03 & -0.15 & -0.30 & -0.06 & -0.28 & -0.23 & -0.09 \\
\hline HR 3 & -0.19 & $-0.35^{*}$ & -0.18 & 0.05 & -0.15 & $-0.42 *$ & -0.08 & -0.26 & -0.15 & -0.14 \\
\hline SDNN 1 & -0.24 & 0.05 & 0.15 & $0.42 *$ & 0.24 & -0.08 & 0.07 & 0.02 & 0.18 & 0.13 \\
\hline SDNN 2 & -0.02 & -0.10 & $0.36^{*}$ & 0.33 & 0.14 & -0.25 & 0.00 & -0.01 & 0.18 & -0.06 \\
\hline BSQ & 0.05 & -0.05 & -0.18 & -0.04 & -0.07 & 0.09 & -0.18 & 0.11 & -0.04 & $0.34 *$ \\
\hline Anxiety & 0.13 & 0.18 & 0.07 & -0.12 & -0.17 & 0.28 & -0.11 & 0.04 & -0.11 & $0.53 * *$ \\
\hline Depression & 0.12 & 0.17 & 0.01 & -0.08 & -0.07 & 0.20 & -0.07 & -0.04 & 0.06 & $0.48 * *$ \\
\hline Hostility & 0.08 & 0.05 & 0.24 & -0.02 & -0.16 & 0.21 & 0.19 & -0.03 & 0.00 & $0.34^{*}$ \\
\hline Pos. Affect & 0.05 & -0.23 & -0.14 & 0.12 & -0.06 & -0.07 & 0.15 & 0.13 & -0.21 & 0.03 \\
\hline Sens. Seek & -0.07 & $0.45^{* *}$ & -0.08 & 0.03 & 0.32 & 0.22 & 0.24 & 0.03 & 0.18 & 0.01 \\
\hline
\end{tabular}

\footnotetext{
$* p<.05$

$* * p<.01$
} 
Table 7. Intercorrelations among Dependent Variables and Coping Measures during Recovery for Young Adults.

\begin{tabular}{|c|c|c|c|c|c|c|c|c|c|c|}
\hline & $\begin{array}{c}\text { Self- } \\
\text { Distraction }\end{array}$ & $\begin{array}{l}\text { Active } \\
\text { Coping }\end{array}$ & Denial & $\begin{array}{c}\text { Beh. } \\
\text { Disengage }\end{array}$ & $\begin{array}{c}\text { Pos. } \\
\text { Reframe }\end{array}$ & Planning & Humor & Accept & Religion & $\begin{array}{c}\text { Self- } \\
\text { Blame }\end{array}$ \\
\hline SBP 1 & -0.05 & 0.12 & -0.26 & 0.08 & 0.04 & 0.12 & -0.05 & 0.07 & 0.17 & 0.24 \\
\hline SBP 2 & -0.18 & -0.09 & -0.23 & 0.05 & -0.10 & 0.05 & -0.22 & -0.05 & -0.02 & 0.30 \\
\hline DBP 1 & 0.13 & -0.03 & -0.22 & 0.08 & 0.30 & 0.15 & -0.06 & $0.40^{*}$ & 0.25 & 0.20 \\
\hline DBP 2 & 0.12 & -0.07 & -0.22 & 0.02 & 0.15 & 0.16 & -0.15 & 0.27 & 0.15 & 0.20 \\
\hline HR 1 & 0.27 & -0.02 & -0.07 & -0.07 & 0.02 & 0.09 & $-0.43 * *$ & 0.02 & -0.29 & 0.15 \\
\hline HR 2 & 0.15 & 0.00 & -0.10 & -0.20 & -0.04 & 0.12 & $-0.51 * *$ & 0.02 & $-0.39 *$ & 0.13 \\
\hline HR 3 & 0.13 & 0.03 & -0.04 & -0.16 & -0.07 & 0.14 & $-0.56 * *$ & -0.02 & $-0.38^{*}$ & 0.22 \\
\hline SDNN 1 & -0.32 & -0.09 & 0.28 & -0.20 & -0.08 & -0.27 & 0.22 & -0.29 & 0.05 & -0.09 \\
\hline SDNN 2 & -0.15 & -0.09 & 0.15 & -0.03 & 0.04 & -0.26 & $0.47 * *$ & -0.16 & 0.19 & -0.04 \\
\hline SDNN 3 & -0.03 & -0.04 & 0.00 & -0.11 & -0.09 & $-0.33^{*}$ & $0.49 * *$ & -0.23 & 0.08 & -0.10 \\
\hline SUDS 1 & 0.30 & 0.09 & 0.01 & 0.28 & $0.35^{*}$ & 0.16 & 0.01 & 0.24 & 0.23 & 0.12 \\
\hline SUDS 2 & $0.36^{*}$ & 0.14 & 0.02 & -0.08 & 0.19 & 0.17 & -0.16 & 0.15 & 0.02 & 0.21 \\
\hline BSQ & 0.29 & -0.05 & 0.05 & 0.09 & 0.09 & 0.00 & 0.32 & 0.22 & 0.22 & 0.18 \\
\hline Anxiety & $0.39 *$ & 0.19 & 0.26 & 0.02 & 0.21 & 0.16 & 0.10 & 0.29 & 0.25 & $0.43^{* *}$ \\
\hline Depression & 0.21 & 0.18 & 0.15 & 0.15 & 0.26 & 0.08 & 0.18 & 0.16 & $0.35^{*}$ & 0.21 \\
\hline Hostility & 0.25 & -0.11 & 0.22 & -0.04 & 0.25 & -0.10 & 0.06 & 0.09 & 0.17 & -0.07 \\
\hline Pos. Affect & -0.05 & 0.07 & 0.00 & 0.18 & 0.10 & -0.03 & 0.27 & 0.06 & 0.17 & -0.10 \\
\hline Sens. Seek & -0.02 & -0.07 & 0.06 & -0.02 & -0.05 & -0.04 & 0.30 & -0.22 & -0.10 & 0.25 \\
\hline
\end{tabular}

\footnotetext{
$* p<.05$

$* * p<.01$
} 
Table 8. Rank Order of Common Themes during the Induction Period by Age Group.

\begin{tabular}{|c|c|c|c|}
\hline Young Adults & $n$ & Older Adults & $n$ \\
\hline Making future health-related plans & 12.00 & Making future health-related plans & 19.00 \\
\hline Reflecting on past healthy behaviors & 11.00 & Reflecting on past healthy behaviors & 11.00 \\
\hline Attempting to keep results in perspective & 11.00 & Reflecting on past unhealthy behaviors & 11.00 \\
\hline Using active coping strategies to calm down & 10.00 & Thinking about family members & 10.00 \\
\hline Thinking about family members & 9.00 & $\begin{array}{l}\text { Not being surprised by the results/results were } \\
\text { expected }\end{array}$ & 10.00 \\
\hline Feeling apathetic about the results & 9.00 & Being surprised by the results & 9.00 \\
\hline Thinking about negative outcomes of the illness & 8.00 & Blaming current results on the test itself & 8.00 \\
\hline Being surprised by the results & 8.00 & Feeling anxious about the results & 8.00 \\
\hline Reflecting on past unhealthy behaviors & 7.00 & Using active coping strategies to calm down & 8.00 \\
\hline Indicating they failed to follow study instructions & 7.00 & $\begin{array}{l}\text { Indicating that the results contradict beliefs about } \\
\text { their health }\end{array}$ & 7.00 \\
\hline Blaming current results on the test itself & 6.00 & Doubting that the test itself is inaccurate & 6.00 \\
\hline $\begin{array}{l}\text { Not being surprised by the results/results were } \\
\text { expected }\end{array}$ & 6.00 & Indicating they failed to follow study instructions & 6.00 \\
\hline Feeling anxious about the results & 5.00 & Feeling apathetic about the results & 6.00 \\
\hline $\begin{array}{l}\text { Thinking about past respiratory testing and } \\
\text { procedures }\end{array}$ & 5.00 & Attempting to keep results in perspective & 5.00 \\
\hline $\begin{array}{l}\text { Indicating that the results contradict beliefs about } \\
\text { their health }\end{array}$ & 4.00 & $\begin{array}{l}\text { Thinking about past respiratory testing and } \\
\text { procedures }\end{array}$ & 5.00 \\
\hline Doubting that the test itself is inaccurate & 4.00 & Linking the results to other health problems & 4.00 \\
\hline Feeling bad about self because of the results & 4.00 & Feeling bad about self because of past behaviors & 4.00 \\
\hline Linking the results to other health problems & 4.00 & $\begin{array}{l}\text { Wanting more information about the test/breathing } \\
\text { problems }\end{array}$ & 3.00 \\
\hline Indicating they had difficulty focusing & 3.00 & Reflecting on personal strengths & 3.00 \\
\hline Feeling bad about self because of past behaviors & 3.00 & Thinking about negative outcomes of the illness & 2.00 \\
\hline
\end{tabular}


Older Adults

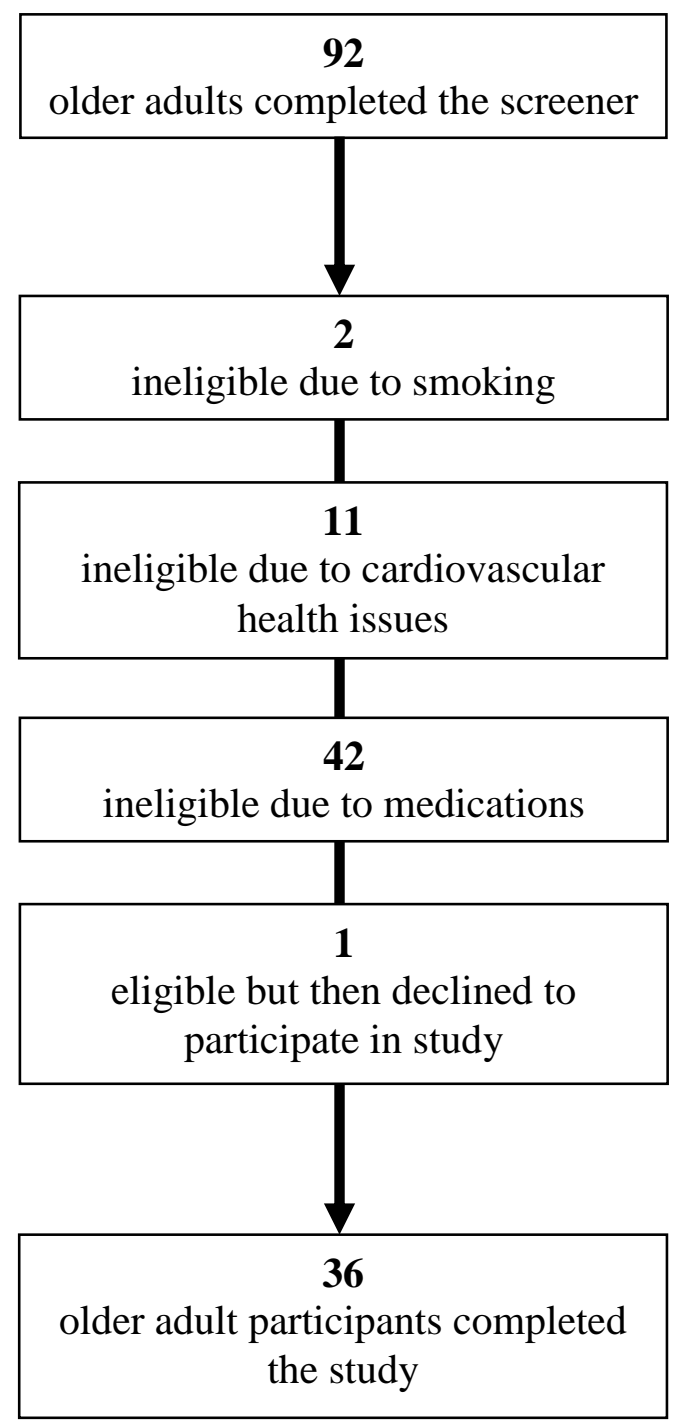

Young Adults

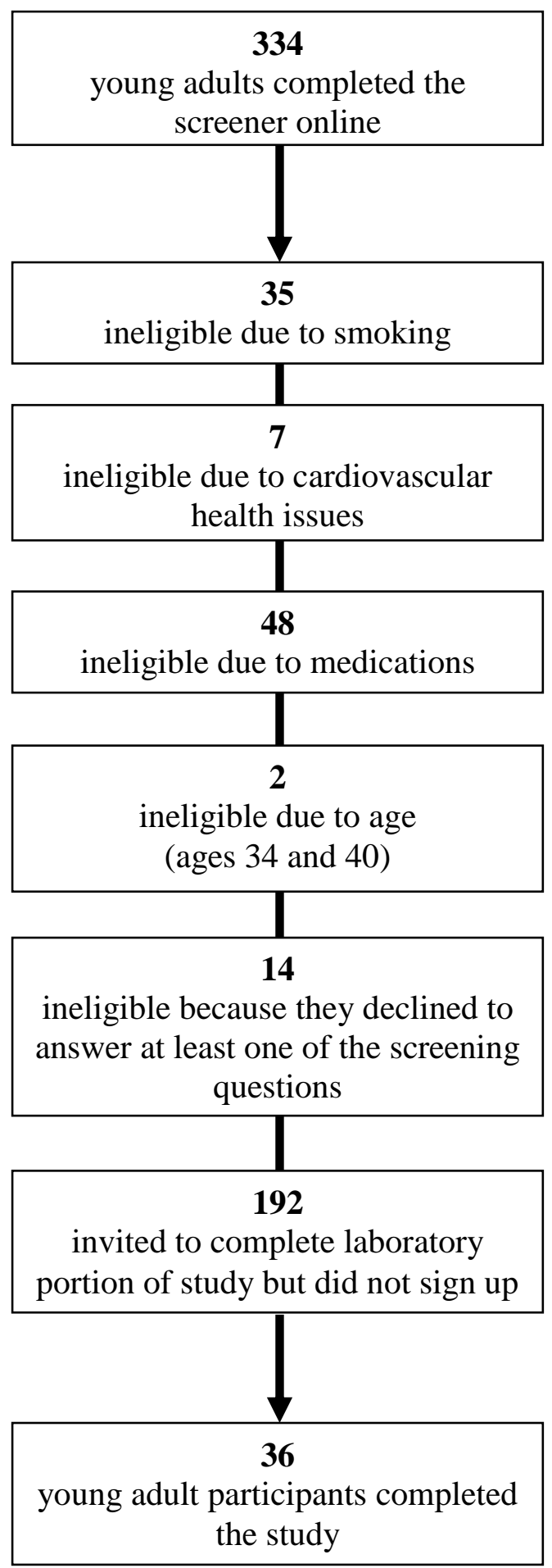

Figure 1. Flowchart depicting individuals who were ineligible for the study. 

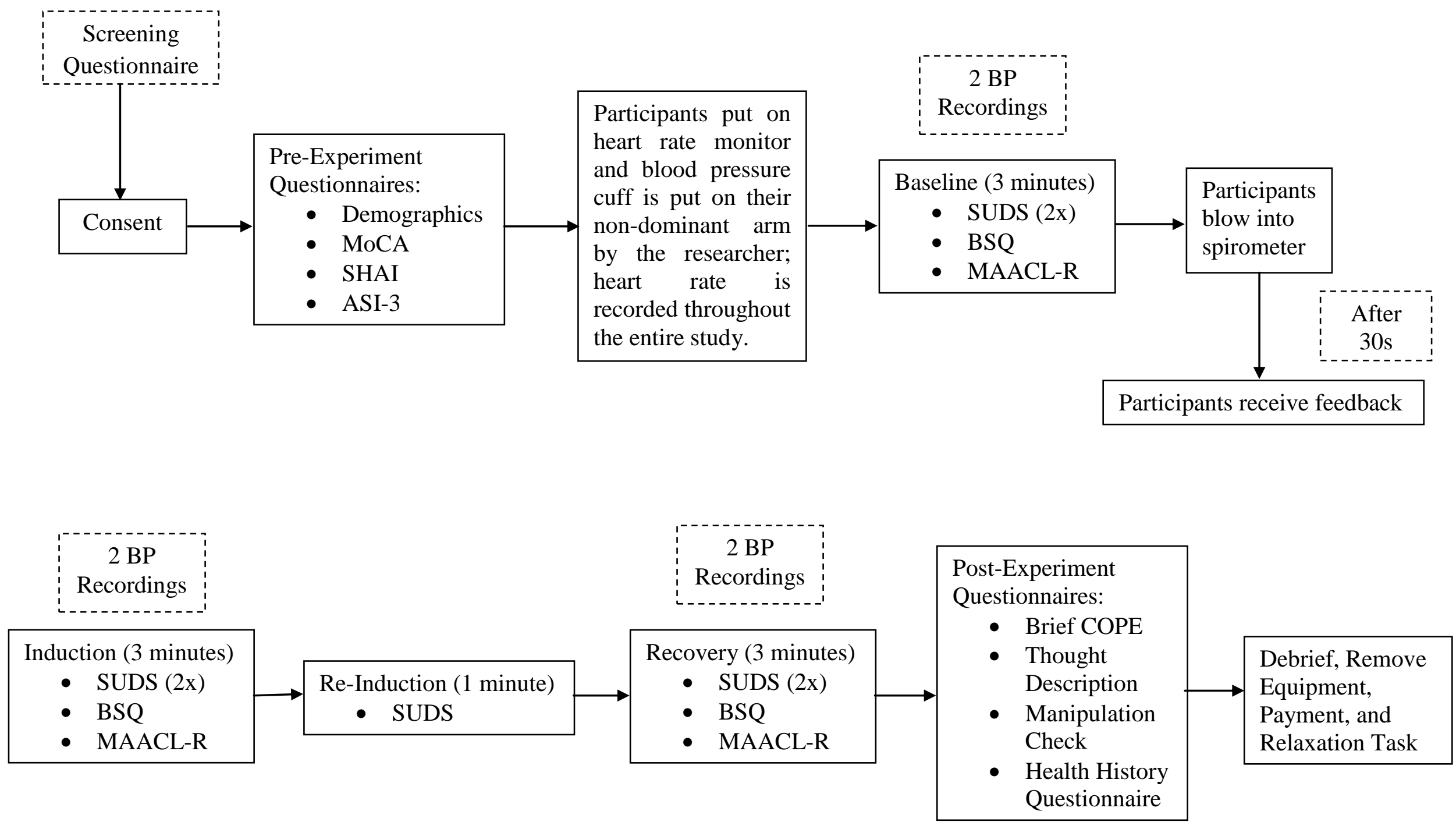

Figure 2. Flowchart of laboratory portion of the procedure. 


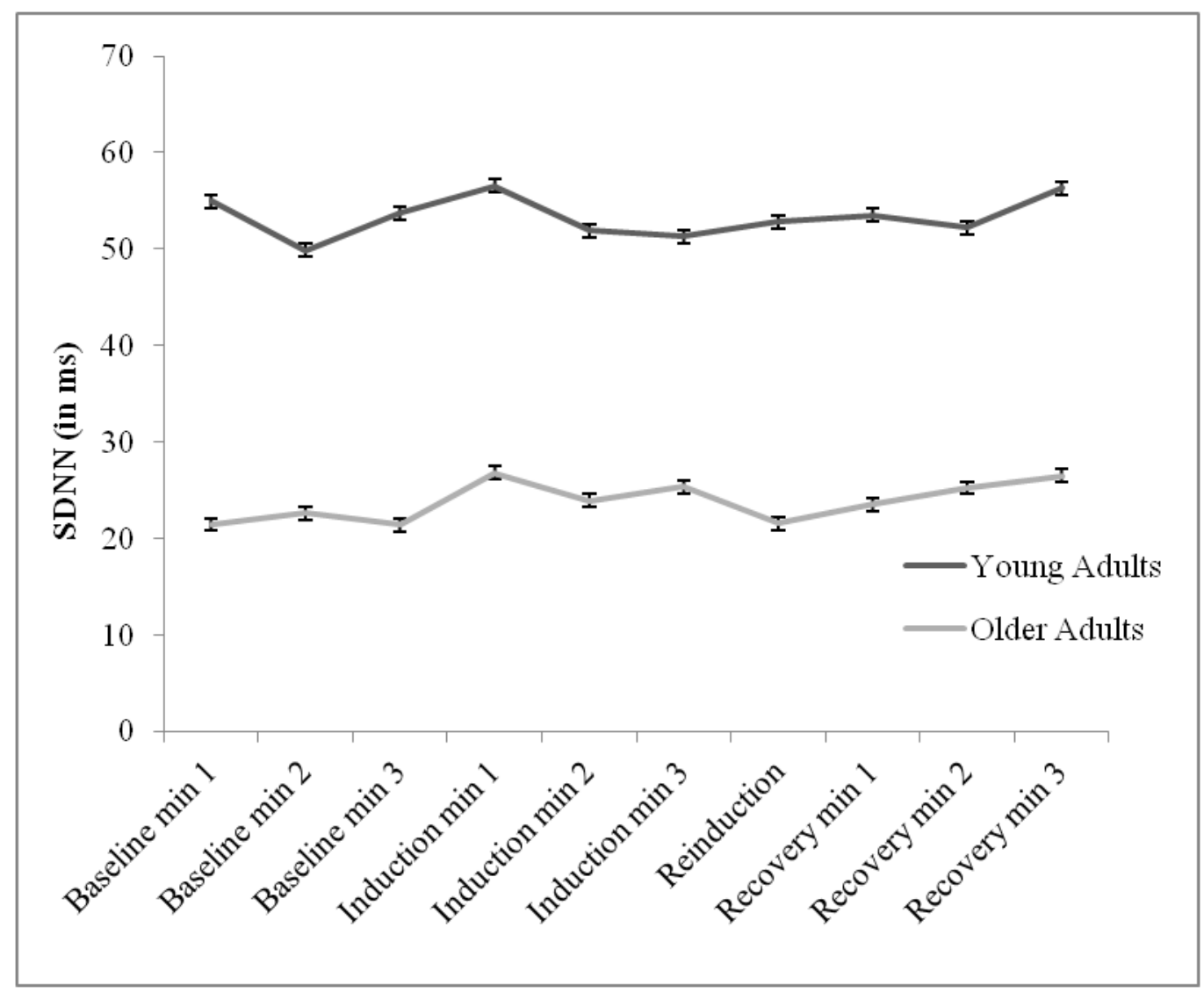

Figure 3. Effect of age on heart rate variability as measured by SDNN (i.e., standard deviation of the inter-beat interval). Error bars represent standard error of the mean. 


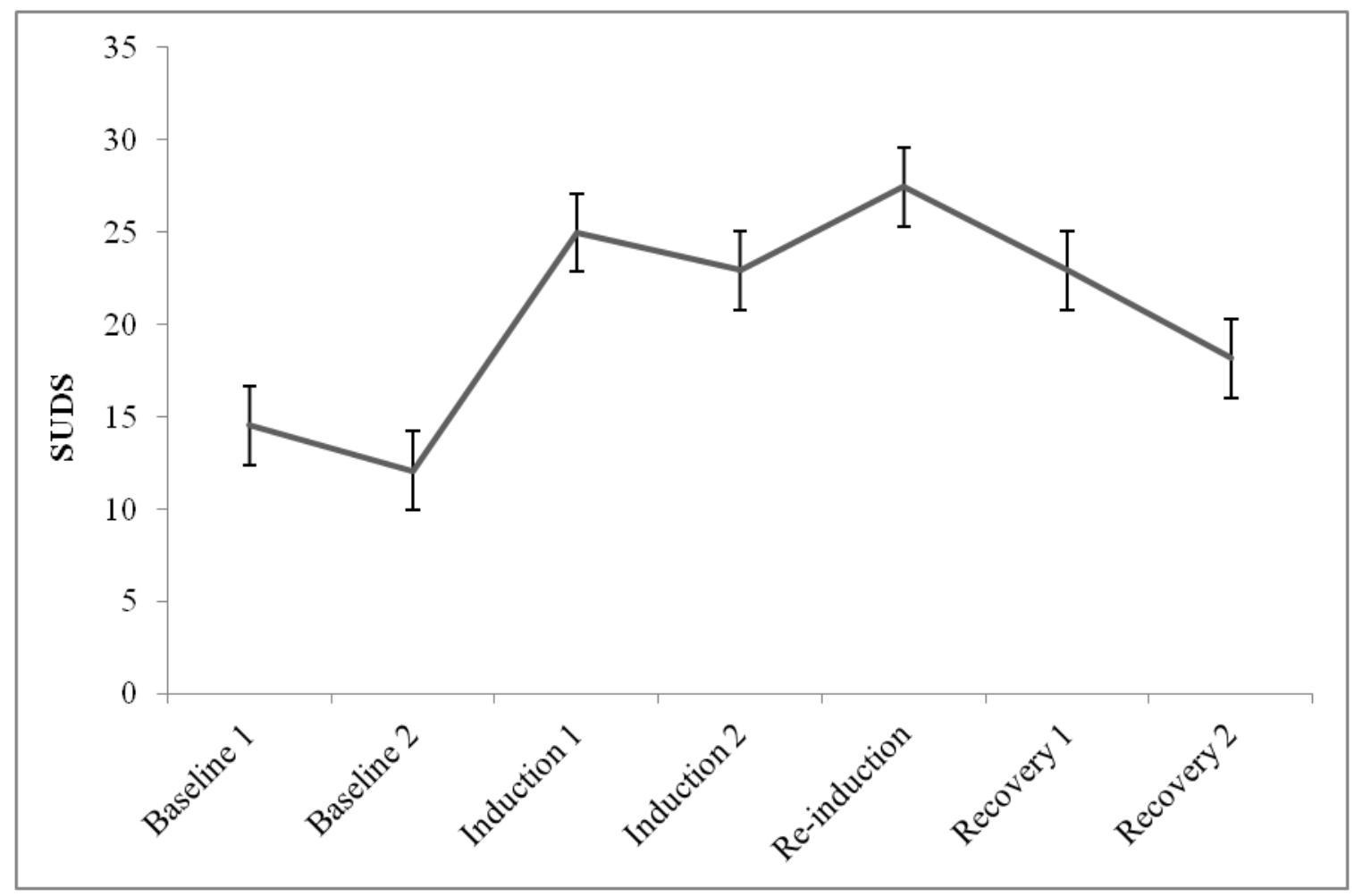

Figure 4. Main effect of time for SUDS ratings. Error bars represent standard error of the mean. 


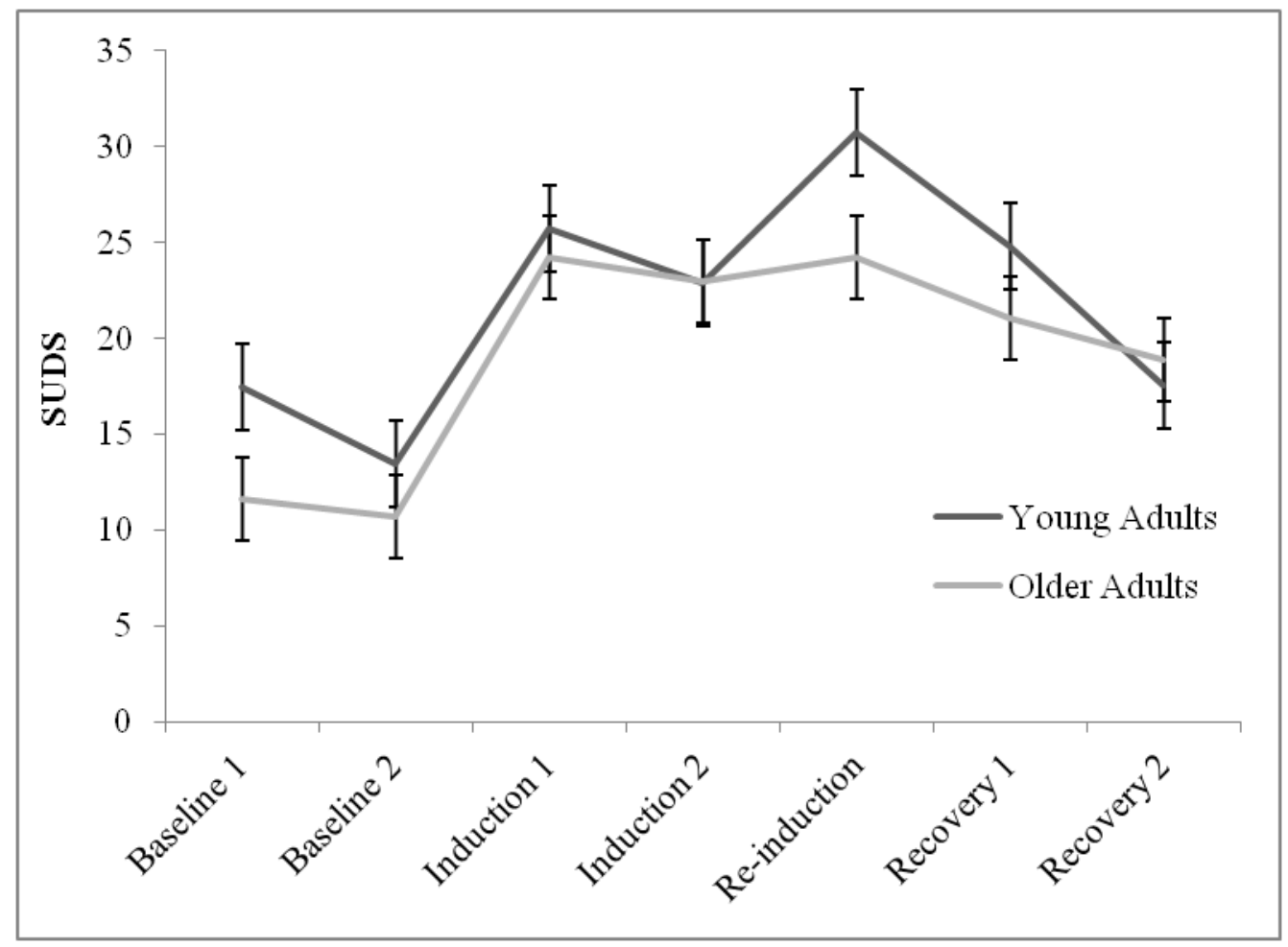

Figure 5. SUDS ratings over time for older and young adults separately. Error bars represent standard error of the mean. 


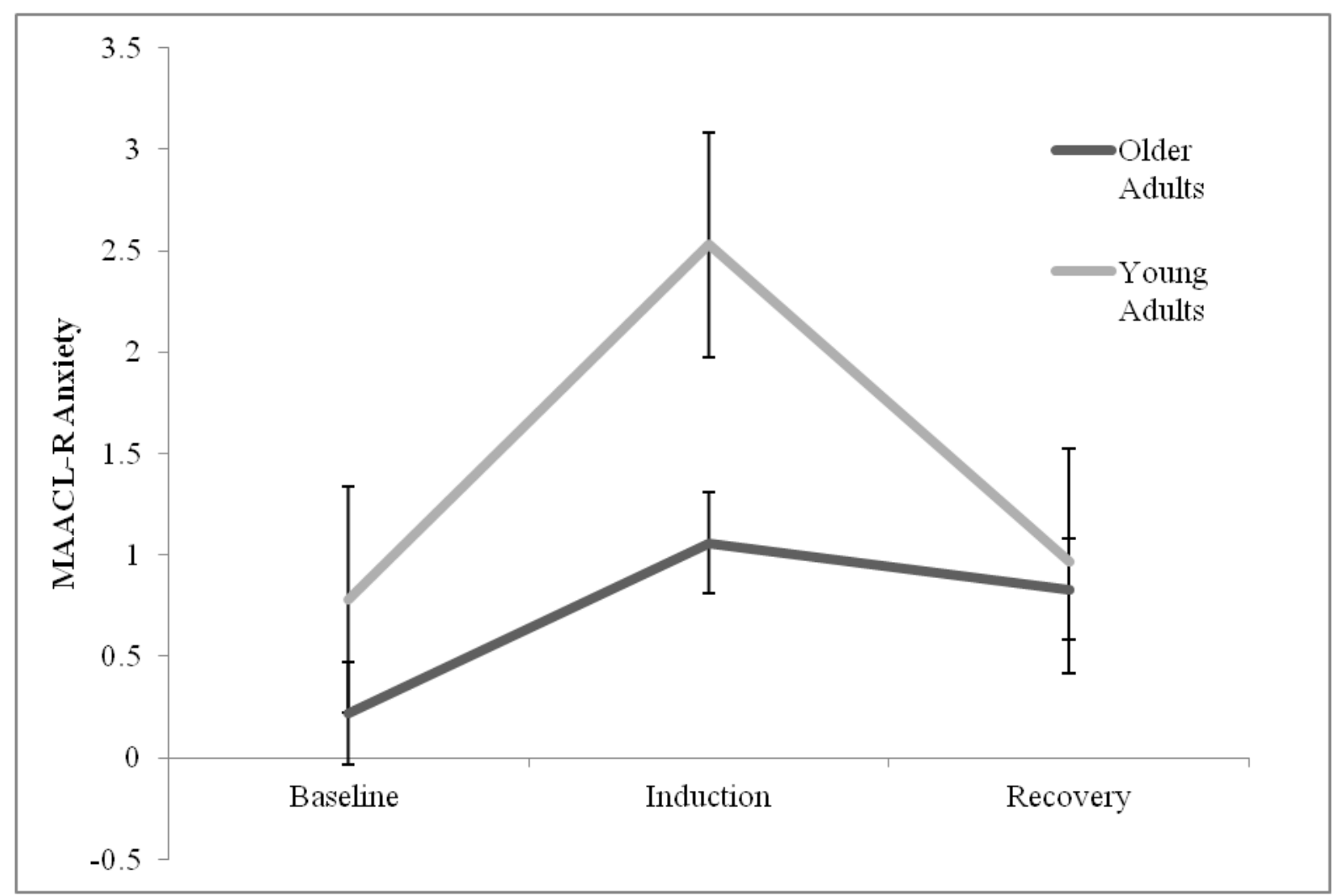

Figure 6. MAACL-R anxiety subscale scores over time in each age group. Error bars represent standard error of the mean. 